\title{
EXPLOSIVE BOILING OF A DEPRESSURIZED VOLATILE LIQUID
}

\author{
Thesis by \\ Riccardo Barbone \\ Department of Mechanical Engineering \\ McGill University \\ Montreal, Quebec, Canada
}

Submitted August 1994

A Thesis Submitted to the Faculty of Graduate Studies and Research in partial fulfillment of the requirements for the degree of Master in Engineering

(C) Barbone 1994 
The author has granted an irrevocable non-exclusive licence allowing the National Library of Canada to reproduce, loan, distribute or sell copies of his/her thesis by any means and in any form or format, making this thesis available to interested persons.
The author retains ownership of the copyright in his/her thesis. Neither the thesis nor substantial extracts from it may be printed or otherwise reproduced without his/her permission.
L'auteur a accordé une licence irrévocable et non exclusive permettant à la Bibliothèque nationale du Canada de reproduire, prêter, distribuer ou vendre des copies de sa thèse de quelque manière et sous quelque forme que ce soit pour mettre des exemplaires de cette thèse à la disposition des personnes intéressées.

L'auteur conserve la propriété du droit d'auteur qui protège sa thèse. Ni la thèse ni des extraits substantiels de celle-ci ne doivent être imprimés ou autrement reproduits sans son autorisation.

ISBN $\quad 0-612-19695-X$ 
Dedicated to my parents and sisters 


\begin{abstract}
The explosive boiling that occurs when a volatile liquid is suddenly vented to the atmosphere has been investigated experimentally. Refiigerant 22 is used as the test liquid and is depressurized from an initial state of equilibrium using a bursting foil diaphragm. The competition between the rates of venting and vapor generation can lead to substantial repressurization within the vessel. The influence of vent area, quantity of liquid, initial pressure and pre-nucleation on the explosive boiling characteristics has been studied in a $260 \mathrm{ml} \mathrm{Teflon-coated} \mathrm{vessel} \mathrm{as} \mathrm{well} \mathrm{as} \mathrm{in} \mathrm{a} 75 \mathrm{ml}$ glass tube. The amount of repressurization is found to be proportional to the pressure drop which determines the degree of superheat attained by the liquid. The time for repressurization is typically an order of magnitude larger than the time for the pressure drop. The repressurization in both vessels reaches a maximum value at an initial saturation vapor pressure of $=2 \mathrm{MPa}$. The dependence of the repressurization on initial pressure observed experimentally is found to be consistent with the predictions of a semi-empirical correlation based on homogeneous nucleation theory. High-speed photography shows that the mode of boiling is dependent on the initial vapor pressure and the surface condition of the vessel walls. Heterogeneous boiling from the walls dominates in the Teflon-coated steel vessel. For initial vapor pressures less than $\approx 1 \mathrm{MPa}$, an evaporation wave propagates at $\approx 0.15 \mathrm{~m} / \mathrm{s}$ from the free surface throughout the length of the glass tube. For higher initial vapor pressures the boiling mode in the glass tube becomes predominantly heterogeneous. Pre-nucleation with $\mathrm{CO}_{2}$ within the refigerant increases the boiling response by promoting heterogeneous boiling.
\end{abstract}




\section{Resumé}

L'ébullition explosive qui suit une depressurizattion rapide d'un liquide volotalile à été étudiée expérimentalement sur une une petite échelle. Le Freon 22 est employée comme liquide de base et est depressurisé d'un état d'équilibre initiale en employants un mécanisme qui perce un diaphragme. La compétition entre le taux d'échappement de vapeur et le taux de génération de vapeur peux mener à une repressurization du contenant. L'influence de la surface du diaphragme, la quantité de liquide, la pression de vapeur initiale et ie pureté du liquide sur les caractéristique de l'ébullition on été étudiée dans un contentant de $260 \mathrm{ml}$, recouvert a l'intérieur d'une couche de Teflon, et dans un tube en verre de $75 \mathrm{ml}$. Le degré de repressurization est proportionnel au degré de dépressurization. La dépressurization détermine le degré de réchauffement atteint par le liquide. Le temps de repressurization est typiquement dix fois plus longs que le temps de dépressurization. La repressurization dans les deux contenants atteint un maximum a une pression de vapeur d'approx. $2 \mathrm{MPa}$. Lal dépendance de la repressurization sur la pression de vapeur initial est consistante avec une corrélation basée sur la théorie de nucleation homogène. A l'aide d'appareil de photographie à hauie viiesssc, on aperçoit que le mode d'ébullition est relié a les conditions de la surface de l'intérieur du contenant et a la pression de vapeur initial. Le contenamt de Teflon est dominé par l'ébullition hétérogène provenant des paroises du contenant. Pour des pressions initiales de vapeur inféricur a approx. $1 \mathrm{MPa}$, une vague d'evaporation ce propage à une vitesse approx. $0.15 \mathrm{~m} / \mathrm{s}$ à travers le tube de verre. Pour des pressions, supérieur le mode d'ébullition devient hétérogèneuse. L'introduction de dioxide de carbon,sous forme de gas, au Freon augmente le degré d'ébullition hétćtogène. 


\section{Acknowledgments}

I would like to thank my advisor, Professor David Frost for his guidance, patience, and continuous support throughout my undergraduate and graduate years at McGill. His incessant advice throughout the preparation of this thesis is also gratefully acknowledged. I wish to thank Professors John Lee and Rom Knystautas for providing an infinite source of motivation. Likewise, I am grateful to Dr. Sam Gorositin and Dr. Aris Makris for the many brainstorming discussions and the help with experimental problems. Thanks to Kathleen Sawer for editing. A very special thanks goes out to honor students Christine Demarais and Jeff Nerenberg for the excellent help with experiments. An extra special thanks also goes to my family that has supported me unconditionally throughout my studies. Above all I wish to thank past and present members of the Shock Wave Physics Group for providing me a stimulating, challenging and rewarding environment. The dedication and dynamism present in the SWPG laboratories at McGill is quite unique and will be missed.

This research was supported by Transport Canada under DSS contract T8200-2-2520/01XSD 


\section{Table of Contents}

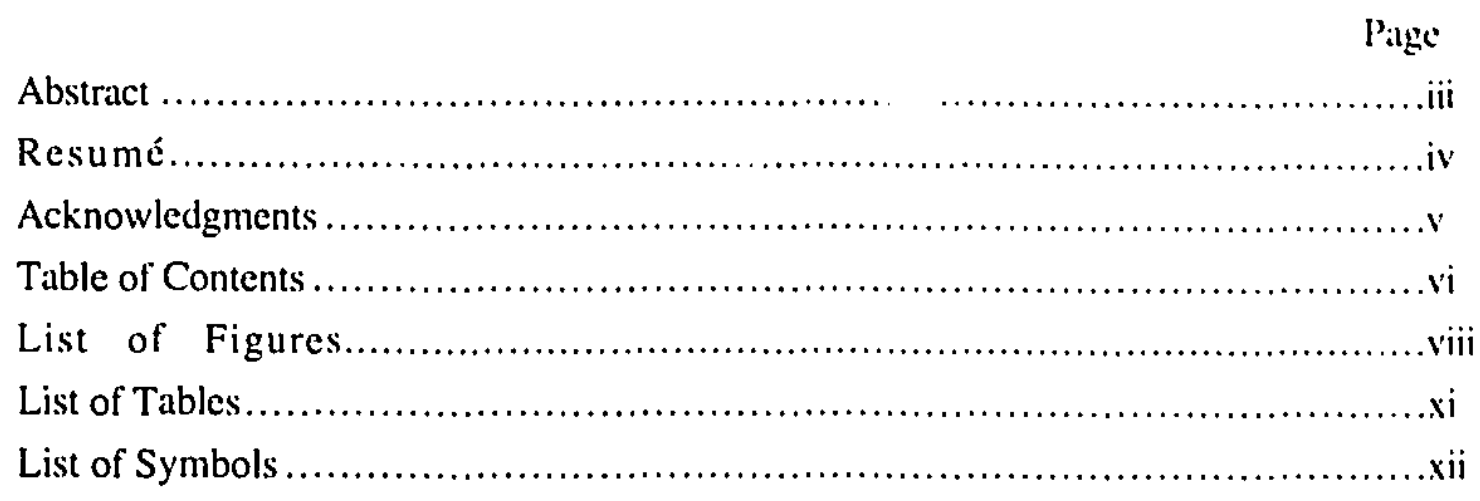

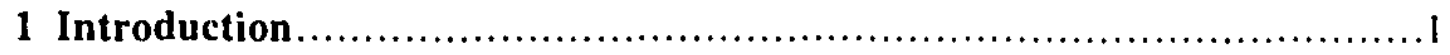

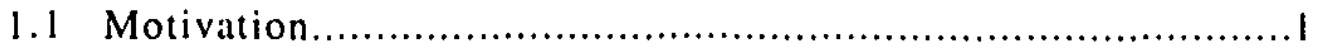

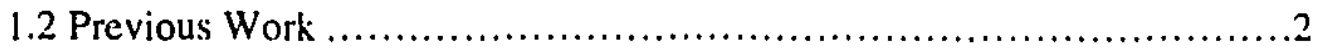

1.3 Objectives ......................................................4

1.4 Outline ..........................................................

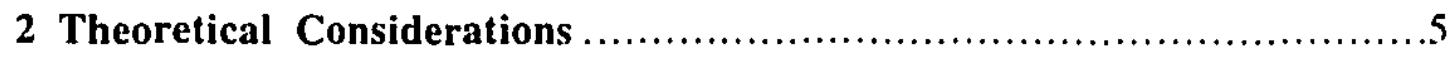

2.1 Superheat of a Liquid...............................................

2.2 Thermodynamic Constraints.......................................6

2.3 Energy Requirements for Bubble Growth and Nucleation.................9

2.4 Heterogeneous Nucleation and Physical Constraints ....................13

2.5 Growth of a Superheated Vapor Bubble ..............................13

2.6 Optimum Conditions for Most Explosive Phase Change......................16

3 Experimental Details ...................................................

3.1 General Description of Experimental Facility ......................... 19

3.2 Experimental Vessels .............................................20

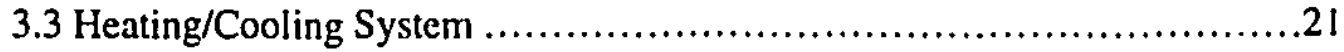

3.4 Diaphragm Rupture System......................................23

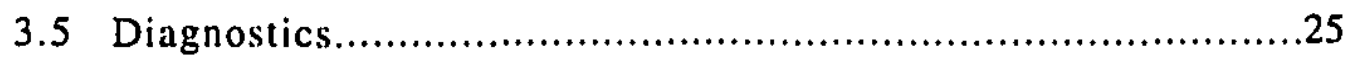

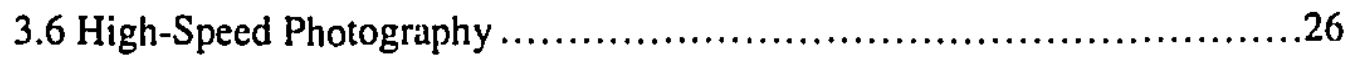

3.7 Experimental Parameters ..........................................27

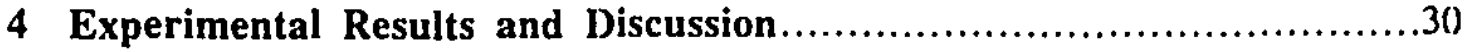

4.1 General Features of Explosive Boiling ...............................30

4.1.1 Typical Pressure Trace...................................... 30 
4.1.2 Relationship between Pressure Drop and Rise.................31

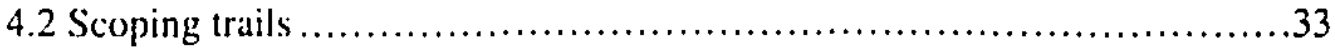

4.2 .1 Location of Transducer ..................................33

4.2.2 Location of Rupture Hole........................................34

4.2.3 O.ientation of Pressure Transducer...................................36

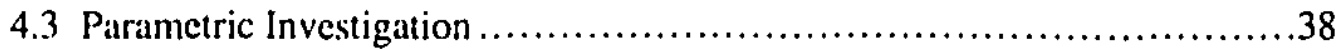

4.3.1 Explosive Boiling in $260 \mathrm{ml}$ Vessel ...........................38

4.3.1.1 Area of Rupture .................................. 38

4.3.1.2 Liquid Fill Volume...............................42

4.3.1.3 Initial Pressure.........................................44

4.3.1.4 Mode of Nucleation................................49

4.3.2 Explosive Boiling in $75 \mathrm{ml}$ Glass Tube.........................53

4.3.2.1 Initial Pressure......................................53

4.3.2.2 Mode of Nucleation................................54

4.3.2.3 Pre-Nucleation Experiments ..........................59

4.4 Other Experiments .................................................61

4.5 Semi-Empirical Model for Pressure Undershoot .........................61

4.6 Thermodynamic Modeling ........................................64

4.6.1 Venting Model ............................................64

4.6.2 Bubble Growth ............................................64

4.6.3 Coupled Venting and Bubble Growth.............................66

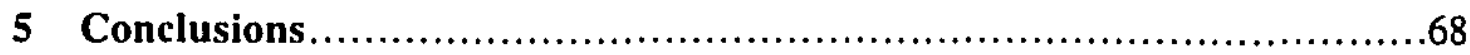

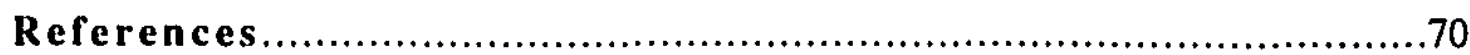

Appendix A : Thermodynamic Properties as a Function of Temperature.................72

Appendix B : Preliminary Experiments.............................................76

Appendix C : Raw Experimental Data in Tabular Form ...........................79

Appendix D : Source Code for Venting Model ..................................85 


\section{List of Figures}

Figure 2.1 - Satturation and spinodal curves for refrigerant 22

Figure 2.2 - Saturation dome with van der Waals Isothermal for $\mathrm{T}=3(\mathrm{~K}) \mathrm{K}$

Figure 2.3 - Isothermal line within the saturation dome obtained from the van der Waals equation of state for $\mathrm{T}=300 \mathrm{~K}$

Figure 2.4 - Free energy necessary for bubble growth

Figure 2.5 - Maximum Degree of Superheat as a function of initial temperature

Figure 2.6 - Variation of Nucleation Rate with Temperature

Figure 3.1 - Rapid Depressurization Facility

Figure 3.2 - Cross-section of Teflon couted $260 \mathrm{ml}$ Stecl Vessel (left) and $75 \mathrm{ml}$ Glass Test Tube assembly (right)

Figure 3.3 - Schematic of $75 \mathrm{ml}$ Glass Test tube assembly showing location of transducers

Figure 3.4 - Special Test Liquid Delivery Attachment

Figure 3.5 - Diaphragm Rupture System

Figure 3.6a - Rupture Blades

Figure 3.6b - Diaphragm Assembly

Figure 3.7 - Pressure Transducer Mounting through Vessel Wall

Figure 3.8 - Photographic Setup

Figure 3.9 - Saturation curve for propane and refrigerant 22

Figure 4.1 - Characteristic pressure history for venting of R-22 and pressurized water

Figure 4.2 - Relationship between pressure rise and pressure drop

Figure 4.3a - $\mathrm{H}_{2} \mathrm{O} / \mathrm{Air}$ trial with vent in vapor space

Figure 4.3b - R22 trial with vent in vapor space

Figure 4.4a - $\mathrm{H}_{2} \mathrm{O} / \mathrm{Air}$ trial with vent in liquid space

Figure 4.4b - R22 trial with vent in liquid space

Figure $4.5 \mathrm{a}$ - Pressure trace of liquid impact trial 
Figure 4.5b - Pressure trace of liquid inapac! trial

Figure 4.6 - Superposition of pressure transient for orifice trials

Figure 4.7 - Influence of area on degree of depressurization and repressurization

Figure 4.8 - Definition of rates of depressurization and repressurization

Figure 4.9 - Intluence of area on rate of depressurization and repressurization

Figure 4.1I - Superposition of pressure transient for liquid fill trials

Figure 4.12 - Influence of liquid fill volume on degree of repressurization and depressurization

Figure 4.13 - Influence of liquid fill volume on rate of pressure drop and rise

Figure 4.14 - Degree of repressurization as a function of initial pressure within steel vessel. A second order polynomial fit through the data illustrates the observed trend

Figure 4.15 - Locus of thermodynamic end states following pressure drop showing the heterogeneous limit of superheat for the $260 \mathrm{ml}$ test vessel.

Figure 4.16 - Influence of initial pressure on normalized repressurization

Figure 4.17- Influence of initial pressure on repressurization for a given depressurization

Figure 4.18 - Influence of initial pressure on rate of depressurization

Figure 4.19 - Influence of initial pressure on rate of repressurization

Figure 4.20 - Schematic of heterogeneous boiling from walls of $260 \mathrm{ml}$ vessel

Figure 4.21 - Sequence of high-siseed photographs showing heterogeneous boiling of R22 from the Teflon coated walls in the $260 \mathrm{ml}$ vessel $\left(\mathrm{P}_{\mathrm{i}}=1.03 \mathrm{MPa}\right)$

Figure 4.22 - Sequence of high-speed photographs showing heterogeneous boiling of R22 from the Teflon-coated walls in the $260 \mathrm{ml}$ vessel $\left(\mathrm{P}_{\mathrm{j}}=1.43 \mathrm{MPa}\right)$

Figure 4.23 - Instantaneous velocity of leading edge of two phase, heterogeneous, boiling wave.

Figure 4.24 - Degree of repressurization as a function of initial pressure within glass tube. A second order polynomial fit through the data illustrates the observed trend.

Figure 4.25 - Breakup of free surface of liquid R-22 contained within a glass tube following depressurization $\left(\mathrm{P}_{\mathrm{i}}=1.20 \mathrm{MPa}\right)$

Figure 4.26 - Evaporation wave displacement versus time $(\mathrm{Pi}=1.03 \mathrm{MPa})$ 
Figure 4.27 - Schematic of the propagation of evaporation wave in liciuid $\mathrm{R}-22$. ( $\mathrm{Pi}=$ $1.03 \mathrm{MPa}$

Figure 4.28 - Sequence of high-speed photographs showing the propigation of evaporation wave throughout length of glass tube. $(\mathrm{Pi}=1.03 \mathrm{MIP}: 1)$

Figure 4.29 - Sequence of high-speed photographs showing the heterogeneous boiling of R-22 within a glass tube. $(\mathrm{Pi}=2.24 \mathrm{MPal})$

Figure 4.30 - Sequence of high-speed photographs showing the heterogencous boiling of $\mathrm{R}-22$ without $\mathrm{CO}_{2}$ within the glass tube. $\left(\mathrm{P}_{\mathrm{i}}=1.20 \mathrm{MP}_{\mathrm{il}}\right)$

Figure 4.31 - Sequence of high-speed photographs showing the heterogencous boiling of $\mathrm{R}-22+\mathrm{CO}_{2}$ within the glatss tube. ( $\mathrm{Pi}=1.38 \mathrm{MPa}$ )

Figure 4.32 - Effect of dissolving $\mathrm{CO}_{2}$ in refrigerant on the boiling responst.

Figure 4.33 - Correlation for pressure undershoot as a lunction of initial icmperature and rate of pressure drop. Two curves shown bound the rates of depressurization observed experimentally.

Figure 4.34 - Comparison of pressure undershoot predicted by the correlation, using the average rate of depressurization of $1285.1 \mathrm{MPa} / \mathrm{s}$, with experimental values.

Figure 4.35 - Superposition of Experimental and Venting model Pressure Traces

Figure 4.36 - Schematic of Bubble Growth and Effect on Vapor Space

Figure A.1 - Saturation Pressure of R22 versus Temperature

Figure A.2 - Gaseous Specific Volume for R22 versus Temperature

Figure A.3 - Fluid Specific Volume for R22 versus Temperature

Figure A.4 - Latent Heal of vaporization for R22 versus Temperature

Figure A.5 - Liquid and vapor specific Heats for R22 versus Temperature

Figure A.6 - Surface Tension for R22 versus Temperature

Figure B.1 - Normalized repressurization as a function of depressurization

Figure B.2 - Influence of initial pressure on depressurization and repressurization

Figure B.3 - End state of liquid following depressurization shown with saturation and sp:nodal curves 


\section{List of Tables}

Table 3.1 - Comparison of thermodynamic properties of refrigerant 22 and Propane

Table 3.2 - Range of Experimental Parameters

Table C.1 - Variation of Area Data (Steel Vessel)

Table C.2 - Variation of Fill Volumes Data (Steel Vessel)

Table C.3 - Variation of initial Pressure (65\% Fill Volume, Steel Vessel, Magnitude Data)

Table C.4 - Variation of initial Pressure (90\% Fill Volume, Steel Vessel, Magnitude Data)

Table C.5 - Variation of initial Pressure (90\% Fill Volume, Preliminary Experiments)

Table C.6 - Variation of initial Pressure (65\% Fill Volume, Steel Vessel, Rate Data)

Table C.7 - Variation of initial Pressure (90\% Fill Volume, Steel Vessel, Rate Data)

Table C.8 - Variation of initial Pressure (90\% Fill Volume, Glass Test Tube)

Table C.9 - Variation of initial Pressure (90\% Fill Volume, Glass Test Tube+CO 


\section{List of Symbols}

\begin{tabular}{|c|c|}
\hline$k$ & Boltzmann constant $[\mathrm{J} / \mathrm{K} \cdot$ molecule $]$ \\
\hline$\theta$ & Contact Angle $\left[{ }^{\circ}\right]$ \\
\hline$\rho_{l i q}$ & Density, liquid $\left[\mathrm{kg} / \mathrm{m}^{3}\right]$ \\
\hline$\rho_{\text {vap }}$ & Density, vapor $\left[\mathrm{kg} / \mathrm{m}^{3}\right]$ \\
\hline$\alpha$ & Evaporation rate per unit area $\left[\mathrm{kg} / \mathrm{m}^{2} \mathrm{~s}\right]$ \\
\hline$h$ & Enthalpy $[\mathrm{J} / \mathrm{kg}]$ \\
\hline$\Delta \Phi$ & Free Energy [J] \\
\hline$\Delta \Phi^{\bullet}$ & Free Energy, heterogeneous [J] \\
\hline$\Delta \Phi^{*}$ & Free Energy, critical $[\mathrm{J}]$ \\
\hline$\Gamma$ & Factor in equation [2] \\
\hline$G b$ & Gibbs Number \\
\hline$\Omega$ & Heat flux density [W] \\
\hline$f$ & Heterogeneous Factor \\
\hline$q$ & Heat flux per unit area $\left[\mathrm{W} / \mathrm{m}^{2}\right]$ \\
\hline$J$ & Nucleation Rate [nuclei $\mathrm{m}^{-3} \cdot \mathrm{s}^{-1}$ ] \\
\hline$J a$ & Jakob Number \\
\hline$L$ & Latent Heat of Vaporization [J/kg] \\
\hline$m$ & Molecular Mass [kg/kmol] \\
\hline$k_{f}$ & Molecular Evaporation Rate $\left[\mathrm{kg} / \mathrm{m}^{2} \mathrm{~s}\right]$ \\
\hline$n$ & Number of vapor bubbles \\
\hline $\begin{array}{l}N_{o} \\
\Delta P_{\text {drop }}\end{array}$ & $\begin{array}{l}\text { Number density of liquid }\left[\mathrm{m}^{-3}\right] \\
\text { Pressure drop [MPa] }\end{array}$ \\
\hline$\Delta P_{\text {total }}$ & Pressure drop, total [MPa] \\
\hline$\Delta P_{\text {rise }}$ & Pressure rise [MPa] \\
\hline$P_{f}$ & Pressure, final $[\mathrm{Pa}]$ \\
\hline$P_{g}$ & Pressure inside bubble [Pa] \\
\hline$P_{i}$ & Pressure, initial $[\mathrm{Pa}]$ \\
\hline$P_{o}$ & Pressure of surrounding liquid [Pa] \\
\hline$P_{\text {sat }}$ & Pressure, saturation $[\mathrm{Pa}]$ \\
\hline$\dot{R}$ & Radial velocity of bubble growth [m/s] \\
\hline$(\Delta P / \Delta t)_{d r o p}$ & Rate of pressure drop $[\mathrm{MPa} / \mathrm{ms}]$ \\
\hline$(\Delta P / \Delta t)_{\text {rise }}$ & Rate of pressure rise $[\mathrm{MPa} / \mathrm{ms}]$ \\
\hline$r^{*}$ & Radius of vapor bubble, critical [m] \\
\hline
\end{tabular}




$\begin{array}{ll}R, r & \text { Radius of vapor bubble }[\mathrm{m}] \\ R_{o} & \text { Radius of vapor bubble, initial }[\mathrm{m}] \\ \sigma & \text { Surface Tension [Pa'm] } \\ C p_{l i q} & \text { Specific Heat, liquid }[\mathrm{J} / \mathrm{kg} \cdot \mathrm{K})] \\ C p_{\text {vap }} & \text { Specific Heat, vapor }[\mathrm{J} / \mathrm{kg} \cdot \mathrm{K})] \\ A & \text { Surface Area }\left[\mathrm{m}^{2}\right] \\ v_{l i q} & \text { Specific Volume, liquid }\left[\mathrm{m}^{3} / \mathrm{kg}\right] \\ v_{\text {vap }} & \text { Specific Volume, vapor }\left[\mathrm{m}^{3} / \mathrm{kg}\right] \\ \Delta T & \text { Superheat }[\mathrm{K}] \\ t & \text { Time }[\mathrm{s}] \\ T_{c} & \text { Temperature, critical }[\mathrm{K}] \\ d & \text { Thermal conduction layer thickness }[\mathrm{m}] \\ T_{f} & \text { Temperature, final }[\mathrm{K}] \\ T_{i} & \text { Temperature, initial }[\mathrm{K}] \\ k & \text { Thermal conductivity, liquid }[\mathrm{W} /(\mathrm{m} \cdot \mathrm{K})] \\ T_{s a t} & \text { Temperature, saturation }[\mathrm{K}] \\ V_{l i q} & \text { Volume of liquid }\left[\mathrm{m}^{3}\right] \\ w & \text { Weighting Factor }\end{array}$




\section{Introduction}

This thesis investigates the influence of thermodynamic and physical parameters on the explosive boiling response of a rapidly depressurized volatile liquid. A volatile pressurized liquid will boil explosively if the equilibrium conditions are suddenly removed, as in the case of rapid depressurization. The boiling response is characterized through the degree and rates of depressurization and repressurization and is dependent on the thermodynamic state of the liquid and physical constraints of the vessel geometry.

The conditions which determine whether a vessel containing pressure liquefied gas (LPG) will undergo a total loss of containment, or simply release its contents in the form of a jet, are not well understood. Undoubtedly the type of scenario that will unfold, in the case of an accident in the transportation of LPG in tanker cars, is of serious concern to regulatory and emergency response authorities. Due to the destructive nature and expense associated with medium and large-scale tests investigating the BLEVE (Boiling Liquid Expanding Vapor Explosion) problem, it has been difficult thus far to clearly establish the influence of different parameters on the rapid boiling processes. Medium scale iests by Birk et. all $\left.{ }^{1}\right]$, involving liquid propane in automotive tanks, have illustrated that the tank wall strength and initial pressure inside the tank play a key role in determining the boiling response and violence associated with the phenomenon, i.e., whether or not a BLEVE will occur. The pressure-time history within the tank after rupture is dependent in a complex way on the geometry, boundary conditions and initial thermodynamic state of the fluid. Using smallscale experiments, it is possible to carry out a systematic parametric investigation (as compared to larger scales), over a relatively well-controlled range of the variables.

\subsection{Motivation}

The sudden depressurization of a liquefied gas can lead to disastrous consequences. The explosive boiling that follows can lead to very rapid repressurizations and ultimately a BLEVE. The underlying phenomenon in a BLEVE is the rapid boiling of a pressure liquefied gas (LPG) contained in a tank following a sudden pressure drop, i.c., loss of equilibrium vapor pressure. The depressurization of a tank containing a volatile liquid can occur either intentionally (e.g., through the operation of a pressure relief valve), or accidentally through a loss of containment, (e.g., due to metal fatigue caused by an external heat source). The liquid remaining in the vessel can flash into vapor and the subsequent 
rapid pressure build-up may then lead to a violent rupture of the tank. Any exhausting liquid-vapor jets may also propel the tank for considerable distances. In the case of a combustible liquid, a violent dispersion of the tank contents can lead to an unconfined vapor cloud explosion. Such accidents have caused extensive damage in the past ${ }^{[2]}$ and are of concern to industries and regulatory agencies involved with the transportation and storage of pressure liquefied gases.

Explosive boiling of a superheated liquid can also be observed in many natural phenomena. A volatile liquid coming into contact with a hotter liquid will result in very rapid heat transfer and phase change leading to a violent production of volatile vapor. Foundries often have severe incidents involving the explosive boiling of cooling water which has accidentally come into contact with molten metal. Not only does this produce great pressure shocks due to the rapid vaporization but also allows for the dispersal of molten metal which eventually causes fire damage. Volcanic eruptions, where suppressed molten magma is suddenly released due to rapid depressurization results in superheated magma which is expelled in a great physical explosion. In this case, contact between subsurface water and the magma may lead to a phreatomagmatic explosion or the rapid exsolution of dissolved gases in the magma may drive the explosion. The rapid superheating of liquids, either by sudden depressurization or heating as in the case of a physical vapor explosion have been studied extensively in the past using small si ale experiments in an attempt to study the phenomenon under controlled conditions.

Rapid evaporation, when produced in a controlled manner has many interesting and practical applications. Spray drying is used to evaporate the volatile constituent of foods in order to produce powdered products. Another use is cooling and flash injection, where fuel can be superheated and finely atomized through a rapid evaporation process. Ink jet printer technology also utilizes rapid evaporation of the ink to form a liquid jet.

\subsection{Previous Work}

Past experimental work on BLEVE-related phenomena has ranged from prototypical scale tests involving railway and automotive tanks containing pressure-liquefied gases to smallscale studies investigating the fundamental dynamics of the boiling of a depressurized liquid. For example, Birk et al.,[1,3] have studied the explosion of automotive propane tanks subjected to a pool fire. They observed that the most violent explosions were obtained when the pressure within the tank at rupture was above a threshold value. 
However, the difficulty of obtaining reliable and reproducible measurements of the pressure history within the tank at large scale, precluded obtaining detailed fundament:al information on the dynamic boiling behavior of the liquid inside. On the other hand, detailed photographic studies of the boiling of depressurized liquids at small scales have been carried out by Hill and Sturtevant ${ }^{[4]}$ and Chaves et al..[5]. They observed and investigated the details of the two-phase evaporation wave that propagated into a superheated liquid within a vertical glass tube. However, in both cases the venting rate was large and no repressurization was observed within the tube.

The rapid depressurization of hot saturated water in a pipe has been studied extensively due to its relevance to nuclear reactor safety, although in this case little repressurization is observed $[6,7]$. Very little repressurization was observed due to the initially low water temperature. For this case Alamgir and Lienhard[6] have developed a semi-empirical model based on homogeneous nucleation theory to predict the pressure undershoot. In studies on the rapid venting of refrigerant tanks, Friedel and Purps $\left[{ }^{[8]}\right.$ and Hervieu $[9]$ have studied the blowdown of refrigerant and propane tanks, respectively. Their work concentrated on the two-phase venting behavior with the aim of modeling the phenomenon to aid the design of pressure relief systems. Their tanks were vented using fast-opening valves, which resulted in rates of depressurization typically two orders of magnitude smaller than the rates obtained in the present study.

Ogiso et al. ${ }^{[10]}$ have also performed experiments with pressurized $\mathrm{H}_{2} \mathrm{O}$ and have observed water hammer effects as well as the impact of liquid fragments (droplets) against the inner surface of the vessel walls and pressure transducer sensing elements. They also concluded that there exists a limiting ratio of venting area to liquid-vapor free surface area for explosive boiling to occur. Below a ratio of $1 / 16$ no overpressures were observed.

Although some qualitative trends have been established, previous studies have not undertaken a systematic parametric investigation of the effects of the various parameters on the explosive boiling process occurring within a small vessel. 


\subsection{Objectives}

The objective of the present study is to investigate the dynamics of the boiling of a rapidly depressurized volatile liquid within a rigid walled vessel, using high-speed photography and fast-response pressure instrumentation. In particular, we concentrate on determining how the rate and amount of repressurization that occurs within the vessel following rapid venting, depends on initial and boundary conditions. The underlying objective throughout the study is to determine the conditions that yield the maximum repressurization within a vessel.

The state of the liquid is controlled through the initial vapor pressure $\left(\mathrm{P}_{i}\right)$ so that saturation conditions exist prior to diaphragm rupture. The use of small scale experiments permits a uniform temperature distribution throughout the pressurized liquid and a relatively wellcontrolled variation of the parameters that may affect the repressurization within the vessel. Such parameters varied include the liquid fill volume, the vent area and the degree of prenucleation of the liquid (as determined by the wall surface condition). Refrigerant-22 (R22 ) is used as the test liquid since it exhibits thermodynamic properties similar to propane, yet is not flammable.

\subsection{Outline}

The concepts of superheat, nucleation and bubble growth are introduced and discussed in Chapter 2. A description of the various components of the experimental facility and experimental procedure is found in Chapter 3. In Chapter 4, the experimental results are presented in three sections. First the general features of the boiling are discussed, followed by the results of scoping trials and the parametric investigation. Chapter 4 also discusses the results of a semi-empirical model and thermodynamic model and their correlation with experimental data. Chapter 5 summarizes the results, concludes the present work and proposes possible directions for further work. 


\section{Theoretical Considerations}

\subsection{Superheat of a Liquid}

In the present study we are interested in the process of explosive boiling initiated by a sudden pressure drop. A sudden isentropic drop of pressure from an initial state of equilibrium, i.e., where liquid and vapor phases are in equilibrium at $P_{i}=P_{\text {sar }}$ and $T_{i}=$ $T_{s a t}$, will result in a reduction of the pressure below the saturation pressure at the initial temperature. To re-establish the equilibrium vapor pressure the liquid will necessarily boil. A sudden drop in pressure, such as in an intentional or accidental rupture of a vessel will bring the liquid to a superheated state. The degree of superheat is defined as the amount by which the state of the liquid has surpassed the saturation state. The degree of superheat is normally expressed as the difference between the temperature following depressurization, $T_{f}$ and the saturation temperature at the pressure of the depressurized state, $T_{s a t}$ and is given by

$$
\Delta T=T_{f}-T_{s a t}\left(P_{f}\right)
$$

The process 1-2, shown in Fig. 2.1 along with the saturation curve and spinodal curve, follows the most likely thermodynamic path taken by a liquid following a sudden loss of pressure. The thermodynamic state of the liquid follows an isentropic expansion from $\mathrm{P}_{\mathrm{i}}$, initially as saturation, to a final pressure of $P_{f}$. For the initial temperature range of interest the isentropic depressurization is well approximated by an isothermal expansion, i.e., $T_{i}=$ $T_{f}$.

The decrease in system pressure below its initial saturation pressure will cause the liquidvapor equilibrium to be disrupted and thereby induce boiling to regenerate the pressure and re-establish equilibrium. The degree of superheat is therefore a measure of the thermal energy available for evaporation, i.e., the greater the superheat the more boiling energy available. The thermal energy available for a given superheat is given by equation [2] where $C p$ is the liquid specific heat and $\Delta T$ is the degree of superheat as defined in equation 1.

$$
\Delta h=C p_{L} \Delta T
$$




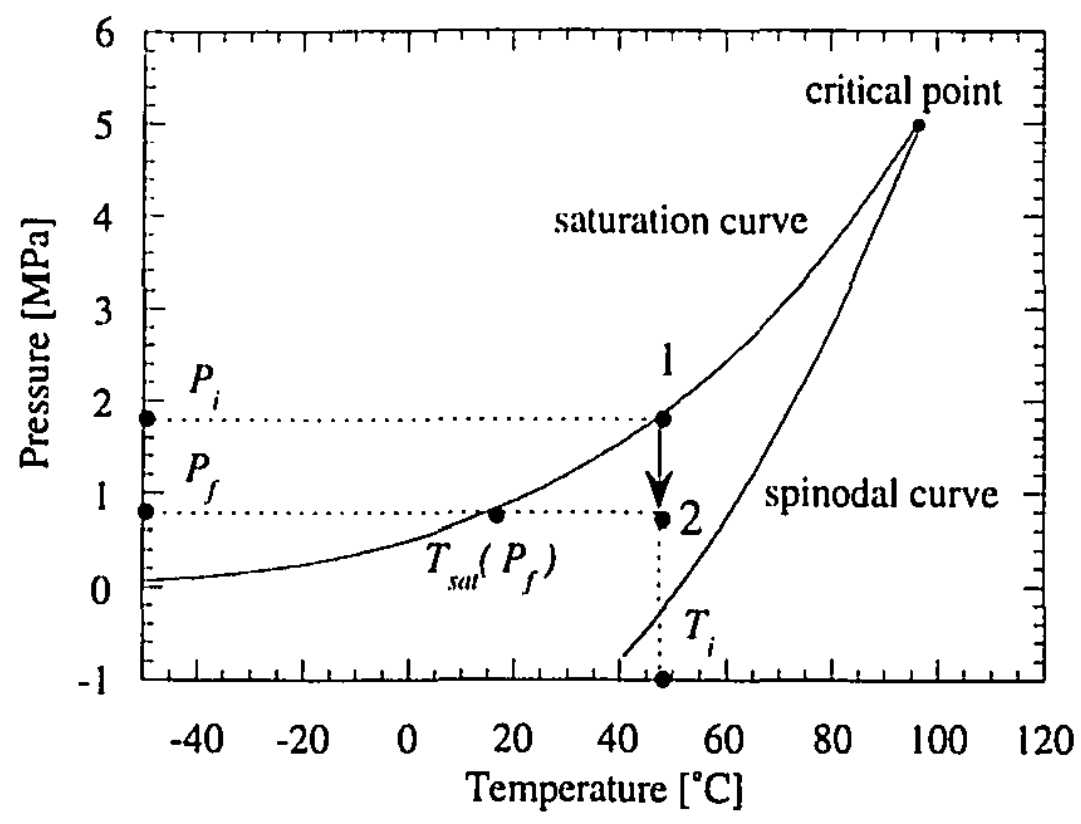

Figure 2.1 - Saturation and spinodal curves for refrigerant 22

Using the available thermal energy it is possible to define a non-dimensional degree of superheat. The Jakob number is the ratio of available thermal energy due to a superheat of $\Delta T$ to the required energy for complete boiling to occur, i.e.,

$$
J a=\frac{\Delta h}{L}
$$

where $L$ is the latent heat of vaporization. The Jakob number represents the fraction of liquid that can be converted to vapor at the expanded pressure $P_{f}$ due to the thermal energy available for a given superheat of $\Delta T$. The liquid specific heat and latent heat of vaporization both vary with temperature and are normally taken at the initial liquid temperature $T_{i}$.

\subsection{Thermodynamic Constraints}

The amount of superheat attainable for a given substance is finite and limited by thermodynamic and physical constraints. The thermodynamic limit of superheat is the greatest degree of superheat possible before the liquid flashes to vapor, i.e., the lowest depressurization that a liquid can withstand before undergoing an explosive phase change. Figure 2.2 shows the pressure-molar volume relationship for refrigerant 22 . The saturation 
dome is bound by the stable sub-cooled liquid on the left and stable superheated vapor on the right. Within the dome is a two-phase mixture of saturated liquid and saturated vapor. Using the van der Waals equation of state, isothermal lines for refrigerant 22 can be drawn over the saturation dome as shown in Fig. 2.2.

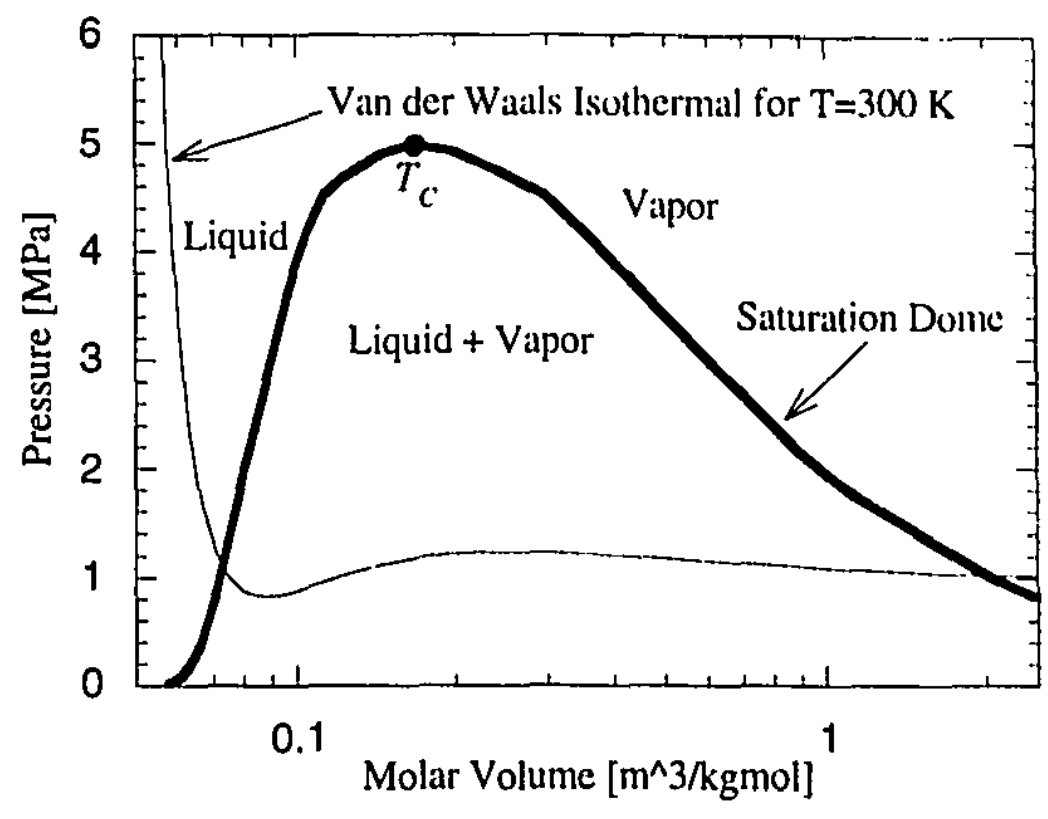

Figure 2.2 - Saturation dome with van der Waals Isothermal for $\mathrm{T}=300 \mathrm{~K}$

Outside the saturation dome the isothermal lines fix the state of the refrigerant for a given pressure and temperature. Within the dome the isothermal lines display the 'van der Waals' loops shown in Fig. 2.3, where regions $b$ and $c$ are non-physical, since the pressure cannot rise with an increase in volume at constant temperature. The non-physical regions, $b$ and $c$, are characterized by the condition $(\partial P / \partial V)_{T} \geq 0$, i.e., the point of inflection where the min-max occurs. The locus of points characterized by the condition passing through the points 1 and 2 defines the spinodal curve.

$$
(\partial P / \partial V)_{T}=0
$$

The spinodal curve and the saturation dome form the boundary for metastable regions $a$ and $d$. In these regions a liquid can be superheated and a vapor supersaturated without a phase change occurring, even though the states lie within the two phase dome. 


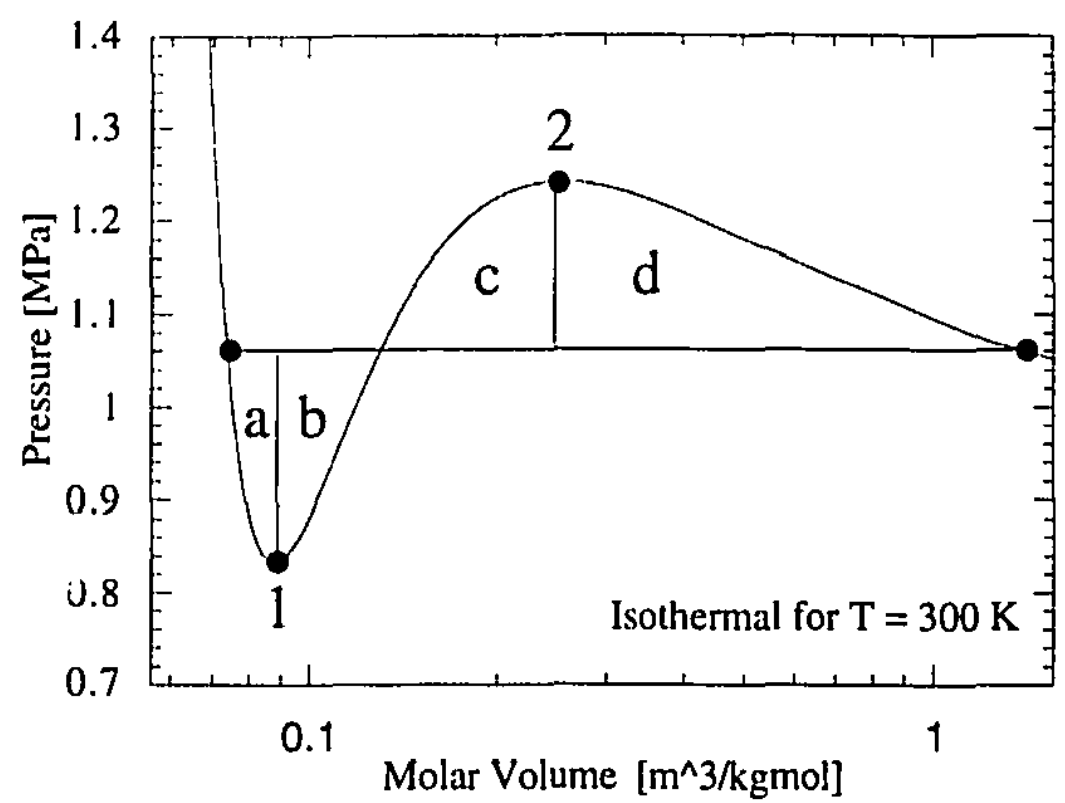

Figure 2.3 - Isothermal line within the saturation dome obtained from the van der Waals equation of state for $\mathrm{T}=300 \mathrm{~K}$

The degree to which a liquid, or vapor can be superheated or supersaturated is limited by the spinodal curve. The spinodal curve is a thermodynamic limit beyond which a liquid cannot remain in a liquid state and as a consequence flashes explosively into vapor upon crossing the spinodal curve. The phenomena associated with this explosive phase change is known as a homogeneous superheat explosion and is expected to be the worst case scenario from the point of view of violence of boiling. The same can be said of vapor which can be only subcooled up to the spinodal curve, where upon crossing this metastable boundary condenses explosively.

Reid ${ }^{11]}$ proposed that a vapor explosion would occur following vessel failure if the depressurization brought the liquid to the superheat limit followed by homogeneous nucleation of the bulk of the liquid. This implies a cutoff pressure or temperature (corresponding to the superheat limit at atmospheric pressure) below which a homogeneous explosion would not occur. This relatively simple criterion for an explosion must be modified to account for additional complexities, such as the presence of impurities or preexisting bubbles within the liquid bulk. For example, if bubbles or other nucleation sites are present within the liquid prior to depressurization, the threshold for boiling to begin is lowered, limiting the amount of depressurization that can be attained. 
Much experimental work has focused on measuring the experimental limits of superheat for various substances $[12]$ in an attempt to verify how close the experimental limits comespond to the theoretical limits as predicted by equation 4 .

\subsection{Energy Requirements for Bubble Growth and Nucleation}

Although the thermodynamic limit of superheat, based on the condition $(\partial P / \partial V)_{T}=0$. yields a limiting value of superheat, it does not however give insight on the mechanism of the explosive boiling that occurs once the limit is reached. A second approach to the explosive boiling of a super heated liquid is the kinetic limit of superheat. The basis of the kinetic limit of superheat deals with the actual growth of a vapor nuclei. Thermal fluctuations within a metastable liquid cause local moiecular scale density variations which produce microscopic vapor nuclei. In response to the surrounding liquid conditions the nuclei will either grow or collapse. The growth of the vapor nuclei will depend primarily on the degree of superheat, i.e., how far the liquid state has penetrated into the metastable region before any boiling occurs.

Suppose we consider the mechanical equilibrium of a spherical vapor nuclei in a liquid at a constant temperature $T_{i}$ and pressure $P_{i}$. For a bubble to exist the vapor pressure inside the bubble must be greater than the surrounding liquid pressure. The amount by which the internal pressure must exceed the external pressure is exactly the energy required to hold the vapor bubble together. Where the surface tension force balances the internal pressure force,

$$
P_{g}=P_{o}+\frac{2 \sigma}{r^{*}}
$$

where $r^{*}$ is the critical nucleus radius, $P_{\mathcal{g}}$ the pressure inside the bubble and $P_{n}$ the pressure of the surrounding liquid. Note that the pressure surrounding the bubble is the pressure at the depressurized state, i.e., $P_{f}=P_{o}$. Nuclei are normally suppressed in a compressed liquid and do not grow due to strong surface tension forces. When a liquid is suddenly depressurized and brought to a superheated metastable state there exists internal vapor overpressure inside the nuclei to promote its growth. All of the nuclei that 'save a radius of $r^{*}$ or greater will grow. Smaller nuclei will not grow. The process of vapor formation in the metastable liquid is referred to as homogeneous nucleation. Homogeneous nucleation 
therefore originates within the bulk of the liquid at the liquid-vapor interface of each microscopic nuclei of radius $\geq r^{*}$.

The rate at which a new phase forms depends on the free energy of an initial, very small critical mass, i.e., nuclei, of the new phase. The rate of phase transition is proportional to the exponential of the free energy of the nuclei being formed, i.e.,

$$
\text { Rate } \propto \exp \frac{-\Delta \Phi}{k T}
$$

where $\Delta \Phi$, the free energy of nucleus formation depends not only on the free energy to form the bulk of the nucleus of the new phase, but also on the surface energy of this vapor nucleus. $k T$ is the mean kinetic energy of the liquid molecules with $k$ as the Boltzmann constant and $T$ as the temperature. Given a sufficiently long time interval, any liquid should evaporate at the boiling point, if heat is added to the system. In practice, however in the absence of pre-existing nucleation sites, considerable superheat is required before even small amounts of boiling occurs. An increase in superheating beyond this, will result in very rapid evaporation. $\Delta \Phi$, therefore increases greatly as the temperature increases.

In a superheated liquid, small vapor nuclei of molecular size will be formed by random density fluctuations $[13\}$. These vapor nuclei, containing only a few molecules, are known as embryos. In a small embryo, the interface and the bulk are of comparable energies and the surface free energy of the embryo must be added to the free energy of evaporation of the material in the bulk of the embryo since the molecules at the surface of the embryo possess an additional free energy. If the embryo is large enough, the bulk term in the free energy of its formation will be equal to the surface energy term, and the embryo will be in stable equilibrium. It is then called a nucleus. On this nucleus more molecules of liquid may evaporate. The bigger the nucleus grows the more stable it becomes, and the interfacial term becoming relatively less important [13].

The free energy of formation of an embryo is found as follows. Consider that in a superheated liquid a small spherical vapor cavity, of radius $r$ has been formed. The total free energy of formation of this embryo may be expressed as a balance of the surface tension, $4 \pi r^{2} \sigma$ and the free energy necessary for evaporation, $\frac{4}{3} \pi r^{3}\left(P_{g}-P_{o}\right)$, i.e., 
$\Delta \Phi=$ Surface free energy of embryo - Free' energy to evaporase bulk of embryo, hence $\Delta \Phi$ becomes

$$
\Delta \Phi=4 \pi r^{2} \sigma-\frac{4}{3} \pi r^{3}\left(P_{s}-P_{0}\right)
$$

The process of evaporation will occur spontaneously if the free energy $\Delta \Phi$ is decreased, or the temperature decreased beyond a certain critical value, that is the ratio $\Delta \Phi / k T$. If we plot $\Delta \Phi$ as a function of $r$ for a constant temperature of $53^{\circ} \mathrm{C}$ and assume that $P_{i}-P_{f}=$ $2 \times 10^{6} \mathrm{~Pa}$ with $\sigma=0.00414 \mathrm{~Pa} \cdot \mathrm{m}$ we see from Fig. 2.4, that at low values of $r$ the free energy is positive. For larger embryos, however, the ratio of volume to surface area increases, and $\Delta \Phi$ reaches a maximum, decreases, and becomes negative for very large embryos. Clearly, $\Delta \Phi$ is decreased with

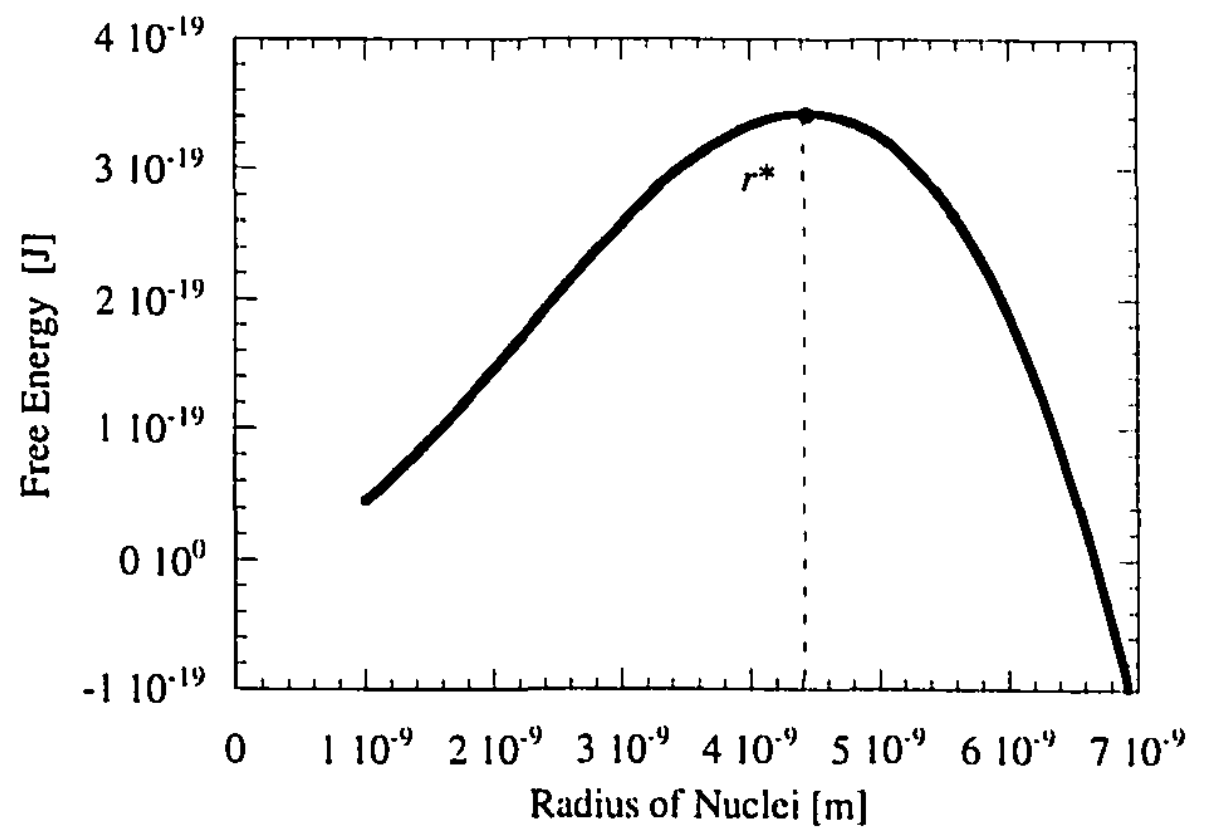

Figure 2.4 - Free energy necessary for bubble growth

further growth after the embryo has reached a radius of $r^{*}$, and an embryo of this critical size, which will continue to grow in the superheated liquid, is a spontaneously formed nucleus. All nuclei of size $r \geq r^{*}$ will continue to grow indefinitely, retaining the liquid molecules that strike it; even a single nucleus will eventually lead to evaporation of a superheated liquid. The latter process, however, would be very slow and, in practice, numbers of nuclei of the order $>10^{7}$ must be formed per $\mathrm{cm}^{3}$ per second for evaporation to proceed at a measurable rate. 
Since the critical radius of nucleus is that at which $\Delta \Phi$ reaches a maximum, it may be calculated from the condition $\partial(\Delta \Phi) / \partial r=0$. From Equation 7 the equilibrium condition $\partial(\Delta \Phi) / \partial r$ gives,

$$
\begin{gathered}
8 \pi r \sigma-4 \pi r^{2}\left(P_{g}-P_{o}\right)=0 \\
r^{*}=\frac{2 \sigma}{\left(P_{g}-P_{o}\right)}
\end{gathered}
$$

From $r^{*}$ we may obtain $\Delta \Phi^{*}$, the free energy of formation of an embryo just large enough to grow,

$$
\Delta \Phi^{*}=\frac{16 \pi \sigma^{3}}{3\left(P_{g}-P_{o}\right)^{2}}
$$

It is important to note that $P_{g}$ is the actual pressure within the critical size vapor nuclei and is not the saturation vapor pressure $P_{i}$ for a given temperature $T_{i}$. The difference between the pressure within the vapor bubble and the pressure outside the bubble, i.e., $P_{g}-P_{o}$, can be found in terms of the initial saturated liquid pressure, $P_{i}$ and the pressure at the depressurized state, $P_{f}=P_{o}$.

$$
\left(P_{g}-P_{o}\right)=\left(P_{i}-P_{f}\right)\left(1-\frac{v_{l i q}}{v_{\text {vap }}}\right)
$$

With a knowledge of $\Delta \Phi^{*}$, the rate of nucleation, $J$, can now be found using Equation 6 . The nucleation rate, or frequency, $J$, has the units of nuclei $\mathrm{m}^{-3} \mathrm{~s}^{-1}$ and is simply the number of nuclei formed in a cubic meter within a second. The nucleation frequency is commonly represented as ${ }^{[12]}$

$$
J=\Gamma k_{f} N_{o} \exp ^{(-\Delta \Phi / k T)}
$$

where $N_{o}$ is the number density of a single activated molecule, $k_{f}$ is the molecular evaporation rate and $\Gamma$ is a factor used to account for the possibility that nuclei larger than $r^{*}$ will decay. Assuming that requals unity introduces little error in predicting J.[12] From classical homogenous nucleation theory[14] the product $\Gamma k_{f}$ can be expressed as $\Gamma k_{f} \approx 2 \sigma / \pi m$ where $m$ is the molecular mass. 


\subsection{Heterogeneous Nucleation and Physical Constraints}

Homogenous nucleation occurs only under the most ideal of conditions and is often overshadowed by heterogeneous nucleation. Foreign bodies and container surfaces provide a source of nuclei to act as centers for vapor formation. This method of nuclei formation, from pre-existing nuclei is called heterogeneous nucleation. In contrast to homogeneous nucleation, where the nuclei are formed within the bulk of the liquid heterogeneous nucleation arises from nuclei originating from pre-existing nuclei. Sources of pre-existing nuclei are dissolved gases and vapor trapped in microscopic cracks and scratches on the container surfaces. The presence of these extra liquid-vapor interfaces reduce the superheat required to maintain a bubble of radius $r^{*}$ in an unstable equilibrium. The energy of formation, i.e., $\Delta \Phi$, of an equilibrium vapor embryo formed from a heterogeneous source is reduced by a factor $f$. Davies ${ }^{[13]}$ has shown that $f$ varies as a function of the contact angle $\theta$ between the surface and the liquid. If a liquid completely wets the surface $\left(\theta=0^{\circ}\right)$ no superheat is required for nucleation to occur since the energy of formation is zero. Usually most surfaces will wet the liquid and $\theta$ will range between $0^{\circ}$ and $180^{\circ}$ where $f$ ranges from 1 to 0 . The relationship between the contact angle and the value of the heterogeneous correction factor $f$ has the form ${ }^{[15]}$

$$
f=\frac{1}{4}\left(2+2 \cos \theta+\cos \theta \sin ^{2} \theta\right) .
$$

The required energy to form a nuclei from a heterogeneous source is therefore nbtained as

$$
\Delta \Phi^{\prime}=f(\theta) \Delta \Phi,
$$

where $\Delta \Phi$ is the required work to form a nuclei from a homogenous source and $f$ is the correction factor for the contact angle $\theta$. The rate of heterogeneous nucleation should also be proportional to the surface density of the number of molecules in the liquid and not to the volume density, No. Therefore the factor $N_{o}$ is replaced by the number of molecules per unit surface area, $N_{o}^{2 / 3}$.

\subsection{Growth of a Superheated Vapor Bubble}

Having addressed the issues of superheat and the criteria for growth of a bubble in a superheated liquid, as well as the rate of nucleation we now turn our attention to the details of a single bubble growing in a superheated liquid. 
The growth of a vapor bubble, emerging from a nuclei of critical size $r \geq r^{*}$ is distinguished by three modes of growth. The first mode, dominated by surface tension, occurs very early and has a negligible influence on the later modes and is therefore neglected. The two later modes are due to the fact that an initially superheated spherical bubble will eventually lose its superheat due to evaporation as it grows. The initial hydrodynamic mode occurs as a consequence of the initially high pressure within the bubble and results in the Rayleigh solution where the bubble grows at a constant velocity and $R(t) \sim t$. The second mode of growth occurs due to heat diffusion across the bubble surface and reduces the velocity of the bubble according to $R(t) \sim t^{1 / 2}$.

The Rayleigh bubble growth equation ${ }^{[16]}$ for a non-viscous incompressible liquid is obtained from the conservation laws of mechanical energy and mass. The energy balance between the kinetic energy of motion and the pressure work done gives,

$$
\int_{R_{v}}^{R} 4 \pi r^{2} \Delta P(t) d r=\frac{1}{2} \int_{R}^{\infty} 4 \pi r^{2} \rho v^{2} d r
$$

From the continuity equation for an incompressible liquid, the volume flow rate through the surface of an arbitrary spherical cavity with evaporation occurring at the boundary.

$$
4 \pi r^{2} v(r, t)=4 \pi R^{2} \dot{R}\left(1-\frac{\rho_{v a p}}{\rho_{l i q}}\right)
$$

The term in brackets on the left hand side of equation 16 is added to account for radial convection on the bubble growth and is of importance only at high pressures[17]. The radial velocity is now found as,

$$
\begin{gathered}
\varepsilon=\left(1-\frac{\rho_{\text {vap }}}{\rho_{\text {liq }}}\right) \\
v(r, t)=\varepsilon\left(\frac{R}{r}\right)^{2} \dot{R} \\
2 \int_{R_{o}}^{R} r^{2} \Delta P(t) d r=\varepsilon^{2} \rho_{l i q} R^{3} \dot{R}^{2}
\end{gathered}
$$


Substituting into the energy balance equation [15] we obtain an integral relation [19] which is then differentiated with respect to time by taking $\dot{R} \partial / \partial R$ of the left side and dividing by $2 R^{2} \dot{R} \rho_{l i q} \varepsilon^{2}$. This gives the Rayleigh equation of motion for a bubble, with $\varepsilon=1$.

$$
\frac{1}{2 R^{2} \dot{R}} \frac{d}{d t}\left(R^{3} \dot{R}^{2}\right)=R \ddot{R}+\frac{3}{2} \dot{R}^{2}=\frac{\Delta P}{\varepsilon^{2} \rho_{\text {liq }}}
$$

In the case of a constant pressure difference, i.e., $\Delta P=$ constant and assuming that there is no acceleration term, the energy balance equation gives an exact relation for the radial velocity,

$$
\dot{R}(t)=\left\{\frac{2 \Delta P}{3 \varepsilon^{2} \rho_{l i q}}\left(1-\left(\frac{R_{o}}{R}\right)^{3}\right)\right\}^{1 / 2}
$$

For the asymptotic solution, where $R / R_{o} \rightarrow \infty$, we see that the radius increases linearly with time as,

$$
R(t) \sim\left(\frac{2 \Delta P}{3 \varepsilon^{2} \rho_{\text {liq }}}\right)^{1 / 2} t
$$

The above solution of the Rayleigh equation is valid for both expansions, $\Delta P>0$ and implosions, $\Delta P<0$. During the initial growth of the vapor bubble, the bubble pressure rapidly decays to the ambient pressure as the bubble expands. Therefore the inertial bubble growth regime only occurs at very early times $(\sim 1 \mu \mathrm{s})$

The second mode of bubble growth is controlled by heat diffusion, where evaporation occurs at the liquid-vapor interface and heat is supplied by the superheated liquid by conduction through a thermal boundary layer. The heat flux per unit area based on a simple heat-diffusion model for the asymptotic growth of a uniformly superheated vapor bubble is

$$
q=\frac{\Omega}{A}=k \frac{\Delta T}{d}=\alpha L
$$

where $\Omega$ is the heat flux density, $A$ the surface area, $k$ the liquid thermal conductivity, $d$ the thickness of the thermal conduction layer at the bubble wall, $\Delta T$ the superheat, $\alpha$ the evaporation rate per unit area and $L$ the specific enthalpy of vaporization. The surface area of a spherical vapor bubble is $4 \pi R^{2}$. The evaporation rate can be written as $\alpha=\rho_{v a p} \dot{R}$ and using equation [23] the heat flux becomes 


$$
q=\rho_{v a p} \dot{R} L=k\left(\frac{\partial T}{\partial r}\right)_{r=R}
$$

In the case of transient heat conduction for a homogeneous semi-infinite body with a phase change, the thickness of the thermal boundary layer is defined as equation [25]. By substituting equation [25] into the heat flux relation, [24] we obtain the bubble growth equation

$$
\begin{gathered}
d=\left(\frac{\pi k t}{\rho_{l i q} C_{p}}\right)^{1 / 2} \\
R(t) \sim 2 \frac{\Delta T}{\rho_{\text {vap }} L}\left(\rho_{l i q} C_{p} k t\right)^{1 / 2} .
\end{gathered}
$$

The initial bubble radius, $R(0)$ has been neglected since the condition $R / R_{o} \rightarrow \infty$ holds for the second mode of bubble growth. We also note that the second mode of bubble growth is characteristic of diffusion as it follows $R(t) \sim t^{1 / 2}$ rather than the constant velocity growth as given by the Rayleigh mode, where $R(t) \sim t$.

\subsection{Optimum Conditions for Most Explosive Phase Change}

Having defined the concepts of superheat, nucleation and bubble growth, we are now in a position to investigate the optimum conditions for which the superheat, nucleation rates and bubble growth rates yield the most explosive boiling.

The maximum possible degree of superheat is associated with a drop in pressure from saturation conditions to the lowest possible state. The lowest possible state is bound by the atmospheric pressure line and the spinodal curve. The maximum possible superheat is shown below in Fig. 2.5 as a function of initial liquid temperature of R-22. We note that the maximum possible degree of superheat, also denoted as the superheat limit, for a given initial saturated liquid temperature increases until a maximum is reached at $53^{\circ} \mathrm{C}$. The superheat limit occurs at the temperature for which the spinodal line intersects the ambient pressure line, in our case atmospheric pressure. Therefore the superheat limit can be achieved if the pressure is dropped to the spinodal curve from an initial liquid temperature 
of at least $53^{\circ} \mathrm{C}$. Since the violence of the boiling is characterized by the degree of superheat, we would expect a greater boiling response near this temperature. For initial liquid temperature below $53^{\circ} \mathrm{C}$ a sudden depressurization to atmospheric pressure would not permit the state of the liquid to reach the spinodal limit and homogeneous bubble nucleation would not occur; thus the boiling will be induced solely heterogeneously, and the boiling process, although still explosive, will be considerably slower.

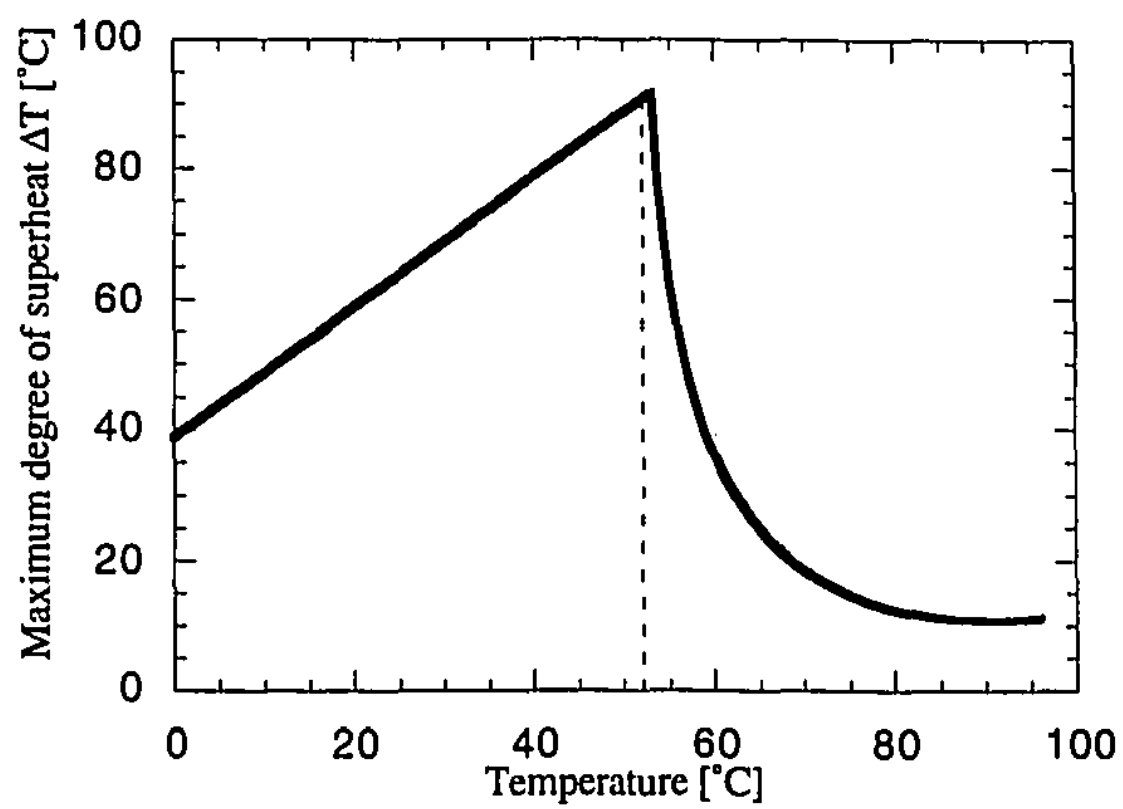

Figure 2.5 - Maximum Degree of Superheat as a function of initial temperature

During the course of the sudden depressurization of a liquefied gas in a steel container the increasing liquid superheat will be halted by heterogeneous boiling from pre-existing liquid vapor interfaces. This has the effect of reducing the degree of superheat below its maximum, as predicted by the thermodynamic superheat limit. The superheat, or pressure drop, that a real liquid can experience before it changes state, will depend on the boundary conditions of the vessel (wall conditions, vent area, geometry), the properties of the liquid and the initial conditions, i.e., temperature. In the case of a system prone to heterogeneous nucleation, where the wall conditions are such that they trap vapor or the liquid contains gaseous impurities, the actual degree of superheat will be lower than the maximum degree of superheat shown in Fig. 2.5. Although the magnitude of the superheat as a function of initial liquid temperature will vary according to the specifics of the particular system the general features should remain the same, i.e., the superheat should increase as a function of temperature and reach a maximum before starting to decrease. The influence of liquid fill 
volume, vent area and degree of pre-nucleation of the liquid (as determined by the wall surface condition) on the magnitude of superheat, as measured by the pressure drop, and the initial temperature at which the maximum superheat occurs will also be discussed in Chapter 4 using the experimental data obtained from both vessels.

For explosive boiling to occur the system must not only be subjected to a superheat condition but must also be able to generate nuclei which are capable of further growth. The nucleation rate $J$, was derived in section 2.3 and was found to be $J=\Gamma k_{f} N_{o} \exp ^{(-\Delta \Phi / k T)}$. All things being equal the temperature $T$, is the most dominant parameter in the nucleation rate relation. The value for $N_{o}$ is $3.7 \times 10^{35}$ which is the generally accepted value for the number density of typical liquids [18]. The typical behavior of the nucleation rate as a function of initial liquid temperature following a sudden depressurization to atmospheric pressure, as given by Fig. 2.5. is shown below (Fig. 2.6.)

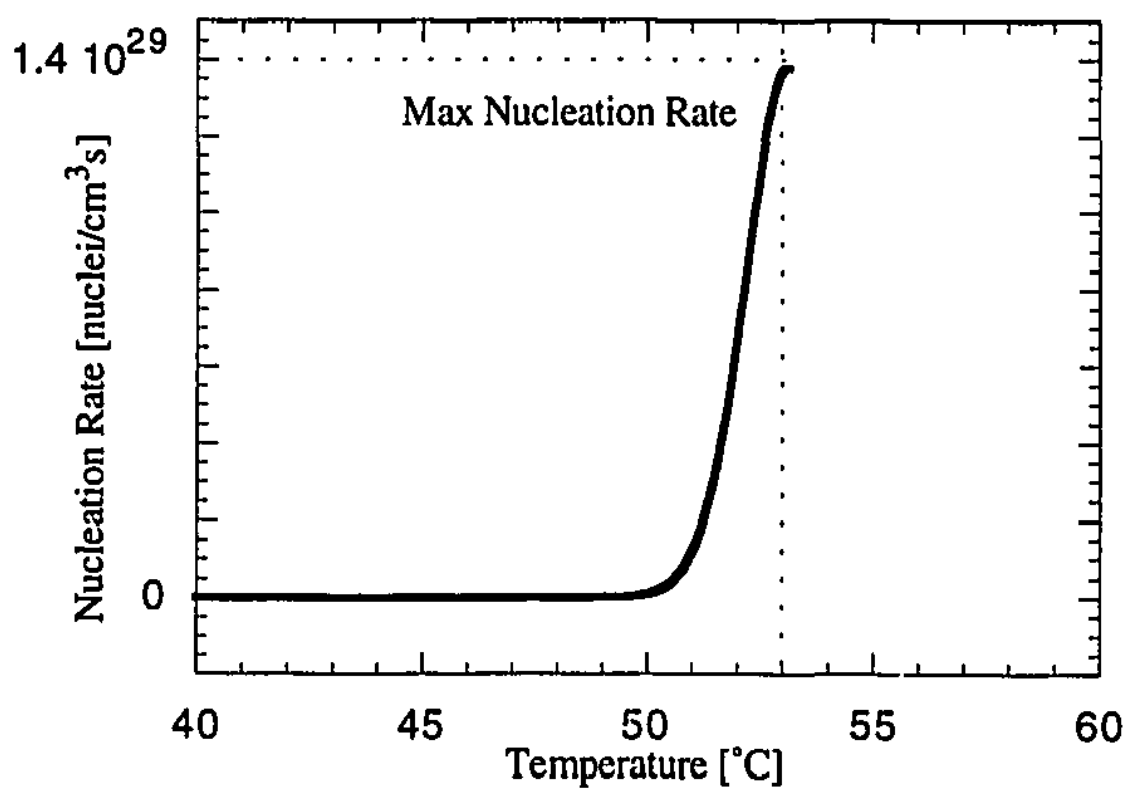

Figure 2.6 - Variation of Nucleation Rate with Temperature

We see that the rate of nucleation remains negligibly low until the temperature reaches close to the limit of superheat at atmospheric pressure, i.e., $T=53^{\circ} \mathrm{C}$. 


\section{Experimental Details}

\subsection{General Description of Experimental Facility}

The rapid depressurization facility used in the present investigation consists of several components and is shown schematically in Fig. 3.1. Two test vessels were used in the present study and are both shown in Fig. 3.2. Both vessels contain a variable area orifice sealed with a brass foil which is ruptured using a pneumatically-driven plunger. The vessels are equipped with ports for the delivery of the test liquid and the measurement of pressure and temperature.

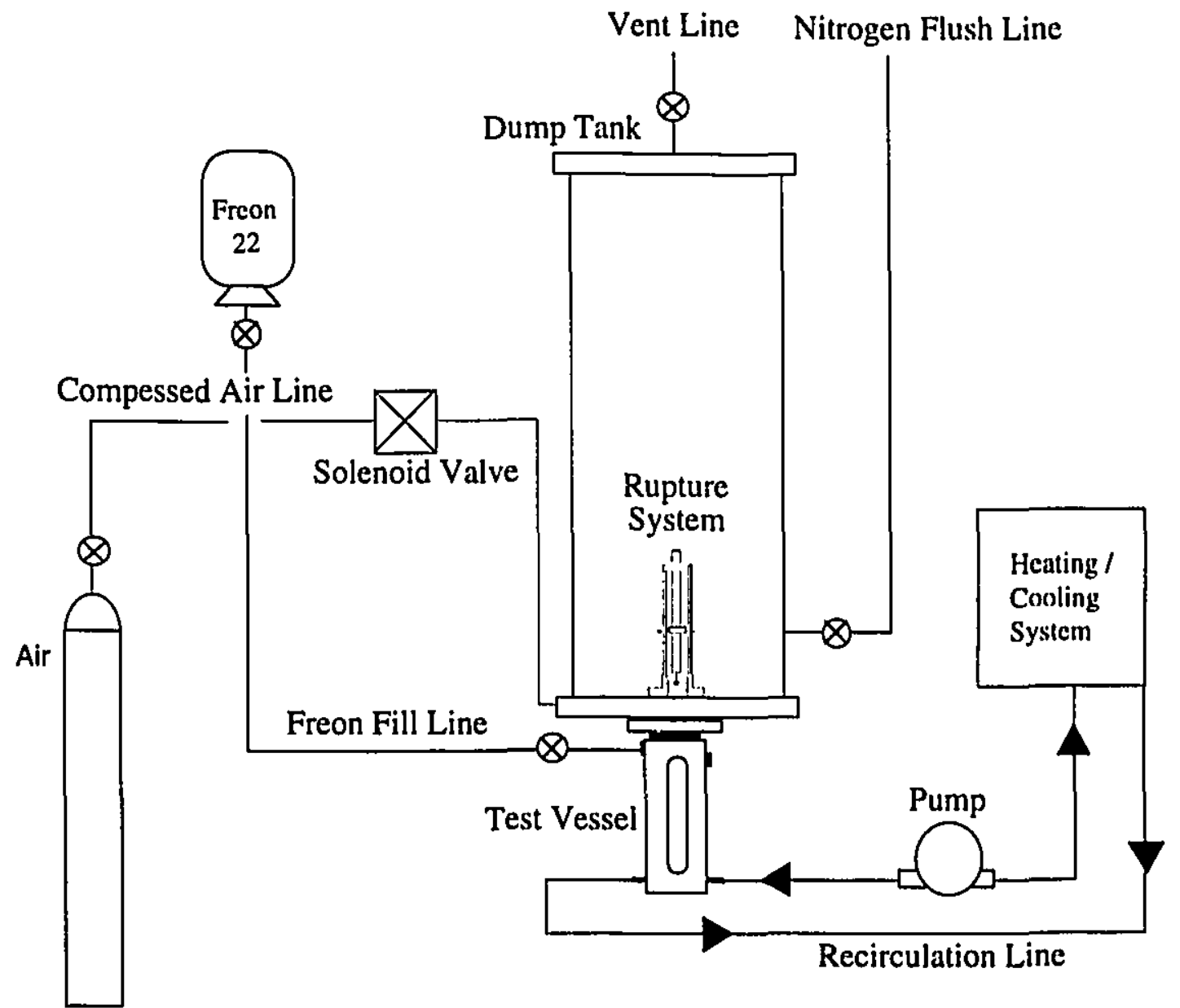

Figure 3.1 - Rapid Depressurization Facility

Introduction of the test liquid (R-22) into the test section from a reservoir is accomplished through a central plumbing control panel and ports on the vessel itself. Static measurements of the vapor pressure within the test volume during the filling process and 
prior to diaphragm rupture is monitored by analog pressure gauges (0-10 psi; 0-900 psi) mounted on the panel. Through various valves located on the panel it is also possible to pressurize the test volume from a compressed air cylinder, operate the pneumatically driven plunger, provide venting, and evacuate the vessel and dump tank volume via an Edward's $370 \mathrm{~W}(1 / 2$ H.P.) vacuum pump. Pressure transducers, mounted at one or more of the access ports of the vessel, are used for transient pressure measurements of the rapid depressurization and boiling processes following diaphragm rupture. The temperature of the test liquid was monitored through the use of specially designed thermocouple mounts fitting through one of the access ports.

A $0.13 \mathrm{~m}^{3}$ "dump tank" directly above the test vessel is used to capture the products of evaporation, i.e., a two phase jet, and the ruptured diaphragm fragments. To eliminate contamination of the laboratory and minimize the risks associated with volatile explosive vapors, the venting products are flushed with nitrogen.

\subsection{Experimental Vessels}

The first vessel consists of a rectangular steel block with a vertical slot $(2 \mathrm{~cm}$ wide $\times 19 \mathrm{~cm}$ high $\times 7.5 \mathrm{~cm}$ deep), forming a test section with a volume of $260 \mathrm{ml}$. To allow for the visual observation of the boiling process glass windows ( $2 \mathrm{~cm}$ thick) are mounted on either side of the slot, with o-ring seals. The vessel is sealed on the top via a diaphragm cap which compresses a diaphragm-foil assembly against the vent hole of the vessel. The interior of the steel vessel is coated with a layer of Teflon to protect the walls against corrosion and to minimize effects of wall nucleation.

The second vessel used in this study is comprised of a $75 \mathrm{ml}$ glass test tube $(2.5 \mathrm{~cm}$ dia., $15.2 \mathrm{~cm}$ long) placed within a $500 \mathrm{ml}$ cylindrical tube. The glass test tube is surrounded by glycerin to reduce diffraction effects and increase the rate of heat transfer from a heat exchanger tube located within the glycerin. Glycerin was chosen because of its high boiling point and is viscous enough to prevent sloshing during the rapid depressurization. The cylindrical tube is comprised of two windows which provide visual access to the whole length of the glass test tube. As in the $260 \mathrm{ml}$ vessel the interior wall of the $500 \mathrm{ml}$ cylindrical tube is coated with Teflon to protect against corrosion and the vent hole is sealed via a diaphragm cap. 


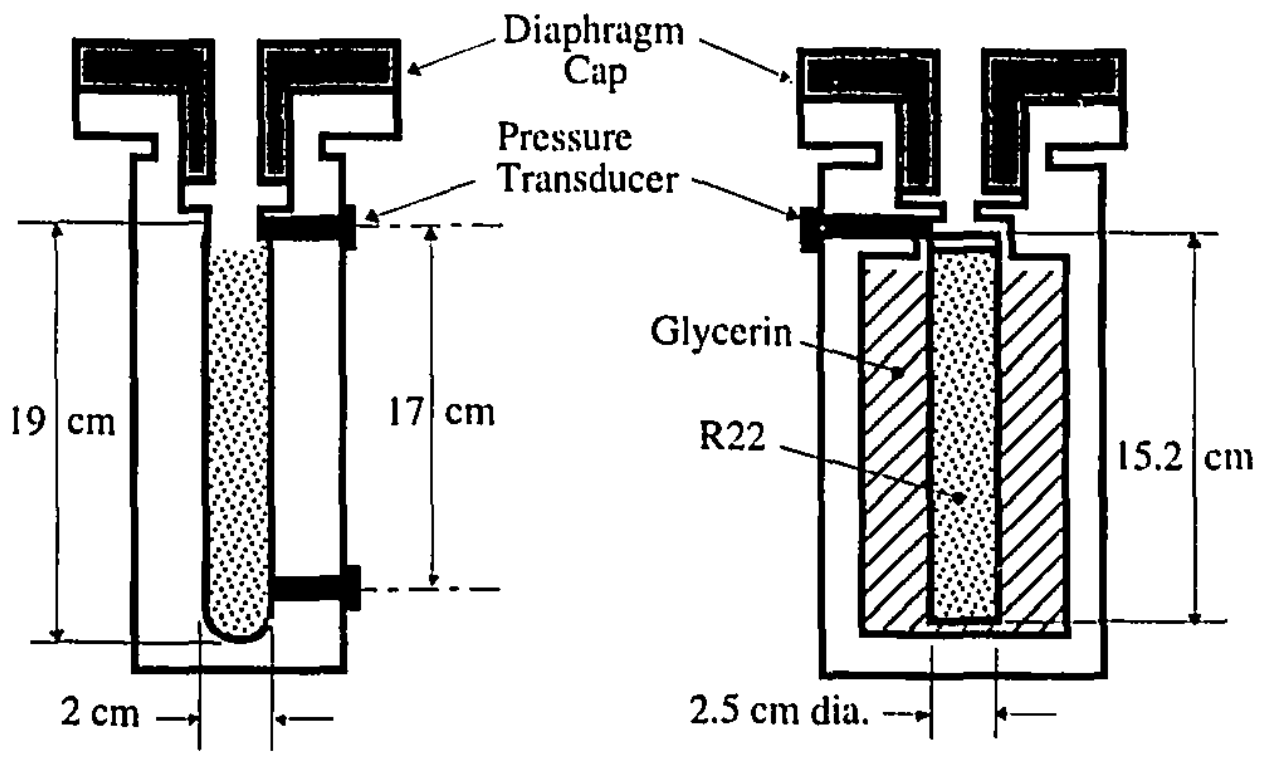

Figure 3.2 - Cross-section of Teflon coated $260 \mathrm{ml}$ Steel Vessel (left) and $75 \mathrm{ml}$ Glass Test Tube assembly (right)

\subsection{Heating/Cooling System}

The temperature of the liquid is controlled by flowing (cold/hot) water through the labyrinth-like slots which are machined into the exterior walls of the $260 \mathrm{ml}$ vessel. This process essentially cools/heats the walls of the $260 \mathrm{ml}$ vessel which are in direct contact with the test liquid. A Cole-Parmer model \#2-MD-HC, $30 \mathrm{~W}$ ( $1 / 25$ horse power) magnetic drive pump, connected to the vessel walls via $12.7 \mathrm{~mm}$ Tygon tubing, is used to recirculate the water. Prior to introducing the test liquid (R-22), the vessel walls are cooled to below $10^{\circ} \mathrm{C}$ by water from an ice-filled reservoir, ensuring that the R-22 inside the vessel is at a lower equilibrium pressure than that in the supply tank (corresponding to a room temperature of approximately $25^{\circ} \mathrm{C}$ ). Once the desired liquid fill volume has been reached, hot water from a heated reservoir is then recirculated through the vessel walls and the temperature is monitored by an Omega CN370 controller. To ensure heating uniformity, as well as to reduce premature non equilibrium boiling, the temperature of the liquid was increased gradually. With the assumption of equilibrium, the liquid temperature can then be inferred from the vapor pressure reading on the panel.

The liquid temperature was also monitored using thermocouples located on the outsidc of the $260 \mathrm{ml}$ vessel and the $75 \mathrm{ml}$ glass test tube. These thermocouples were calibrated to determine the temperature of the liquid inside the test liquid. The calibration of the $260 \mathrm{ml}$ 
vessel consisted of placing one thermocouple within the test liquid and one on the outside wall of the vessel. It was found that, due to the gradual increase in temperature of the test liquid and the high heat capacity of the steel vessel, once the test liquid was at the proper temperature the difference between the thermocouple readings of the temperature of the liquid and the external wall of the vessel was within $2^{\circ} \mathrm{C}$.

Similar to the $260 \mathrm{ml}$ vessel the temperature of the test liquid in the $75 \mathrm{ml}$ test tube is controlled by flowing water from a hot temperature reservoir through a single pass heat exchanger loop located within the glycerin. The calibration in this case consisted of simultaneously monitoring the temperature of five thermocouples as a function of time. Figure 3.3 shows the location of the five thermocouples which record the temperature of the water in the test tube, the water in the vessel (surrounding the test tube), the inside wall of the vessel, the outside wall of the vessel and the incoming water. For a range of recirculation flow rates and initial temperatures it was found that the temperature at locations $\mathrm{T} 4$ and $\mathrm{T} 5$ differed by less than $1^{\circ} \mathrm{C}$ after 10 minutes. After a recirculation time of 20 minutes, thermocouples T2-T6 had reached steady-state conditions and were all within $3^{\circ} \mathrm{C}$. The time required to heat the liquid within the vessel is between $20-40$ minutes with the present system and thus for all subsequent trials only one thermocouple (at position T6) was used to monitor the temperature. The $260 \mathrm{ml}$ vessel had a thermocouple located at position T2.

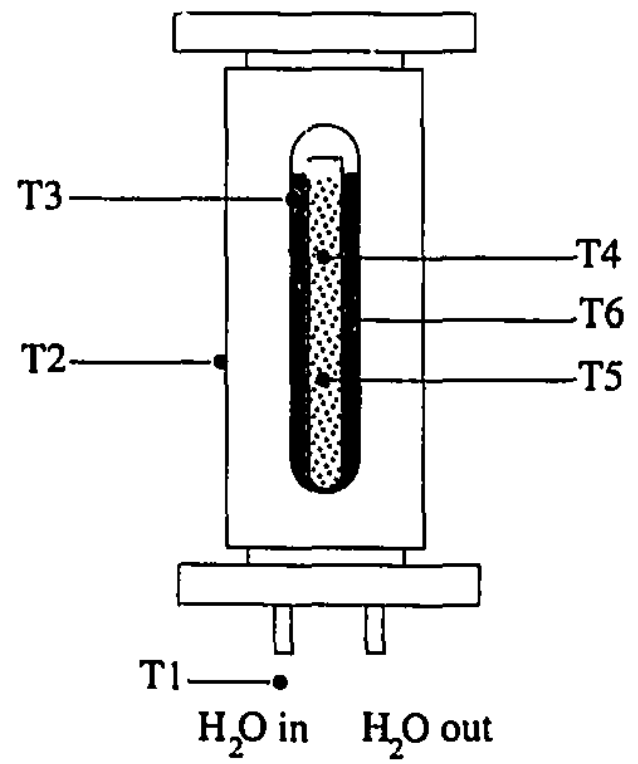

Liquid surrounding test tube

Liquid inside test tube

T1 : Initial recirculating hot water

$\mathrm{T} 2$ : Outside surface of vessel wall

T3 : Inside surface of vesselwall

T4 : Inside test tube position 1

T5 : Inside test tube position 2

T6: Inside liquid surrounding tube

Figure 3.3 -Schematic of $75 \mathrm{ml}$ Glass Test tube assembly showing location of transducers 
Prior to intrsducing the test liquid within the test tube, the glycerin surrounding the test tube was pre-heated to the desired test temperature. The test liquid (R-22) was then filled into a small stainless steel cylinder and heated to the desired temperature through a constant temperature bath. This process rapidly and uniformly heats the R-22. Once the glycerin and the R-22 were at the same temperature, the R-22 was injected within the glass test tube through a port via high pressure air. To properly introduce the test liquid within the test tube a special attachment was machined in Delrin, shown below in Fig. 3.4. The attachments consists of an annular groove in which the test tube sits, an angled filling spout and a transducer port. The Delrin attachment sits within the vessel along with another Delrin attachment to hold the bottom end of test tube.

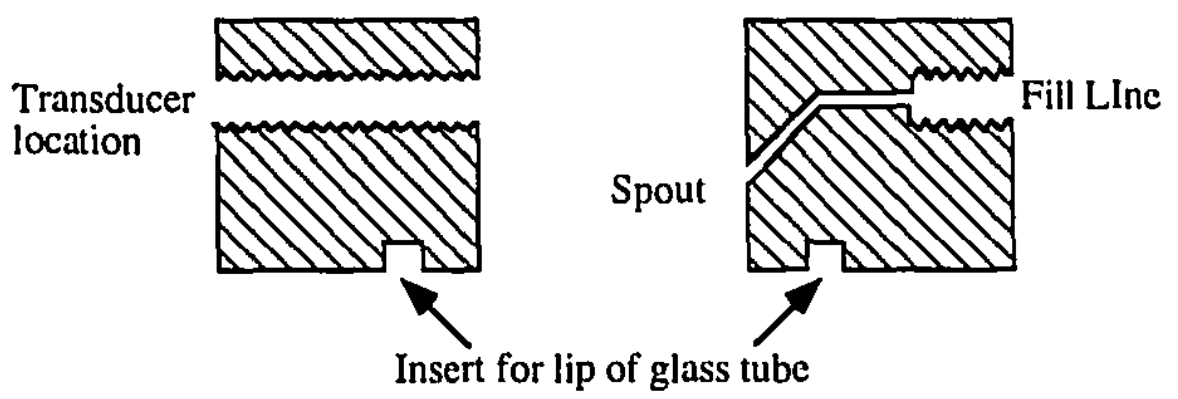

Figure 3.4 - Special Test Liquid Delivery Attachment

\subsection{Diaphragm Rupture System}

The diaphragm rupture system consists of a pneumatically driven plunger $(75 \mathrm{~mm}$ stroke length), activated by a solenoid valve supplying air at $1 \mathrm{MPa}$ (150 psi), as shown in Fig. 3.5. It takes approximately $80 \mathrm{~ms}$ between the time the solenoid valve is activated and the time for the leading edge of the plunger to reach the diaphragm.

The tip of the plunger consists of a crossed spear-like blade, as illustrated in Fig. 3.6a. Other plunger blades, such as a cross were considered, also shown in Fig. 3.6a, but the spear configuration proved to be the one which offered the least obstruction to the flow and the cleanest rupture and thus was used almost exclusively. The entire rupture assembly is located within the dump tank and is mounted on a flange, attached by bolts to the diaphragm cap resting on the top end of the test vessel. 


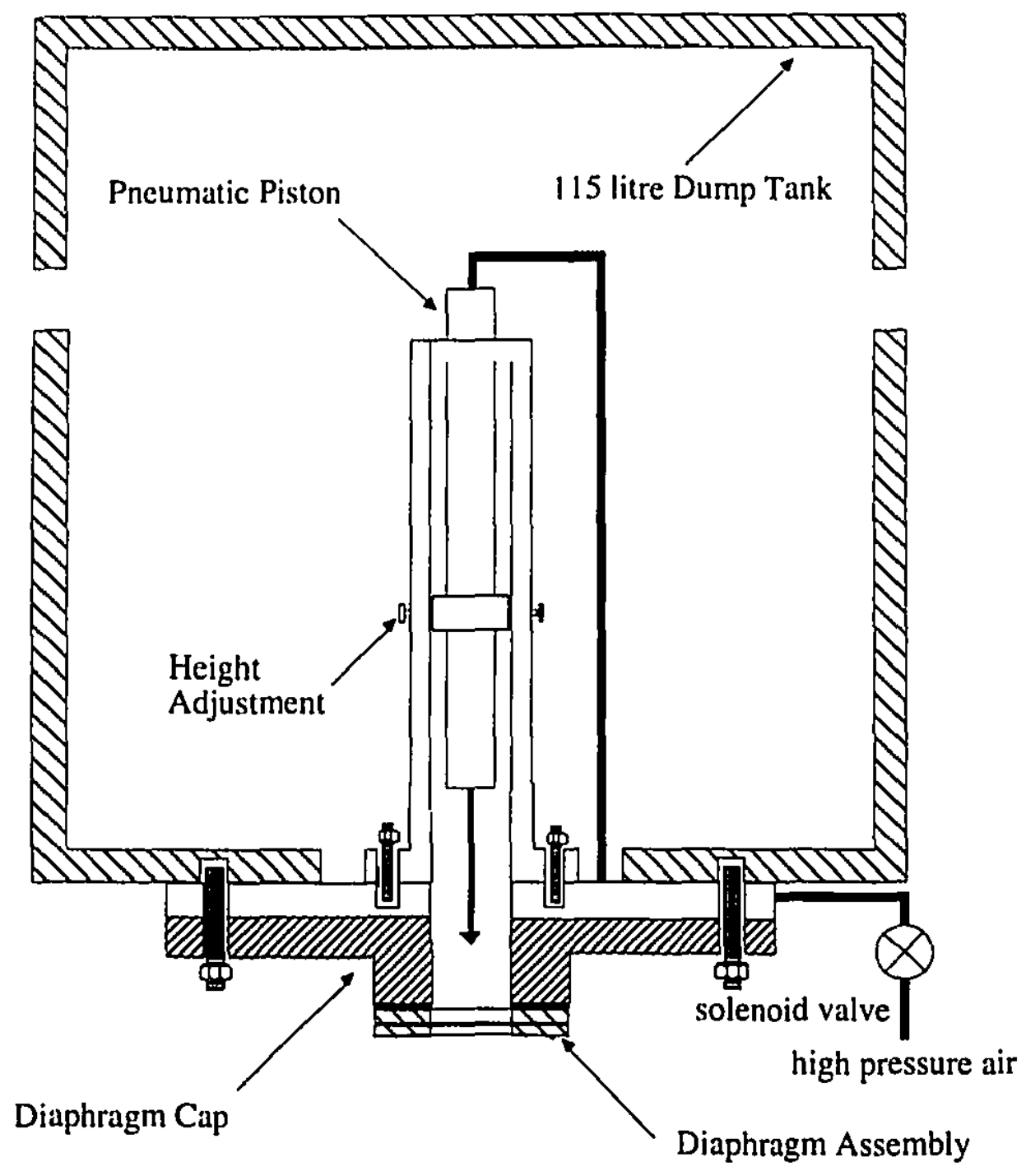

Figure 3.5 - Diaphragm Rupture System

The diaphragm assembly consists of a brass foil, sandwiched between two aluminum disks, shown schematically in Fig. 3.6b. O-rings and elevated rims provide a seal between the vapor pressure within the vessel (lower end) and the outside. The area of rupture is controlled by varying the size of the bore in the aluminum discs. The thickness of the brass foil is chosen to be the minimum value such that: (a) the diaphragm assembly, including the particular foil can withstand a one-hour stress deformation period at the desired test pressure, and (b) to allow for a complete rupture, meaning that the rupture hole is free of any brass debris, indicating a rapid burst. As a result of the large range of initial pressures tested, 0.7-3.6 $\mathrm{MPa}$ (100-525 psi); the foil thickness was varied in the range of $25-100 \mu \mathrm{m}$ (1/1000"- 4/1000"). 


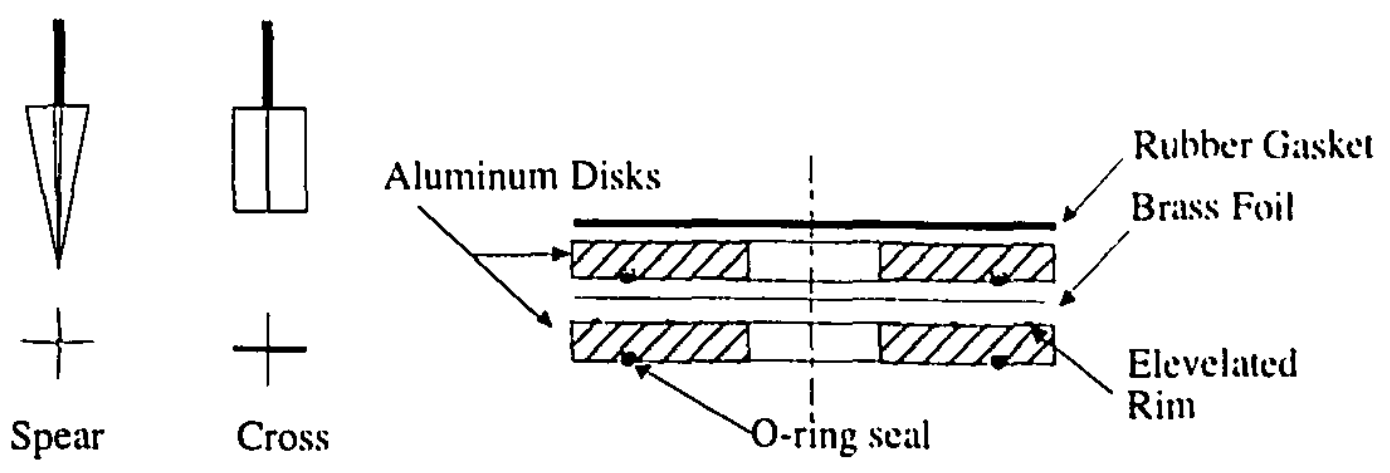

Figure 3.6a - Rupture Blades

Figure 3.6b - Diaphragm Assembly

\subsection{Diagnostics}

Fast response (1 $\mu$ s nominal risetime) piezoelectric transducers (PCB 113A24) are used for dynamic pressure measurements of the boiling process. The signal is amplified via an amplifying element attached to the transducer which is powered by a PCB4808 power unit and then recorded by a LeCroy $9314 \mathrm{M}$ digital oscilloscope ( $100 \mathrm{MHz}$ maximum sampling rate with 10,000 points per channel). The oscilloscope is triggered by the sudden pressure drop associated with the diaphragm rupture. Since the piezoelectric crystal will respond not only to pressure changes but also to temperature and wall loadings, the transducer is mounted within a Delrin casing as shown in Fig. 3.7. This provides thermal insulation and shielding of the transducer body from the vessel walls. In addition, to minimize the influence of rapid cooling of the liquid on the transducer during the boiling process following diaphragm rupture, a thin layer of silicone is applied to the surface of the sensing element. To obtain the best dynamic representation of the actual pressure-time history, DC coupling was used. This had the effect of increasing the discharge time of the transducer (time where the output signal of the piezoelectric crystal goes to zero). For most of the experiments the transducer was mounted as shown in Fig. 3.7. In the case of the second vessel the pressure transducer was located just at the lip of the glass test tube.

In some trials a second transducer was installed on the $260 \mathrm{ml}$ vessel, located $170 \mathrm{~mm}$ below the transducer in the vapor space, so as to monitor the pressure in the liquid as well. In trials with two transducers, it was possible to deduce expansion wave speeds along the length of the vessel, after diaphragm rupture. 


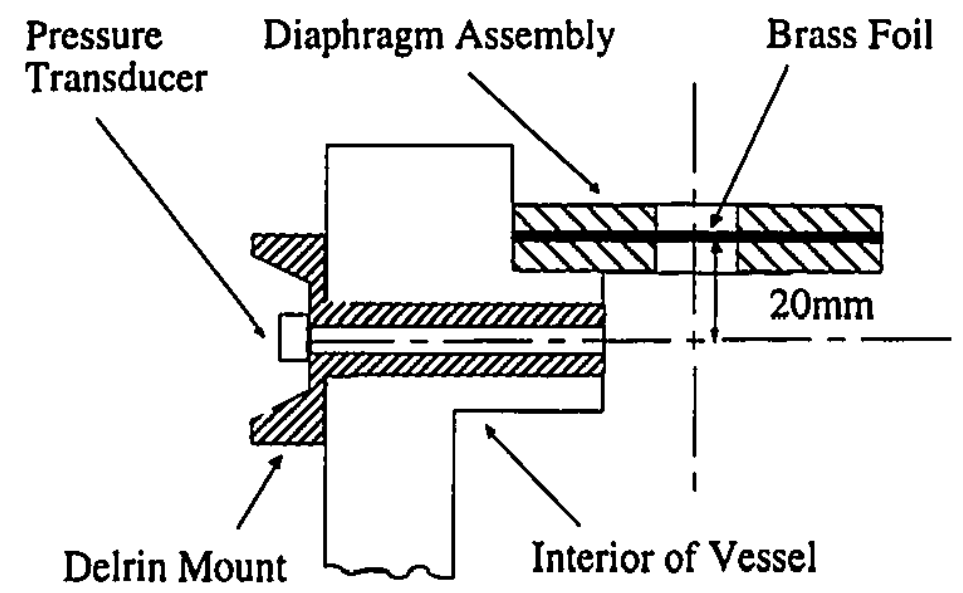

Figure 3.7 - Pressure Transducer Mounting through Vessel Wall

The pressure snsducers were calibrated regularly with an "in-house" calibration facility. This essentially consisted of mounting the transducer on a small reservoir, sealed by a selfbursting foil diaphragm, and increasing the pressure slowly until the diaphragm ruptured. By monitoring the static pressure just prior to diaphragm rupture using an analog gauge and recording the pressure drop to ambient conditions on an oscilloscope, it was possible to deduce the calibration of the transducer.

\subsection{High-Speed Photography}

Using a $16 \mathrm{~mm}$ Hycam 41-0004 high-speed camera we were able to obtain insight into the rapid boiling processes through high-speed cinematography. Back lighting was provided by two 1000 watt tungsten flood lamps. In order to uniformly distribute the light within the test section a glass diffuser was placed between the test section and the flood lamps, (see to Fig. 3.8.) The test section was filmed at both close-up and far field positions using 200 and 500 ASA Kodak motion picture film. The Hycam camera can achieve framing rates between 100-10000 frames per second (fps). Framing rates used for the present study were in the range between $1500-8000$ fps. The feasible framing rate is determined by the acceleration rate of the camera to the steady-state operating speed, the length of film on the reel and the duration of the event being filmed. Only $30.5 \mathrm{~m}$ (100 ft) film lengths were used in the present study. For most tests, this allowed a maximum framing rate of $5000 \mathrm{fps}$, giving a test time for recording the event of approximately $350 \mathrm{~ms}$. The exposure time for each frame was found by taking the reciprocal of the framing rate and dividing it by 2.5 The camera was equipped with an external triggering capability which 
sent a signal at a pre-set film length. This signal was used to trigger the solenoid valve, driving the pneumatically operated plunger.

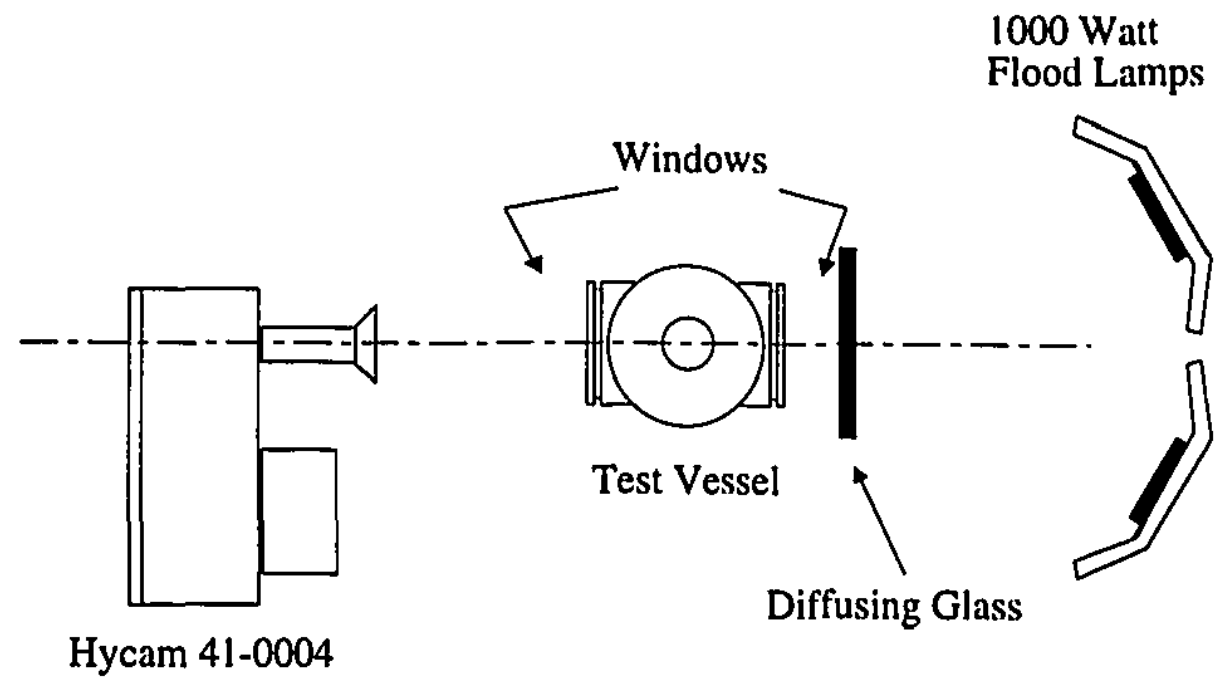

Figure 3.8 - Photographic Setup

In the experiments involving the second vessel with the glass test tube the diffusing glass was inserted within the glycerin between the test tube and the glass window.

\subsection{Experimental Parameters}

Liquefied refrigerant-22 $\left(\mathrm{CHClF}_{2}\right)$ was used in the present experiments as a simulant for propane (an important pressure-liquefied fuel for heating and transportation) because it has very similar thermodynamic properties (saturation curve, critical conditions), yet is not flammable. The pressure-temperature representation of the saturation curves, as well as the properties of R-22 and propane, are shown in Fig. 3.9 and Table 3.1, respectively. Refrigerant-22 was also chosen because it is the only refrigerant permitted by the Montreal Accord on the control of Fluorocarbons. The Montreal Accord set forth guidelines restricting the usage of refrigerants and assessed that R-22 was the least Ozone-damaging and would be the last of the Freons to be eliminated by 1996 . Important thermodynamic properties of R-22 as a function of temperature[19,20] can be found in Appendix A. 


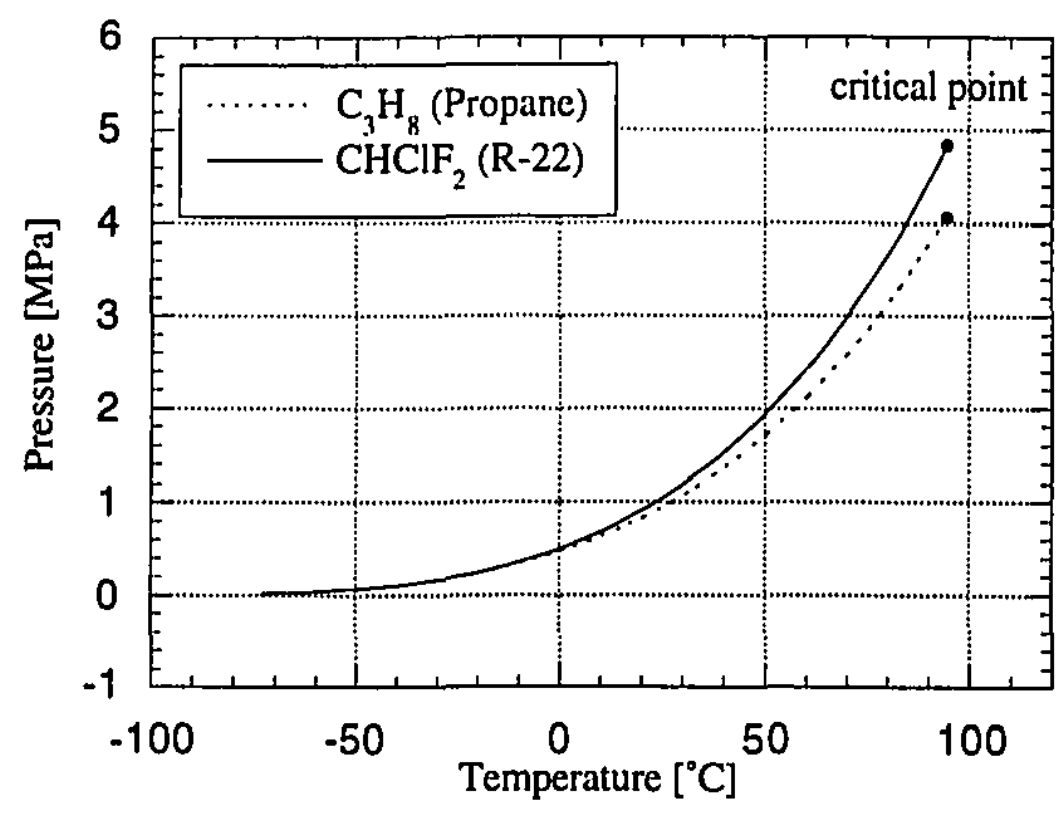

Figure 3.9 - Saturation curve for propane and refrigerant 22

Table 3.1 - Comparison of thermodynamic properties of Refrigerant 22 and Propane

\begin{tabular}{|c|c|c|c|}
\hline & Unit & Refrigerant 22 & Propane \\
\hline Ciemical Formula & - & $\mathrm{CHClF}_{2}$ & $\mathrm{C}_{3} \mathrm{H}_{8}$ \\
\hline Chemical Name & - & Dilluorochloromethanc & Propane \\
\hline Molecular Weight & $\mathrm{kg} / \mathrm{kg}-\mathrm{mol}$ & 86.48 & 44.09 \\
\hline Boiling Point @ $1 \mathrm{~atm}$ & $\mathrm{~K}$ & 232.41 & 231.25 \\
\hline Vapor Pressure @ $25^{\circ} \mathrm{C}$ & $\mathrm{MPa}$ & 1.039 & 0.9478 \\
\hline Critical Temperature & $\mathrm{K}$ & 369.17 & 369.82 \\
\hline Critical Pressure & $\mathrm{MPa}$ & 4.9776 & 4.2362 \\
\hline Critical Density & $\mathrm{kg} / \mathrm{m}^{3}$ & 524.77 & 197.38 \\
\hline Specific Heat Vapor @ $25^{\circ} \mathrm{C}$ & $\mathrm{J} / \mathrm{kg}-\mathrm{K}$ & 863 & $\mathrm{n} / \mathrm{a}$ \\
\hline Specific Heat Liquid @ $25^{\circ} \mathrm{C}$ & $\mathrm{J} / \mathrm{kg}-\mathrm{K}$ & 1236 & $\mathrm{n} / \mathrm{a}$ \\
\hline Latent Heat of Vaporization $@ 25^{\circ} \mathrm{C}$ & $\mathrm{kJ} / \mathrm{kg}-\mathrm{K}$ & 180.6 & 335.18 \\
\hline Surface Tension @ $25^{\circ} \mathrm{C}$ & $\mathrm{N} / \mathrm{m} \times 10^{3}$ & 7.95 & $\mathrm{n} / \mathrm{a}$ \\
\hline \multicolumn{4}{|c|}{ Properties obtained from reference \#[19,20] } \\
\hline
\end{tabular}

In studying the explosive boiling of R-22, different parameters were varied, including: initial pressure, liquid fill fraction, vent area after diaphragm rupture, wall surface conditions of the vessel, and to a lesser degree, the level of pre-nucleation. The initial 
thermodynamic state of the liquid at diaphragm rupture is determined by the initial pressure, since the fluid is maintained at saturation conditions through heating. The vent area is expected to have a strong influence on the rate of depressurization, which affects the rate of vapor generation due to boiling. The liquid fill fraction is defined as the ratio of liquid volume to the total volume of the vessel, and was varied for a range of initial pressures. The range of parameters are summarized in Table 3.1 .

Table 3.2 - Range of Experimental Parameters

\begin{tabular}{|l|c|}
\hline PARAMETER & RANGE \\
\hline \hline Initial Vapor Pressure & $0.8-3.6 \mathrm{MPa}$ \\
\hline Orifice Area & $12.5-280 \mathrm{~mm}^{2}$ \\
\hline Liquid Fill Volume & $24-90 \%$ \\
\hline Pre-nucleation & $\mathrm{CO}_{2}$ \\
\hline Surface of Wall & Teflon, Glass \\
\hline
\end{tabular}

The degree of pre-nucleation, either within the liquid itself using dissolved gases or particulates, or at the vessel wails in contact with the liquid, controls the number of liquidvapor interfaces (or nuclei) available for boiling. Solid surfaces generally promote heterogeneous boiling which requires far less thermal energy (superheat) than homogeneous boiling for the growth of microscopic vapor nuclei. Homogeneous boiling through the growth of microscopic vapor nuclei manifests itself as violent boiling throughout the bulk of the liquid. Heterogeneous boiling limits the degree of superheat that can be achieved during depressurization. In theory the best interface for suppressing heterogeneous nucleation is another liquid, in essence a contact angle of $0^{\circ}$, as though no interface is present. Although surrounding the refrigerant with another liquid was not feasible, several different wall surfaces were considered in an attempt to reduce heterogeneous nucleation. The steel vessel walls were first coated with Teflon. This reduced the heterogeneous nucleation slightly and served more as a protective coating to prevent rusting. Another alternative that was tested was Polyacrylamide gel. Although it does not react with $\mathrm{R}-22$, it proved to be difficult to work with and impractical to attach onto the vessel walls. A small glass cuvette, made from panes of glass attached together along the edges, was also used and significantly reduced the number of surfacc heterogeneous nucleation sites. Due to the method of construction of the glass cuvctte, nucleation still occurred along the corners of the glass pane edges. A limited number of tests were also conducted using R-22, pre-nucleated with $\mathrm{CO}_{2}$ gas and are documented in section 4.3.2. The $\mathrm{CO}_{2}$ was dissolved into the refrigerant by pressurizing it for 48 hours at pressures ranging from 1-2 $\mathrm{MPa}$. 


\section{Experimental Results and Discussion}

Scoping trials were performed with the $260 \mathrm{ml}$ vessel in the initial phase of this study to elucidate the general features associated with the explosive boiling, within the context of the current experimental facility. A further objective was to identify the appropriate experimental parameters that were to be varied and their range. High-speed cinematography and transient pressure measurements were taken to record the boiling response of the rapidly depressurized liquid. Pressure measurements constitute the principal diagnostic means in the parametric study and as such, it was deemed important to first assess the effect of a variation in the location of the pressure transducer within the test volume on the pressure transient measured. The insight gained from these scoping trials was implemented and a series of tests was carried out to determine the qualitative dependence of the repressurization, that occurs when the pressurized liquid refrigerant is suddenly vented, on initial and boundary conditions. Parameters which were varied include: vent area, relative proportion of liquid to vapor volume, initial thermodynamic state of the liquid, and surface conditions of the vessel walls. The effect of different parameters on the explosive boiling is obviously coupled and thus only one parameter was varied between trials, while the others were kept constant.

\subsection{General Features of Explosive Boiling}

\subsubsection{Typical Pressure Trace}

The influence of the volatile liquid, R-22 on the pressure history within the $260 \mathrm{ml}$ test vessel, following sudden depressurization, is illustrated by the pressure-time profile displayed in Fig. 4.1. Initial conditions correspond to a saturated pressure of $1.4 \mathrm{MPa}$ and liquid fill volume of $90 \%$. For reference purposes, the lower pressure trace shows the pressure history in the vessel measured near the orifice when the vessel is filled with ambient temperature water, instead of R-22, under identical conditions of liquid fill volume and vent area, and pressurized with air to an initial pressure of 1.4 $\mathrm{MPa}$ prior to venting. In the $\mathrm{Air}-\mathrm{H}_{2} \mathrm{O}$ system, the pressure drops rapidly to near ambient pressure and the presence of the water does not significantly influence the venting process, as indicated by the plateau in Fig. 4.1. The water serves as a means of reducing the vapor space and due to the low vapor pressure of the water at room temperature, does not boil. In sharp 
contrast, when saturated R-22 at the same initial pressure and liquid fill volume is vented, il sudden boiling response is triggered within the vessel.

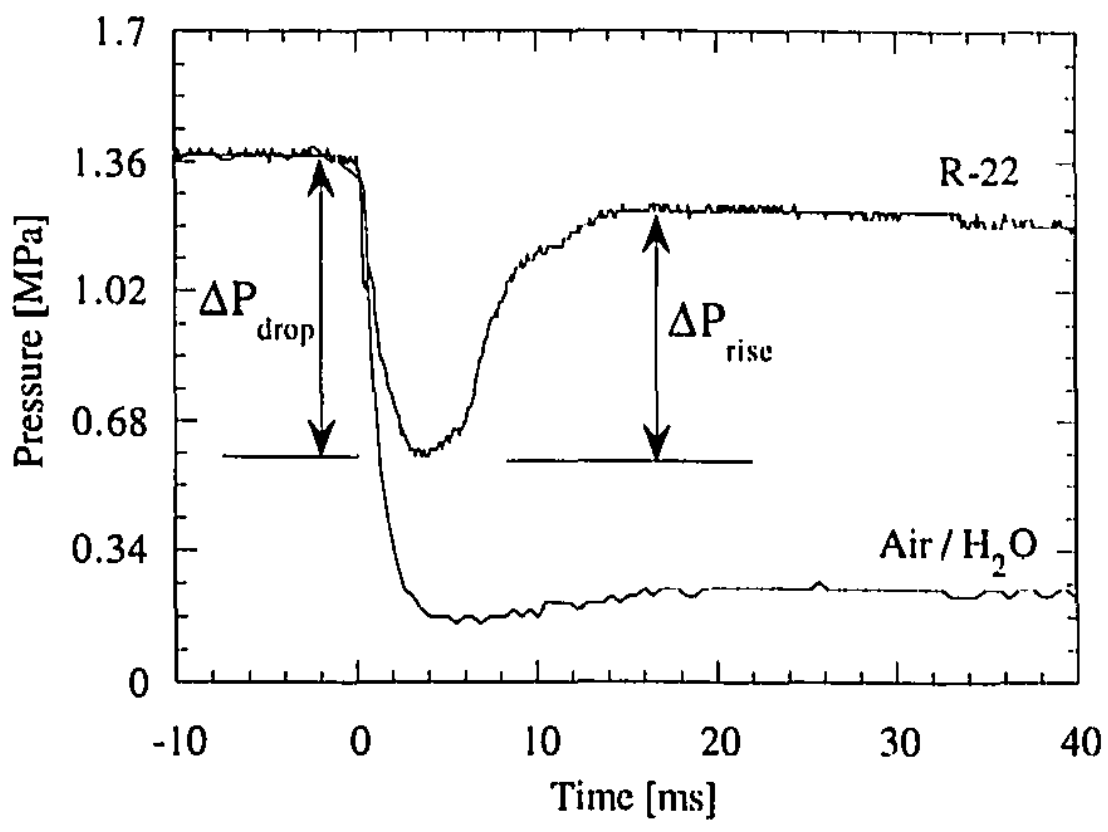

Figure 4.1 - Characteristic pressure history for venting of R-22 and pressurized walter

The character of the subsequent rapid boiling is a function of the level of superheat achieved by the initial depressurization and will generally cause a transient repressurization within the vessel. In the present tests, the level of repressurization was not observed to significantly exceed the initial pressure. This is consistent with the findings of Hiscoke and Birk ${ }^{[21]}$ and Birk and Cunningham ${ }^{[3]}$. Furthermore, this repressurization is short lived as the mass of boiling refrigerant within the vessel is being continuously vented, causing the pressure to drop once again at later times $(t>40 \mathrm{~ms})$ eventually reach atmospheric pressure. Note also that the initial relatively slow rate of depressurization for $\mathrm{R}-22$, relative to air, is a consequence of the relatively large molecular weight of the refrigerant. The pressure drop and rise, denoted as $\Delta \mathrm{P}_{\text {drop }}$ and $\Delta \mathrm{P}_{\text {rise, }}$, respectively, are defined with reference to the pressure trace in Fig. 4.1.

\subsubsection{Relationship between Pressure Drop and Rise}

The degree of explosive boiling, i.e., the rate of vaporization of the liquid, is driven by the amount of superheat experienced by the liquid. By varying the initial vapor pressure, it is possible to subject the liquid, upon sudden depressurization, to various degrees of 
superheat. The degree of superheat is directly related to the amount of pressure drop, therefore qualitatively the superheat and pressure drop below saturation can be used interchangeably to describe the potsitial of the liquid to boil explosively.

One of the most noticeable characteristic features of the explosive boiling is the relationship between the repressurization and depressurization as shown in Fig. 4.2. Figure 4.2 contains data from three sets of experiments. Two were performed with the $260 \mathrm{ml}$ vessel, each with a fixed orifice diameter of $19 \mathrm{~mm}$ and fill volume of $65 \%$ and $90 \%$ respectively. The third set of data corresponds to tests performed in the $75 \mathrm{ml}$ glass test tube with a orifice diameter of $9.5 \mathrm{~mm}$ and a fill volume of $90 \%$.

For all three sets of data there exists a strong correlation between the degree of superheat attained by the liquid and the corresponding amount of repressurization. Although, due to geometrical and volume differences in the tests performed in the $75 \mathrm{ml}$ glass test tube and the $260 \mathrm{ml}$ vessel, the magnitude of the repressurization for a given depressurization are different, as shown in Fig. 4.2. However, both vessels yielded results exhibiting the same qualitative behavior.

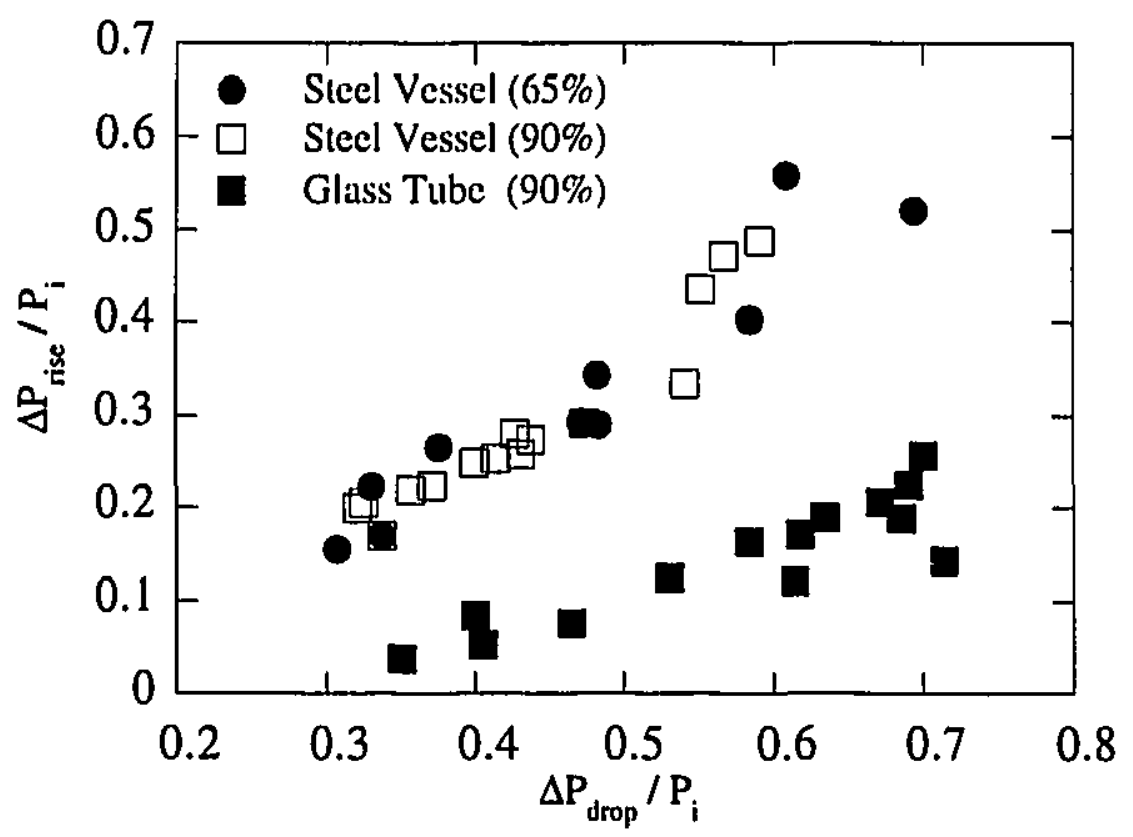

Figure 4.2 - Relationship between pressure rise and pressure drop 


\subsection{Scoping trails}

\subsubsection{Location of Transducer}

As the main diagnostic, the pressure transducer should be positioned so that the measured pressure properly reflects the response of any explosive boiling within the vessel. In order to assess any differences in the pressure history within the vapor and liquid space, pressure transducers were mounted at different locations within the vessel. Two pressure transducers were mounted at adjacent ports on the vessel, $17 \mathrm{~cm}$ apart (see Fig. 3.2). At at liquid fill volume of $90 \%$, the top transducer was initially entirely exposed to the vapor space, while the lower one was in contact with the liquid. A test was conducted using ambient temperature water as the liquid, pressurized to $1.08 \mathrm{MPa}$ with air vapor. Figure 4.3a shows that there is practically no difference, in both the magnitude and rate of depressurization, measured by the top (vapor) and bottom (water)

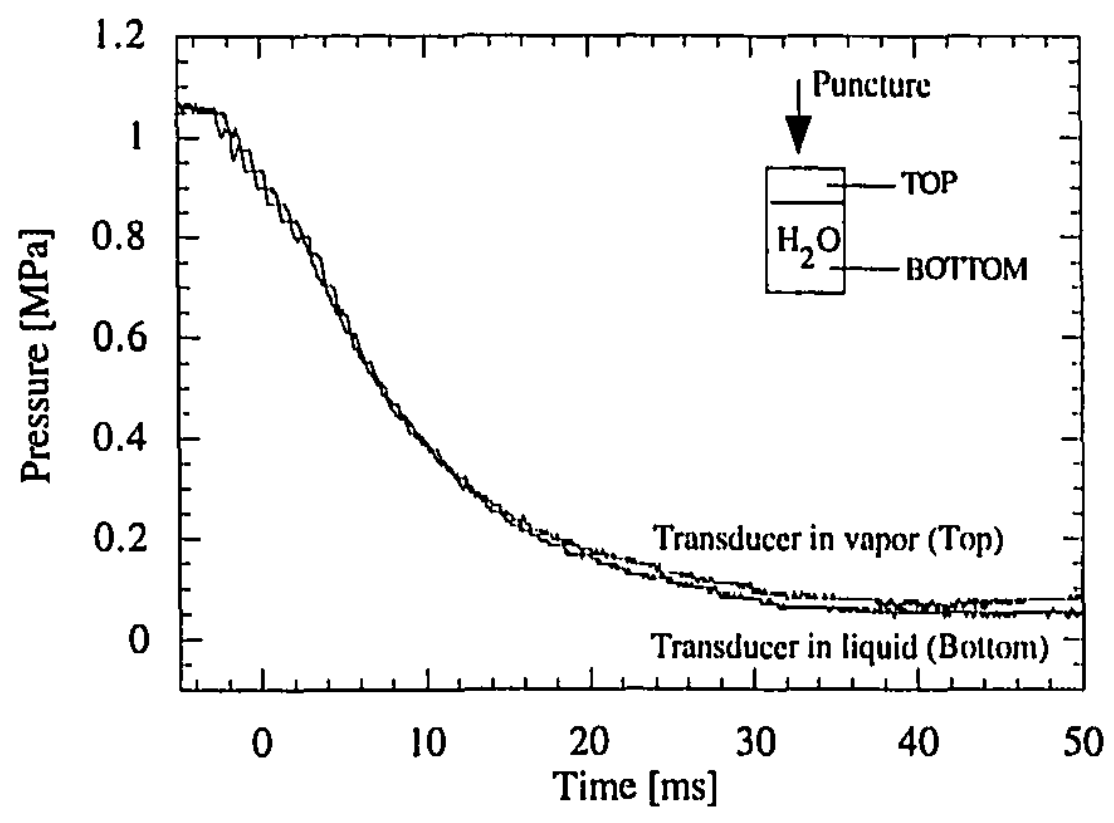

Figure $4.3 \mathrm{a}-\mathrm{H}_{2} \mathrm{O} /$ Air trial with vent in vapor space

transducers, following puncture of the diaphragm. To examine the boiling response of the volatile liquid at different locations, the water was replaced by $\mathrm{R}-22$ at $90 \%$ liquid fill volume and a saturation pressure of $1.25 \mathrm{MPa}$. Figure $4.3 \mathrm{~b}$ shows that the general features, as measured by the transducers in both the vapor and liquid space are very similar. The time delay in the onset of the pressure drop between the two traces corresponds to an expansion wave speed of $\approx 370 \mathrm{~m} / \mathrm{s}$, which is consistent with the sound 
speed in liquid R-22. The rates of depressurization and repressurization measured in the liquid correspond closcly to those in the vapor space and the magnitude of the repressurization is practically the same in both cases. The evident difference between the two signals is in the magnitude of the pressure drop. The pressure undershoot is larger in the vapor space (top) compared to that in the liquid (bottom), where a plateau in the pressure appears to be reached between 1-5 ms. This is most likely due to the location of the transducer in the vapor space being much closer to the vent area and thus more sensitive to any pressure drop. Heterogeneous boiling taking place along the vessel walls within the relatively confined liquid can increase the local pressure measured at the bottom transducer location and prevent as large a pressure drop, as measured in the vapor space near the vent, from materializing. In fact it is likely that heterogeneous boiling will preferentially occur around the plug that houses the lower transducer. It appears that the location of the transducer in the vapor space (near the vent area) is a more sensitive indicator of the pressure transient and thus better characterizes the boiling response of the liquid and subsequent repressurization in the vessel.

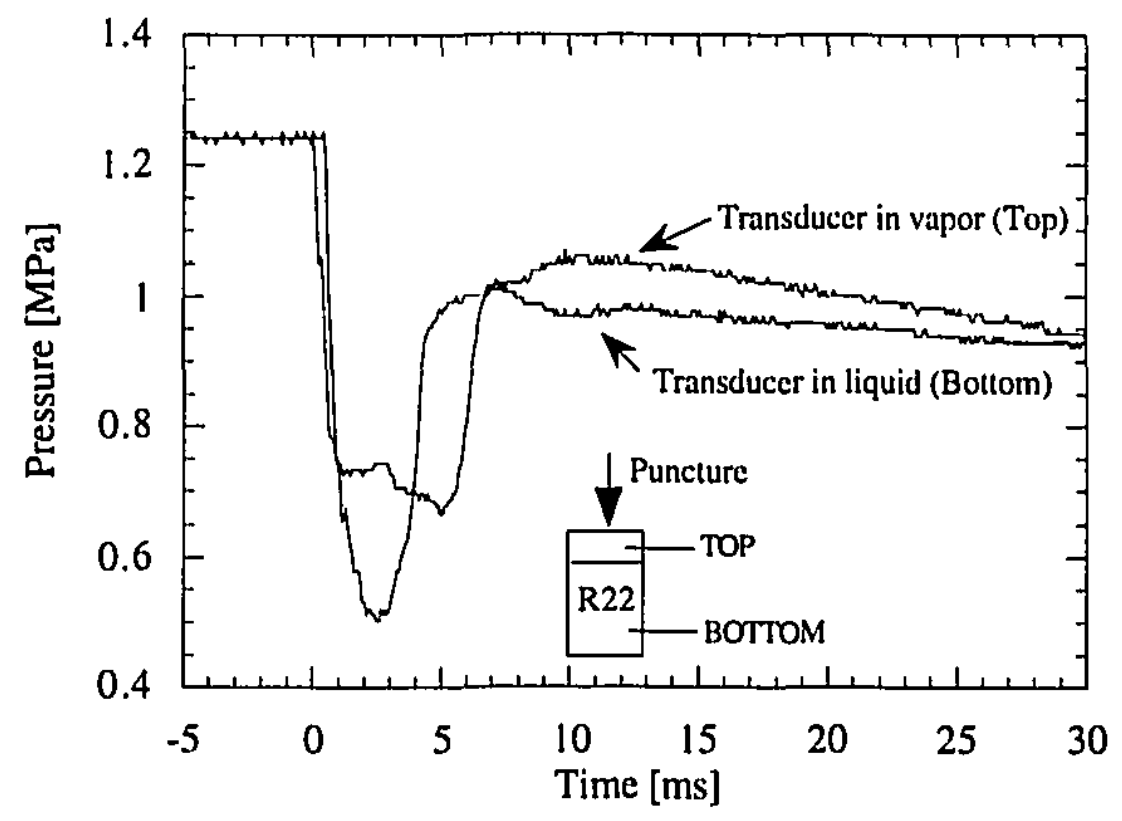

Figure 4.3b - R22 trial with vent in vapor space

\subsubsection{Location of Rupture Hole}

The next set of experiments within the scoping trials deal with the effect of location of the vent area, i.e., whether the vent is punctured in the liquid or vapor space. These tests were performed using a $200 \mathrm{ml}$ aluminum vessel. By rotating the vessel $180^{\circ}$ and rupturing a diaphragm in the liquid space it was possible to examine the effect of the transducer 
location on the pressure measurement. Since the occurrence of a BLEVE is dependent on the boiling response within the vessel, it is of interest to qualitatively examine the differences in the pressure profile obtained from ruptures in the liquid and vapor space. Although our small-scale tests do not determine if a certilin set of conditions and parameters will lead to a BLEVE, qualitative information on the effect of experimental and thermodynamic parameters on repressurization is important in assessing the potential for explosive boiling, which may contribute to the development of a BLEVE.

Two pressure transducers were used, one located in the vapor space, as shown in the small caption in Fig. 4.4a, and one located in the liquid space. When pressurized water at 2.0 $\mathrm{MPa}$ is suddenly vented through a hole in the liquid space, Fig. 4.4a shows that the pressure history recorded in the different regions of the vessel, i.e., liquid and vapor, are very similar. If R-22 is used instead of pressurized water at the same initial pressure and liquid fill volume, a somewhat different pressure transient is recorded in the vapor and liquid regions, as shown in Fig. 4.4b. Although the rate and overall magnitude of depressurization appear to be the same at different locations within the vessel, there is little repressurization observed by the transducer in the liquid, located near the rupture hole, since the vent is located beneath the liquid. Heterogeneous boiling taking place within the vessel at the liquid-vapor interface causes a pressurization in the vapor space much sooner than any repressurization at the location of the transducer in the liquid.

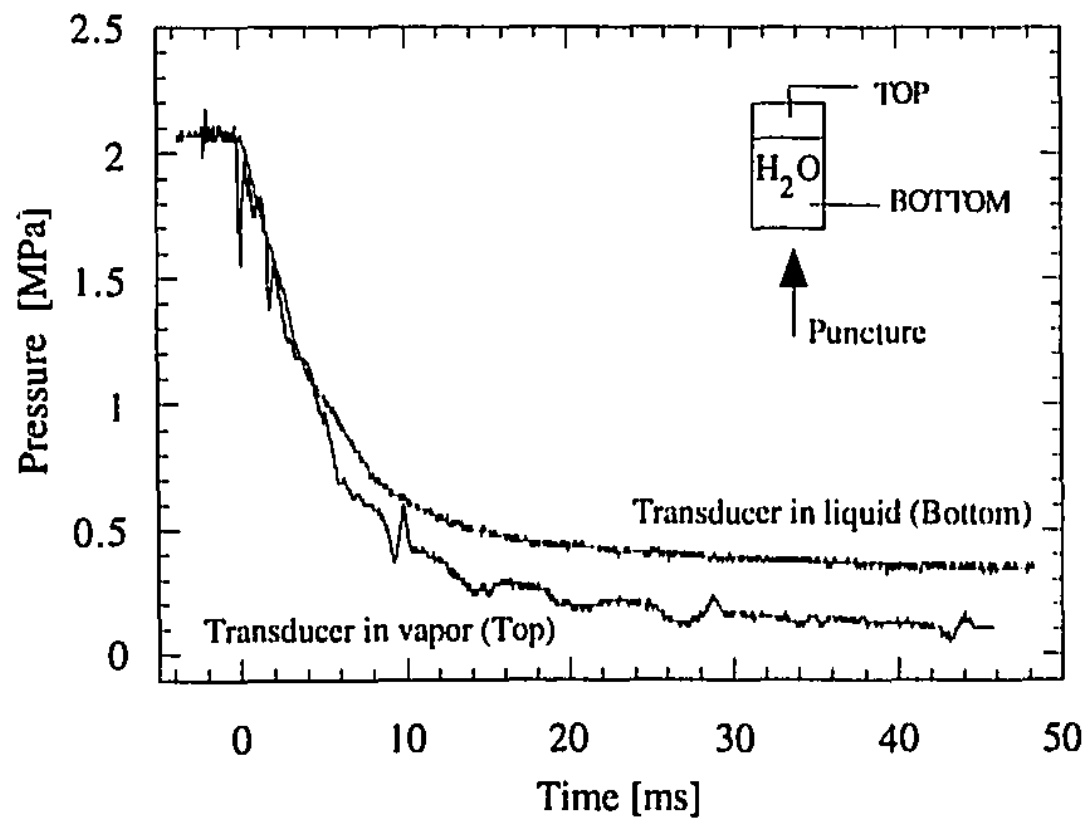

Figure $4.4 \mathrm{a}-\mathrm{H}_{2} \mathrm{O} / \mathrm{Air}$ trial with vent in liquid space 


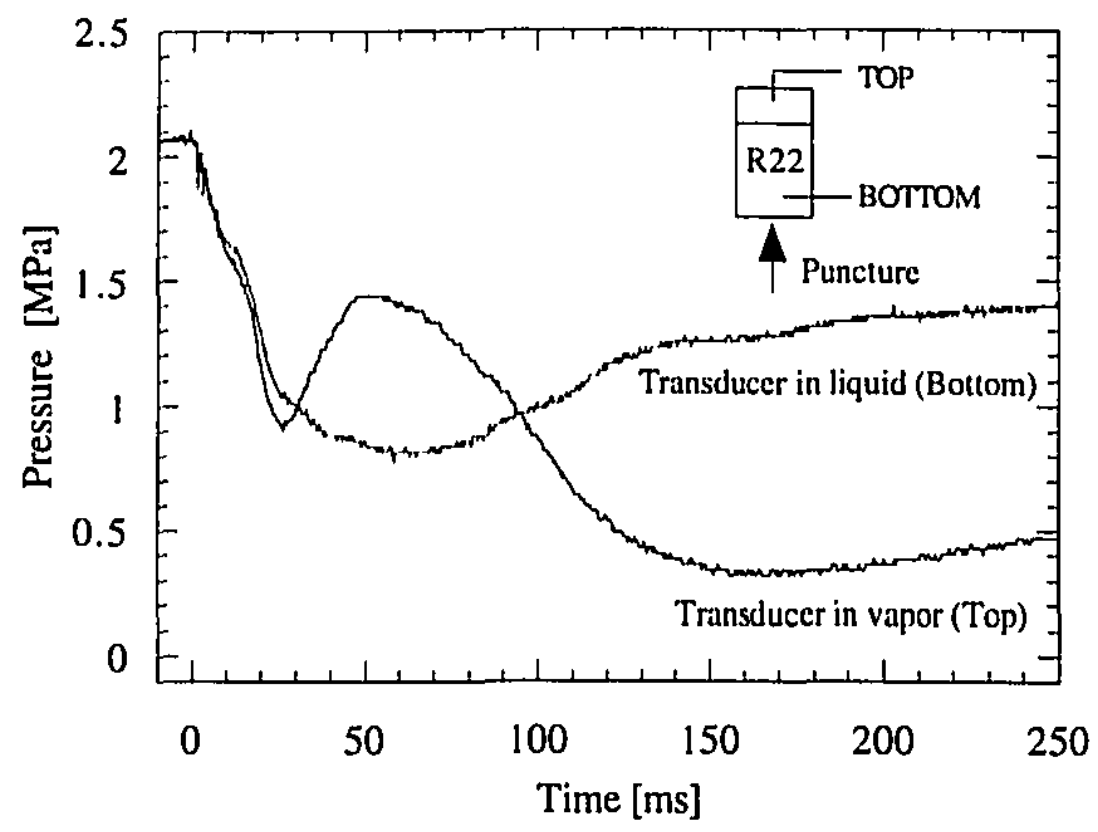

Figure 4.4b - R22 trial with vent in liquid space

Due to the compressibility of the vapor, the vapor space experiences large pressure fluctuations and thus provides a more representative history of the transient pressure field within the vessel, irrespective of whether the rupture takes place in the liquid or vapor space.

\subsubsection{Orientation of Pressure Transducer}

Next the orientation of the transducer with respect to the two-phase venting flow, and its effect on the pressure measurement, was examined. The test section was mounted horizontally, with the windows facing vertically. The upper window was replaced with a plate that contained the venting hole in the center. Transducers were mounted on the top (vapor) part of the vessel, at either side of the vent, in an orientation facing the liquid surface directly. Upon sudden depressurization, the free liquid surface broke up into liquid fragments which were swept towards the vent hole, effectively stripping away a portion of the liquid refrigerant before it had time to participate in the boiling. Fiscoke and Birk[21] have observed that the mass of liquid remaining in the vessel after the experiment is much lower than what is expected based on a theoretical isenthalpic expansion of the vapor. Therefore a certain percentage of the liquid $i$, lost through the two phase venting. Since the transducers are directly facing the liquid surface, the stripped liquid fragments may directly impact the transducer surface. If this occurs, large pressure spikes would be superimposed 
on the pressure profile due to the sudden depressurization. Figure 4.5a shows that large pressure spikes are indeed recorded as the R-22 is vented following diaphragm rupture, demonstrating the effect of the collision of liquid droplets with the pressure transducer. The duration of these spikes ranges from 0.1-0.2 $\mathrm{ms}$, as illustrated in the magnified segment of Fig. 4.5a, shown in Fig. 4.5b.

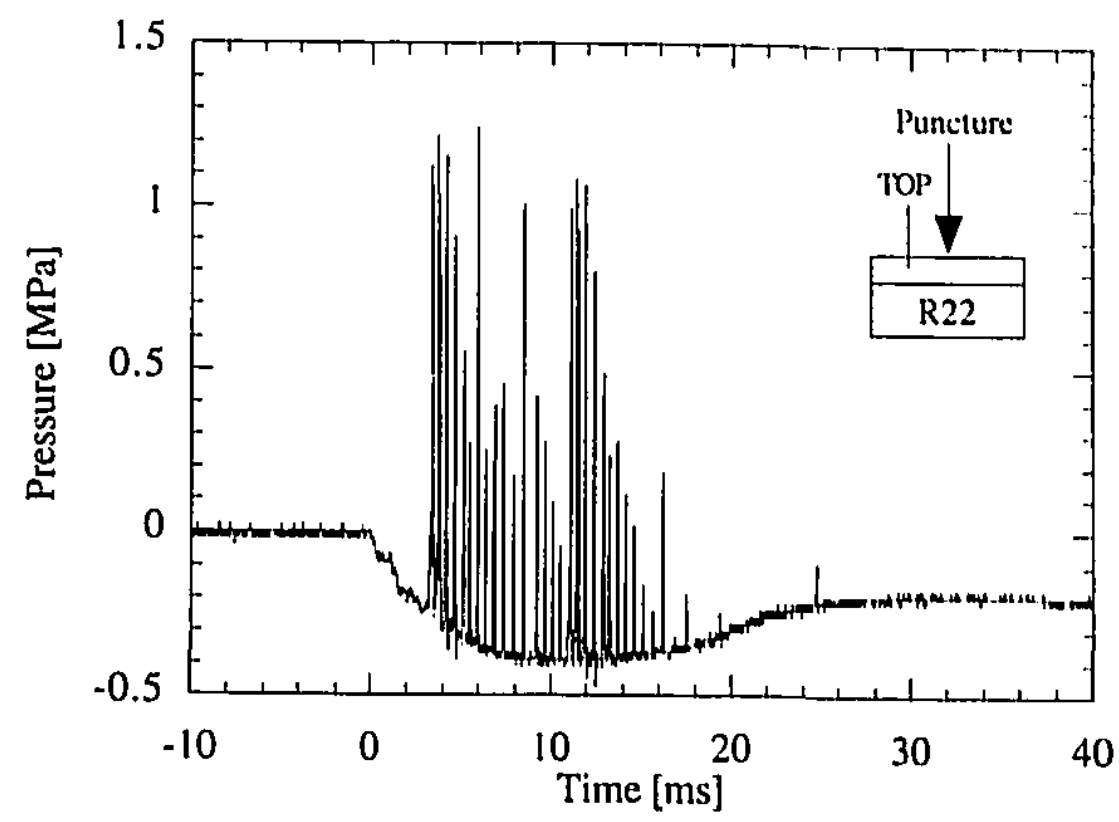

Figure 4.5a - Pressure trace of liquid impact trial

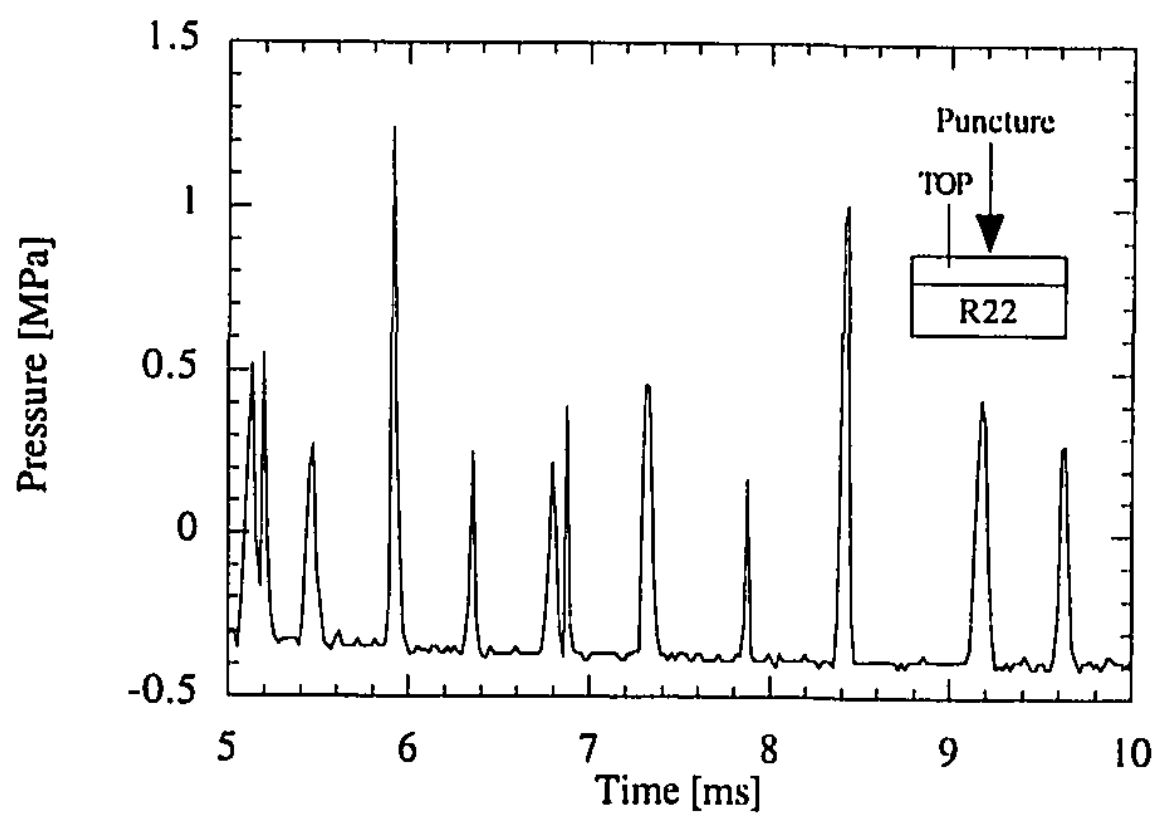

Figure 4.5b - Pressure trace of liquid impact trial 
Similar results have also been reported by Ogiso et al. ${ }^{[10]}$ who used a long verticallymounted tube filled with compressed heated water with pressure transducers mounted along the length and at both ends of the tube. Upon sudden depressurization from a vent near the top, the transducers located at the top end measured very large and rapid pressure impulses. These impulses were attributed to the impact of liquid droplets colliding against the pressure transducer sensing element. When the sensing element was shielded from direct impact it proved to completely 'filter' out the pressure spikes. Large amplitude pressure spikes, superimposed on the depressurization trace following tank rupture, have also been observed by Venart and Sollows[22]. Although other mechanisms have been proposed by these authors (the BLECBE model) to account for the reported spikes, it is interesting to note that the average spike duration is similar to that in the present observations (Fig. 4.5b). It seems that particular attention must be paid to both the location and orientation of transducers with respect to any oncoming flow during the rapid venting, in order to avoid distortions in the pressure signal and any possible misinterpretation of the abnormally large amplitudes that can sometimes be measured. Consequently, in the present study, pressure transducers were mounted with their face parallel to any two-phase flow during the rapid venting process as shown in Fig. 3.2.

\subsection{Parametric Investigation}

A parametric study was carried out to examine the influence of vent area, liquid fill volume, initial pressure and surface material of the vessel wall, on the explosive boiling of a suddenly depressurized vessel contiaining pressure liquefied R-22. This was accomplished by varying one parameter at a time and measuring the rate and magnitude of depressurization and repressurization following the sudden rupture of a diaphragm.

\subsubsection{Explosive Boiling in $260 \mathrm{ml}$ Vessel}

\subsubsection{Area of Rupture}

The vent area influences the venting rate which in turn determines the degree of superheat that can be reached upon sudden depressurization. Due to the vent area constriction and the vapor generation from the boiling liquid within the vessel, there exists a competition between the vapor venting and generation rates as demonstrated by the pressure-time profile measured (see Fig 4.1) within the vessel. 
To isolate the influence of the orifice area, the liquid fill volume was held constant at $90 \%$ and the orifice diameter was varied. Figure 4.6 shows the superposition of several pressure traces each with a different orifice area. For purposes of comparison, the pressure traces were normalized with their corresponding initial pressure. Experiments by Friedel and Purps[8] using a 107 liter vessel and different vent areas show similar qualitative trends, indicating that although the present test vessel is 400 times smaller in volume, it qualitatively reproduces the phenomena observed at larger scales. Figure 4.6 further shows that the asymptotic value of repressurization of the vessel for large times, i.e., $t>30 \mathrm{~ms}$, is similar in each case and therefore not a strong function of orifice areil.

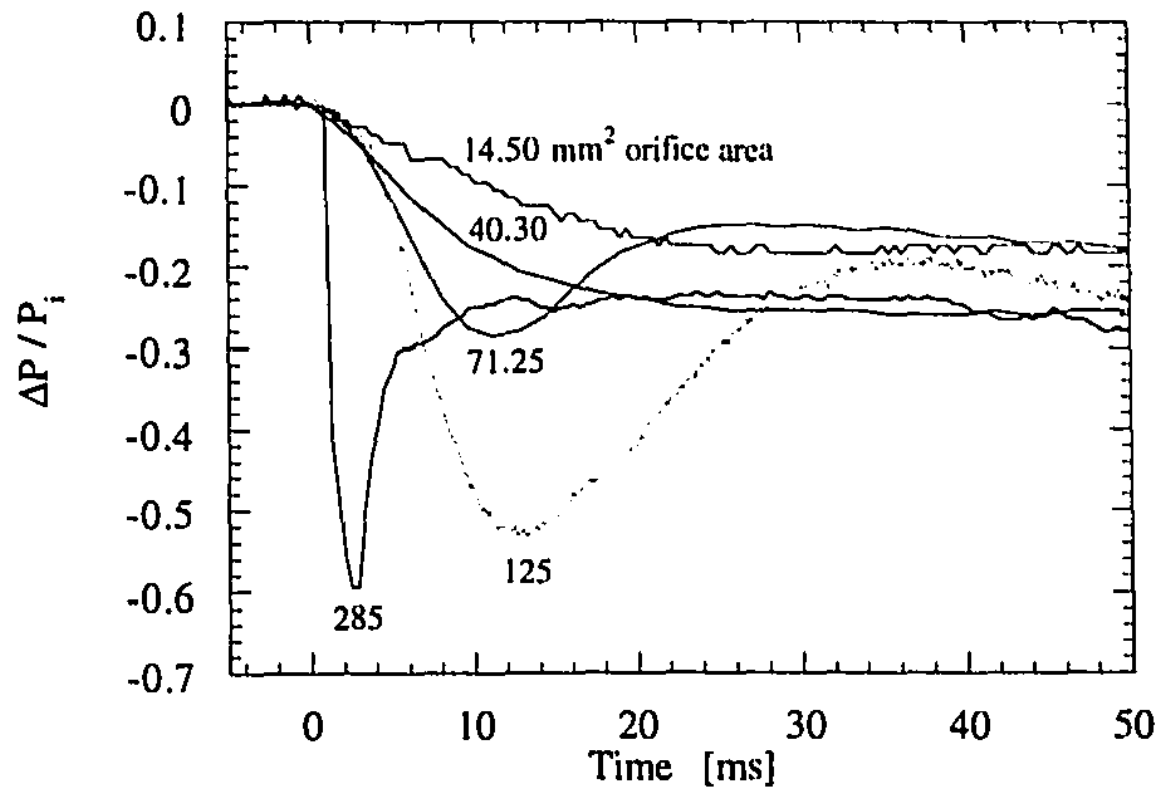

Figure 4.6 - Superposition of pressure transient for orifice trials

An examination of Fig. 4.7 clearly shows that the amount of pressure drop increases with increasing orifice area. A larger vent area permits a greater rate of depressurization, which allows the pressure to drop lower. The repressurization is also related to the vent area, as a greater pressure drop will invariably lead to greater superheat which increases the boiling potential of the liquid and is characterized by an increase in repressurization. 


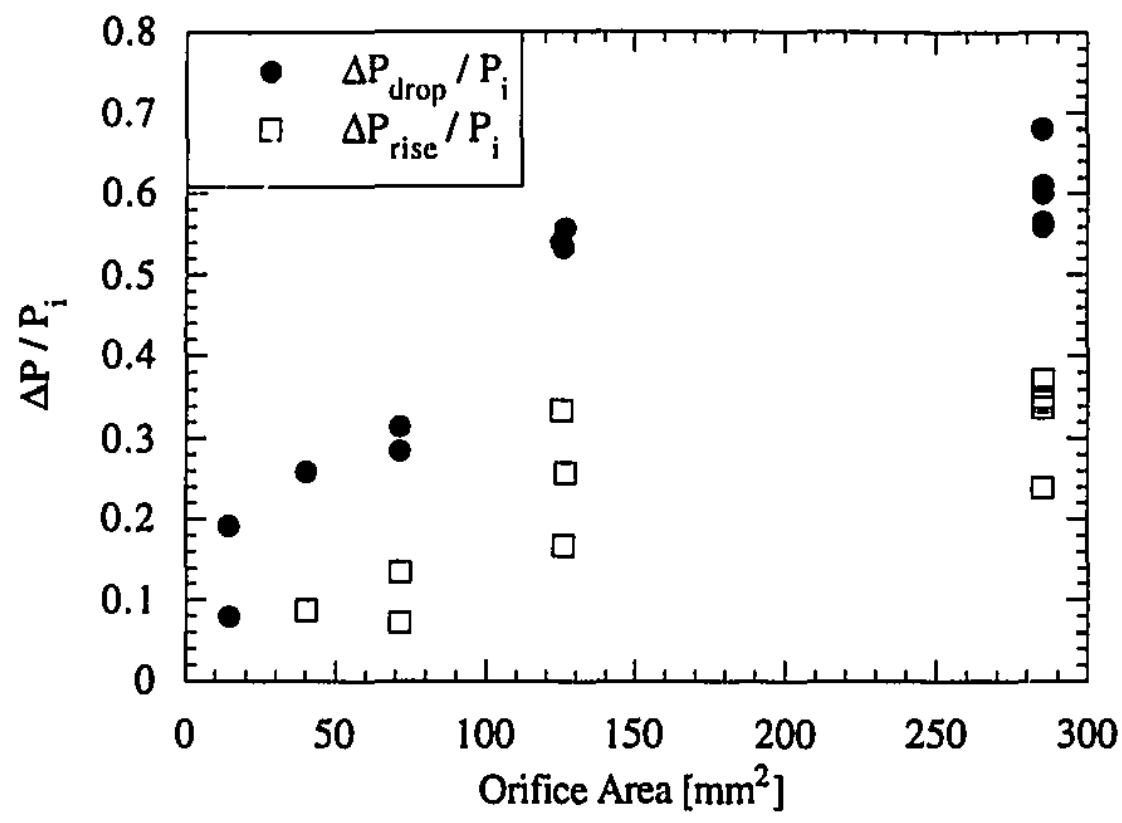

Figure 4.7 - Influence of area on degree of depressurization and repressurization

The largest vent area, corresponding to the $285 \mathrm{~mm}^{2}$ orifice area, is characterized by the highest rate of depressurization and repressurization. Note that the pressure drop shown in Fig. 4.7 is normalized with the initial pressure. For the largest vent area, corresponding to the $285 \mathrm{~mm}^{2}$ orifice area, the pressure can drop to $60 \%$ of the initial pressure, whereas the $14.50 \mathrm{~mm}^{2}$ orifice area provides a drop of less than $20 \%$ of the initial pressure. The maximum achievable drop in pressure would correspond to reaching atmospheric pressure.

In an attempt to identify the rate of depressurization which would most reproducibly represent the characteristic rate of pressure drop and rise, as experienced by the liquid refrigerant after the sudden rupture of the diaphragm, several rates were defined. Figure 4.8 shows a typical pressure trace for a depressurization experiment. Upon sudden rupture of the diaphragm the pressure falls at its greatest rate, represented by $(\Delta P / \Delta t)_{1}$.

The rate of pressure drop then typically decreases to $(\Delta P / \Delta t)_{2}$, until the pressure decay is halted and the pressure begins to recover at a rate of $(\Delta P / \Delta t)_{3}$. Using the rates of depressurization, $(\Delta P / \Delta t)_{1}$ and $(\Delta P / \Delta t)_{2}$, it is possible to obtain a weighted average of the rate of pressure drop. From the percentage of the total pressure drop, $\Delta P_{\text {total }}$ that each rate covers, the weighting factors ( $w_{i}$, where $\left.i=1,2\right)$ multiplied by the corresponding rate, an average weighted rate of depressurization can be obtained:

$$
(\Delta P / \Delta t)_{\text {avg }}=w_{1}(\Delta P / \Delta t)_{1}+w_{2}(\Delta P / \Delta t)_{2}
$$




$$
\begin{gathered}
w_{1}=\left(\Delta P_{1} / \Delta P_{\text {total }}\right) ; w_{2}=\left(\Delta P_{2} / \Delta P_{\text {total }}\right) \\
\Delta P_{\text {total }}=\Delta P_{1}+\Delta P_{2} \\
w_{1}+w_{2}=1
\end{gathered}
$$

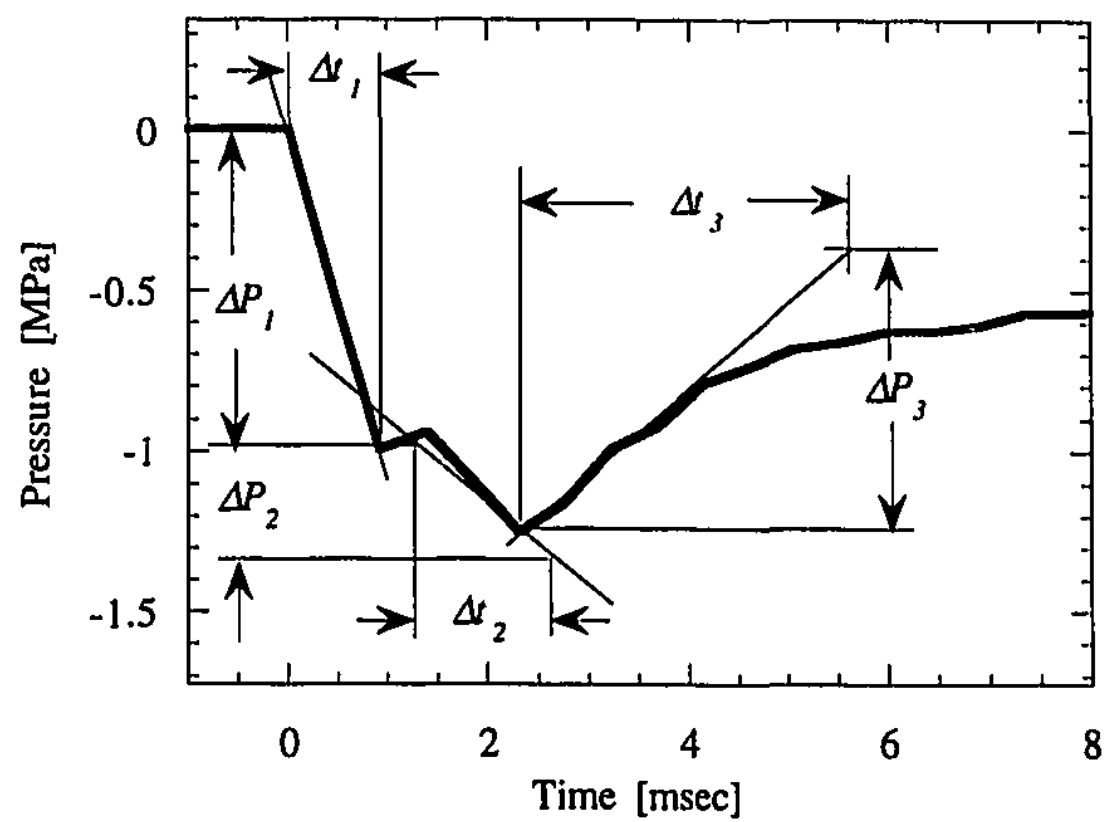

Figure 4.8 - Definition of rates of depressurization and repressurization

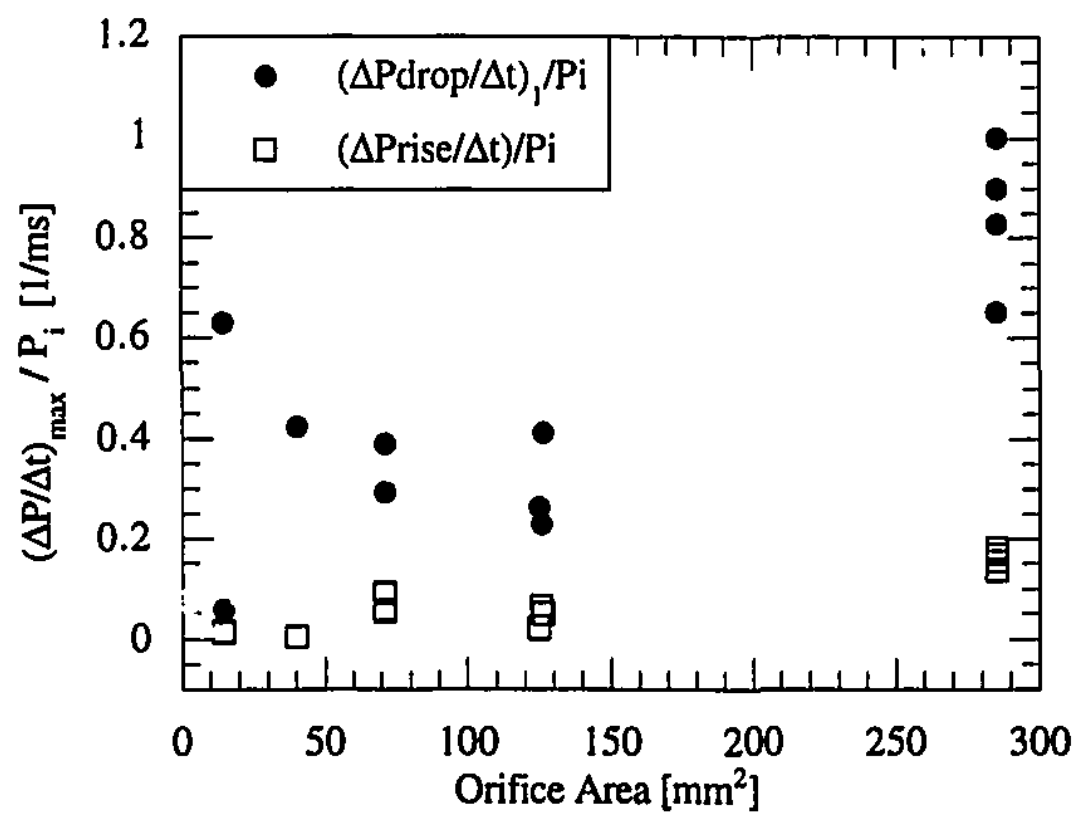

Figure 4.9 - Influence of area on rate of depressurization and repressurization 
By plotting the different results for these rates versus the parameter varied, it was found that the depressurization rate which was most reproducible was the maximum rate of depressurization, $(\Delta P / \Delta t)_{1}$. For this reason, in all subsequent figures, the rate of depressurization refers to the maximum rate given by $(\Delta P / \Delta t)_{1}$. The rate of repressurization was defined as the maximum slope on the pressure-time trace for a significant level of initial pressure rise. The influence of orifice area on the rates of pressure drop and rise are shown in Fig. 4.9. As can be expected, the rates of pressure drop and rise both increase with increasing vent area.

\subsubsection{Liquid Fill Volume}

The next parameter varied was the liquid fill volume. Keeping the orifice area constant at a diameter of $19 \mathrm{~mm}$ and the initial pressure at $3.15 \mathrm{MPa}$ (450 psi), the liquid fill volume was varied from $24 \%$ to $90 \%$. The liquid fill volume defines the percentage of liquid that occupies the total vessel volume of $260 \mathrm{ml}$. Figure 4.11 shows a superposition of several pressure traces, corresponding to different liquid fill volumes, at the same initial pressure and orifice area.

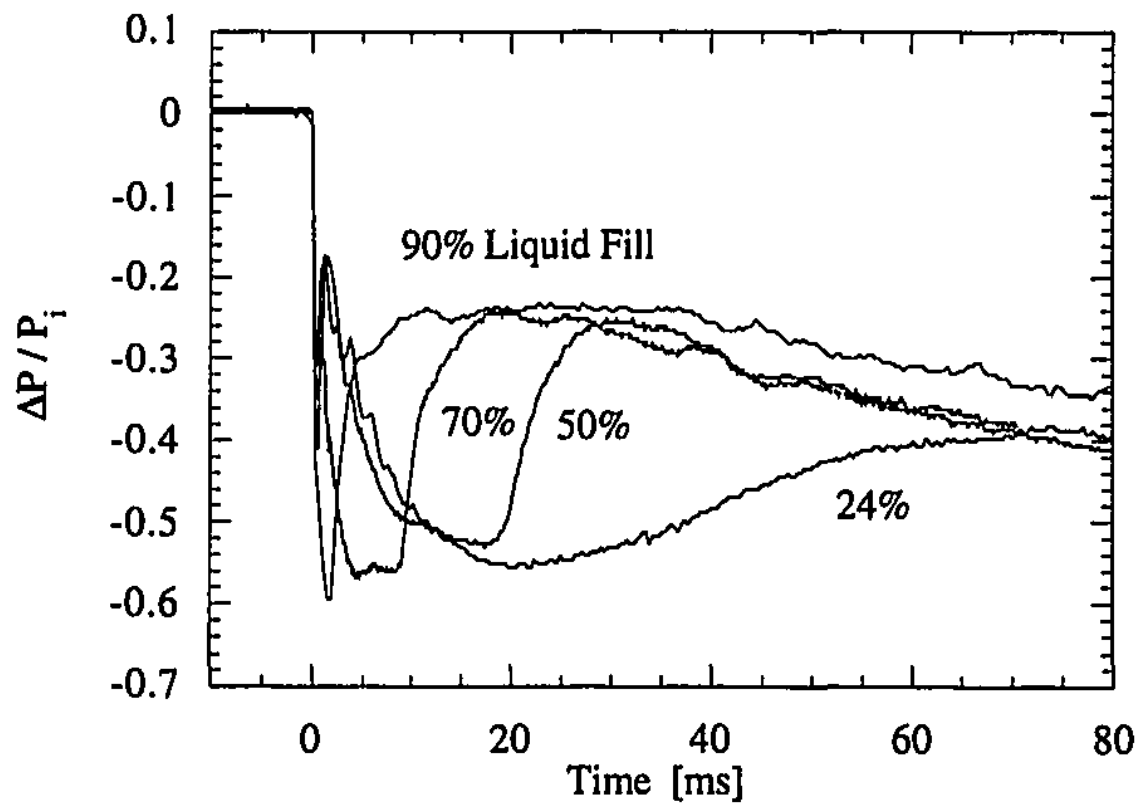

Figure 4.11 - Superposition of pressure transient for liquid fill trials

The effect of the liquid fill volume on the explosive repressurization delay time, i.e., the time at which the repressurization has reached its maximum, can be seen in Fig. 4.11. The greater the liquid fill volume the earlier the maximum repressurization occurs. For example, the $90 \%$ liquid fill volume test has a repressurization delay time of $10 \mathrm{~ms}$ whereas the $24 \%$ liquid fill volume tests yields a repressurization time of $70 \mathrm{~ms}$. 
Figures 4.12 and 4.13 show, respectively, the effect of fill volume on the degree and rate of depressurization and repressurization. A greater liquid fill volume, signifying a smaller vapor space, increases both the degree and rate of repressurization. The reason for this is that a greater liquid fill volume implies that a larger quantity of liquid is available for boiling, thus enhancing the amount of vapor generated within a relatively smaller initial vapor space and increasing the repressurization. On the other hand the degree and rate of depressurization, which is a strong function of vent area and initial pressure, does not exhibit as strong a dependence on the liquid fill volume. Increasing the liquid fill volume, decreases the quantity of vapor above the liquid and

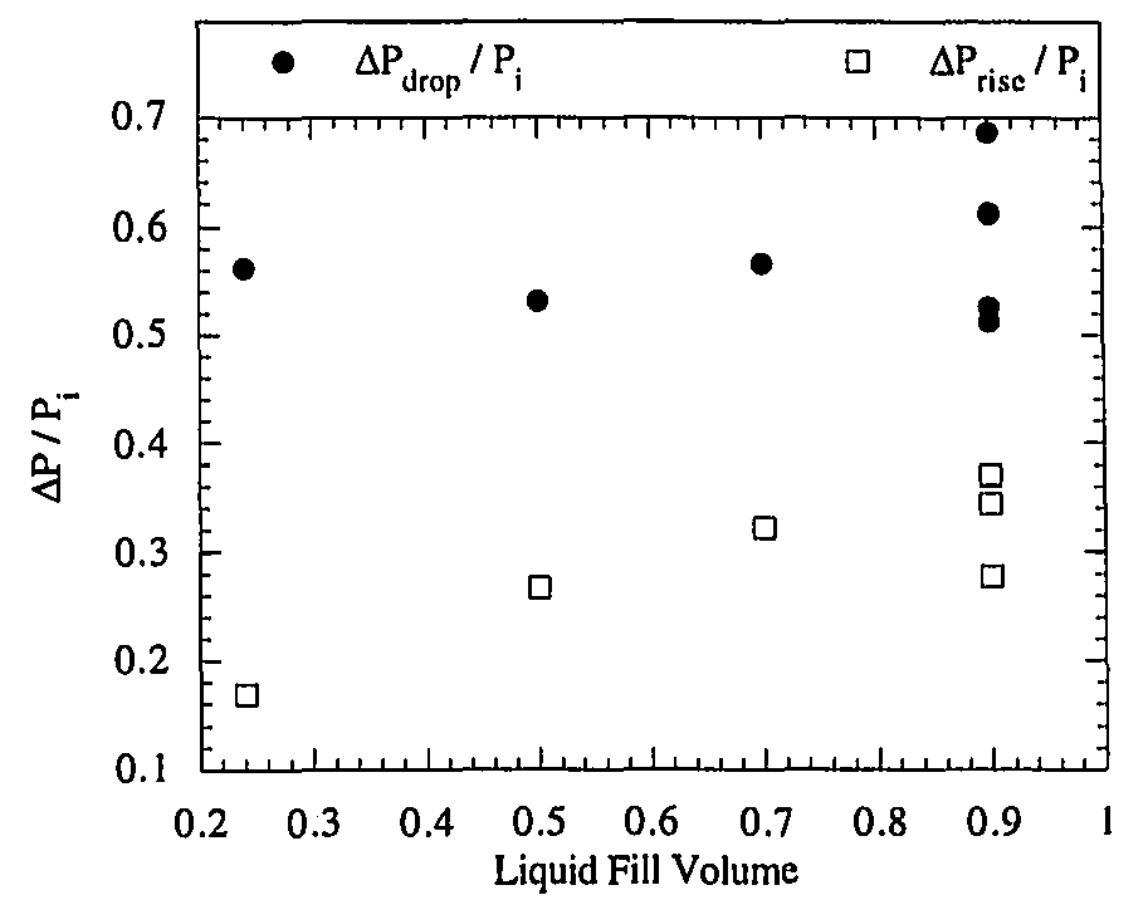

Figure 4.12 - Influence of liquid fill volume on degree of repressurization and depressurization 


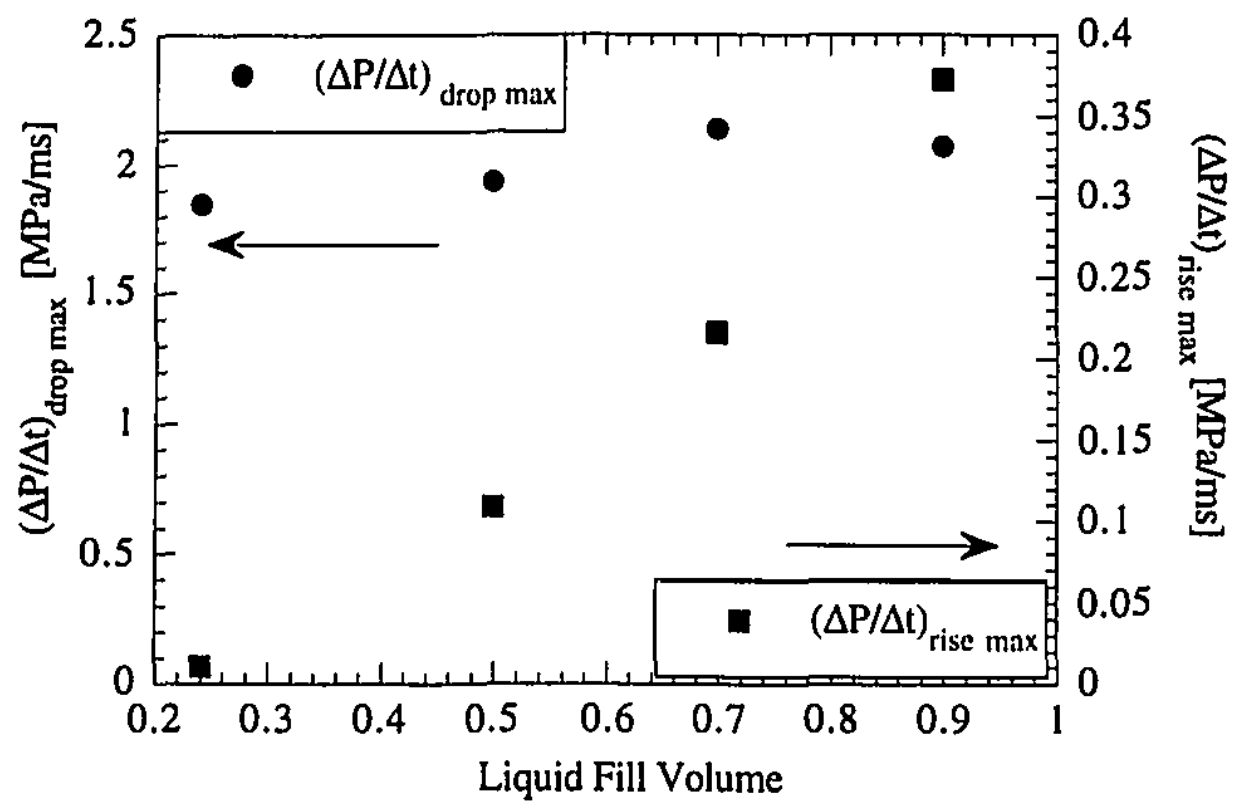

Figure 4.13 - Influence of liquid fill volume on rate of pressure drop and rise

causes an increase in the venting rate. This has the effect of increasing the rate of production of vapor as evidenced through the repressurization. Although the quantity of liquid present will influence the amount of vapor generated, it does not influence the rate of vapor production. It is the increased rate of depressurization, which is a consequence of the increased liquid fill volume (decreased vapor space), that increases the ability of the liquid to explosively vaporize. Figure 4.13 also shows the difference in the magnitude of the rates of depressurization and repressurization. The rates of repressurization are typically an order of magnitude smaller than the rates of depressurization.

\subsubsection{Initial Pressure}

The objective of the next series of tests was to determine the role of the initial thermodynamic state of the liquid on the repressurization following the sudden rupture of the diaphragm. These tests were carried out with fill volumes of $65 \%$ and $90 \%$ with the 19 $\mathrm{mm}$ diameter orifice. Careful monitoring of the state of the R-22 ensured that saturation conditions existed immediately prior to depressurization. Figure 4.14 shows the repressurization within the vessel as a function of the initial pressure for both liquid fill volumes. For the $65 \%$ fill case, the repressurization increased with initial pressure to a maximum for a pressure between 2 and $2.5 \mathrm{MPa}(290-360 \mathrm{psi})$, then began to decrease. The 90\% liquid fill case also shows a similar behavior although the scatter in the results is larger. The increase in scatter may be due to the relatively small amount of vapor that is 
initially present, such that small variations in the liquid fill volume will generate significant variations in the subsequent venting and repressurization rates, as shown in Fig, 4, 12.

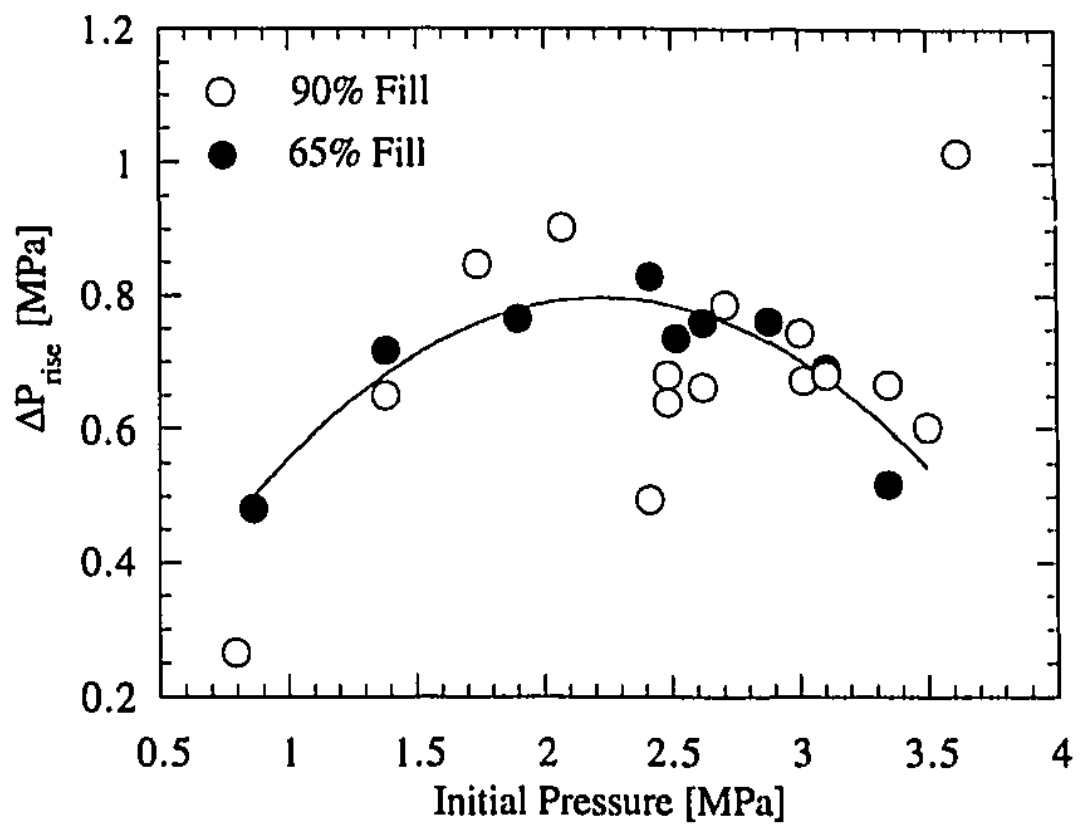

Figure 4.14 - Degree of repressurization as a function of initial pressure within steel vessel. A second order polynomial fit through the data illustrates the observed trend.

Figure 4.15 shows the saturation and spinodal curves for $\mathrm{R}-22$ which bound the metastable region. Path 1-2 corresponds to an isentropic expansion from a pressure of $2.06 \mathrm{MPa}$ (and a saturation temperature of $53^{\circ} \mathrm{C}$ ) to atmospheric pressure which yields the greatest possible degree of superheat at atmospheric pressure. Th. state of the liquid following depressurization for both the $65 \%$ and $90 \%$ liquid fill volume trials is also shown in Fig. 4.15. Although no homogeneous boiling was observed, the locus of data points indicates that there is a limit of superheat that is determined by heterogeneous boiling. Even though the degree of superheat attained will depend on the geometry of the vessel as well as the surface properties of the vessel walls, it is interesting to note that the maximum degree of superheat is attained at a liquid temperature that is similar to that predicted by homogeneous nucleation theory.

The fact that several points at the highest initial temperatures appear slightly to the right of the spinodal curve indicates that in these trials the liquid temperature was not uniform and in fact the average temperature of the liquid was at a value lower than the saturation temperature corresponding to the initial pressure. 


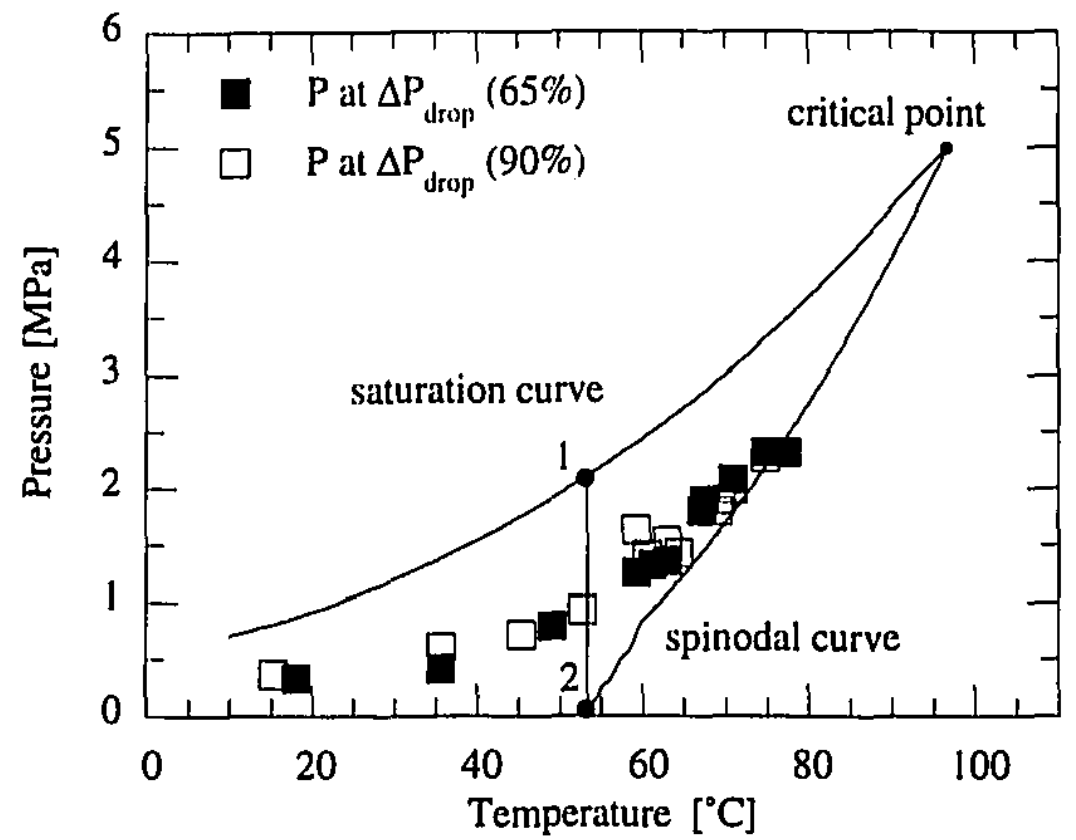

Figure 4.15 - Locus of thermodynamic end states following pressure drop showing the heterogeneous limit of superheat for the $260 \mathrm{mI}$ test vessel.

If the magnitude of repressurization in Fig. 4.14 is normalized with initial pressure we obtain Fig. 4.16 which shows trends similar to those observed by Hiscoke and Birk[21]. The vessel ( $721 \mathrm{ml}$ volume) used by Hiscoke and Birk is comprised of thick walls, a fast opening clamp and was oriented horizontally. It is interesting to note that the basic features of the explosive boiling response remain the same regardless of scale, orifice size and test liquid (they used propane instead of R-22).

We also note that the magnitude of repressurization never exceeds the magnitude of depressurization. Although there were no overpressures measured exceeding the initial pressure, one should not underestimate the potentially dangerous and destructive nature of the repressurization process. The explosive boiling, which is caused by the sudden rupture, or in an accident scenario by a sudden loss of containment, will repressurize the contents of the already weakened vessel, and may lead to complete vessel failure. Therefore it is not only the absolute level of repressurization but also the rate of repressurization that is important since the stress exerted due to the sudden repressurization may be sufficient to cause the crack from the initial rupture to grow and ultimately destroy the vessel. 


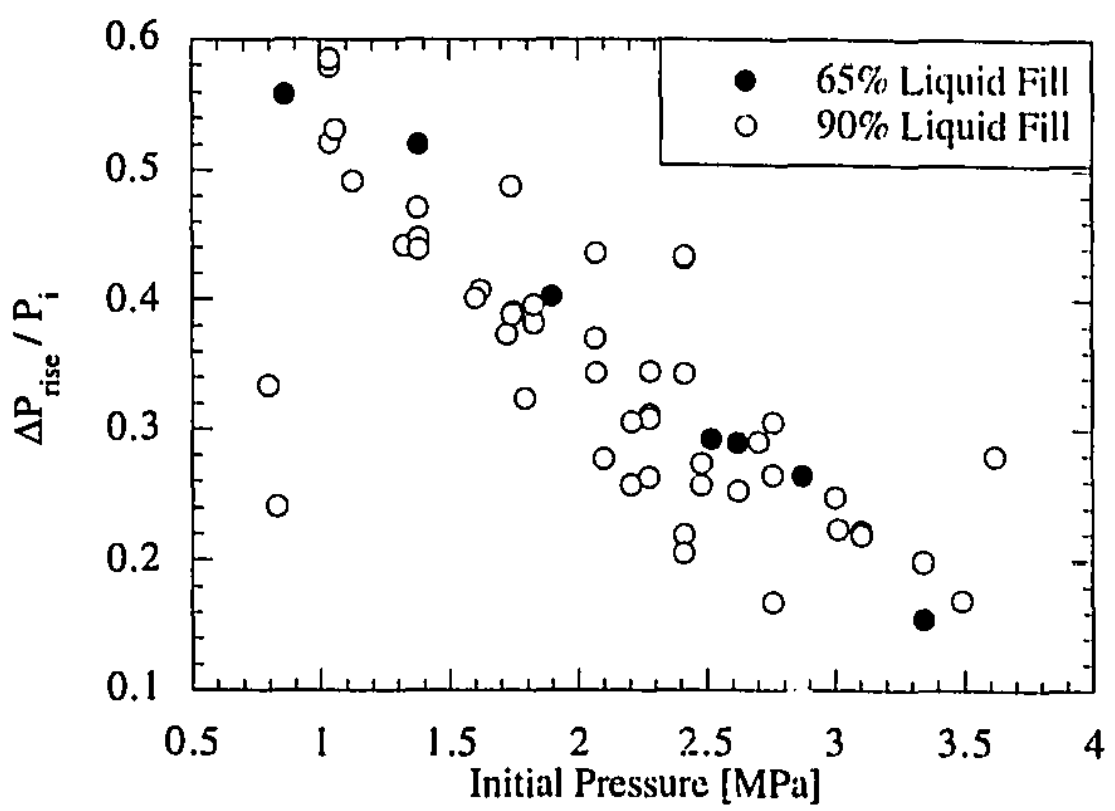

Figure 4.16 - Influence of initial pressure on normalized repressurization

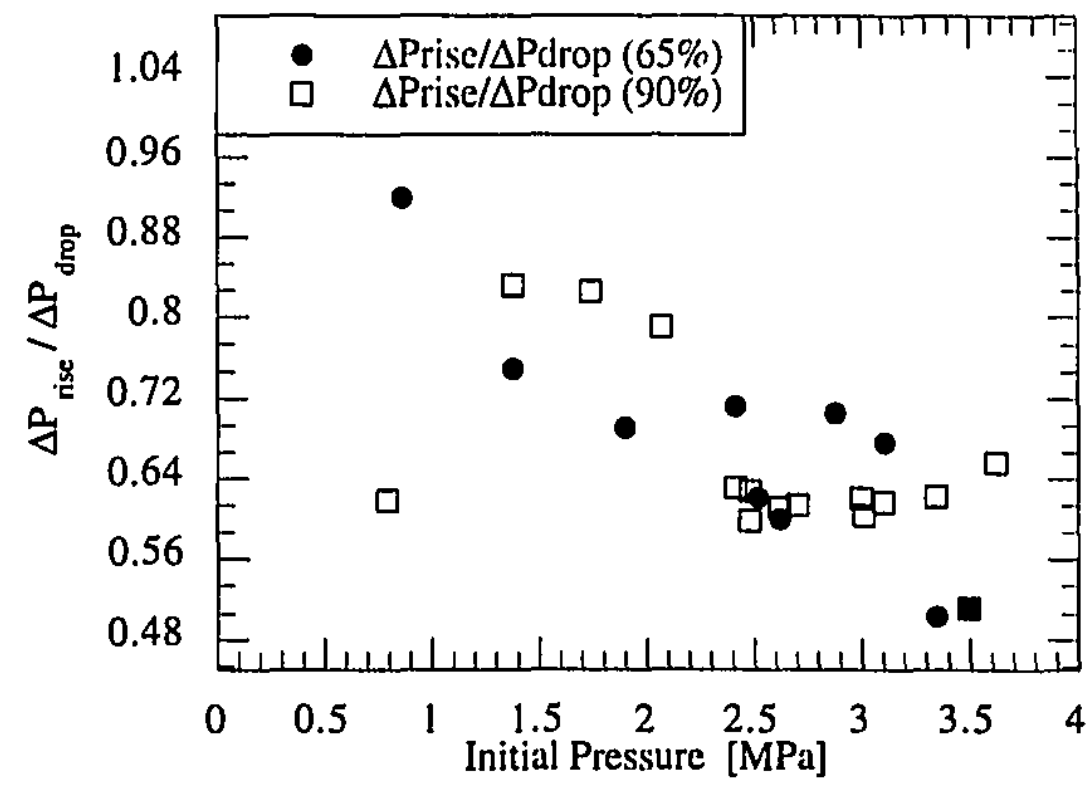

Figure 4.17 - Influence of initial pressure on repressurization for a given depressurization

Figure 4.17 shows another way to visualize the data. The ratio of the magnitude of repressurization and magnitude of depressurization gives an indication as to how much repressurization is obtained for a given magnitude of depressurization. By plotting the ratio $\Delta$ Prise/ $\Delta$ Pdrop versus the initial pressure, we observe that the ability of the liquid to repressurize for a given degree of depressurization diminishes as the initial pressure 
increases. This indicates that although the magnitude of repressurization is lower at lower initial pressures the relative ability of the liquid to repressurize is higher at lower initial pressures as compared to higher initial pressures. This perhaps indicates that more of the liquid participates in the boiling process at lower initial pressures. Since the degree of twophase venting increases with increasing initial pressure a greater fraction of the liquid is expelled through the two-phase venting and there is less available for boiling within the vessel.

The influence of the initial pressure on the rates of depressurization and repressurization are shown in Fig. 4.18 and Fig. 4.19, respectively. Both of the rates increase as the initial pressure is increased. It should be noted that the dependence of the rates on the initial pressure differs from that exhibited by the magnitudes (refer to Fig. 4.14). Figures 4.18 and 4.19 indicate that there is no apparent maximum value reached at any level of initial pressure and very little difference can be discerned in the rates for the $65 \%$ and $90 \%$ liquid fill volumes.

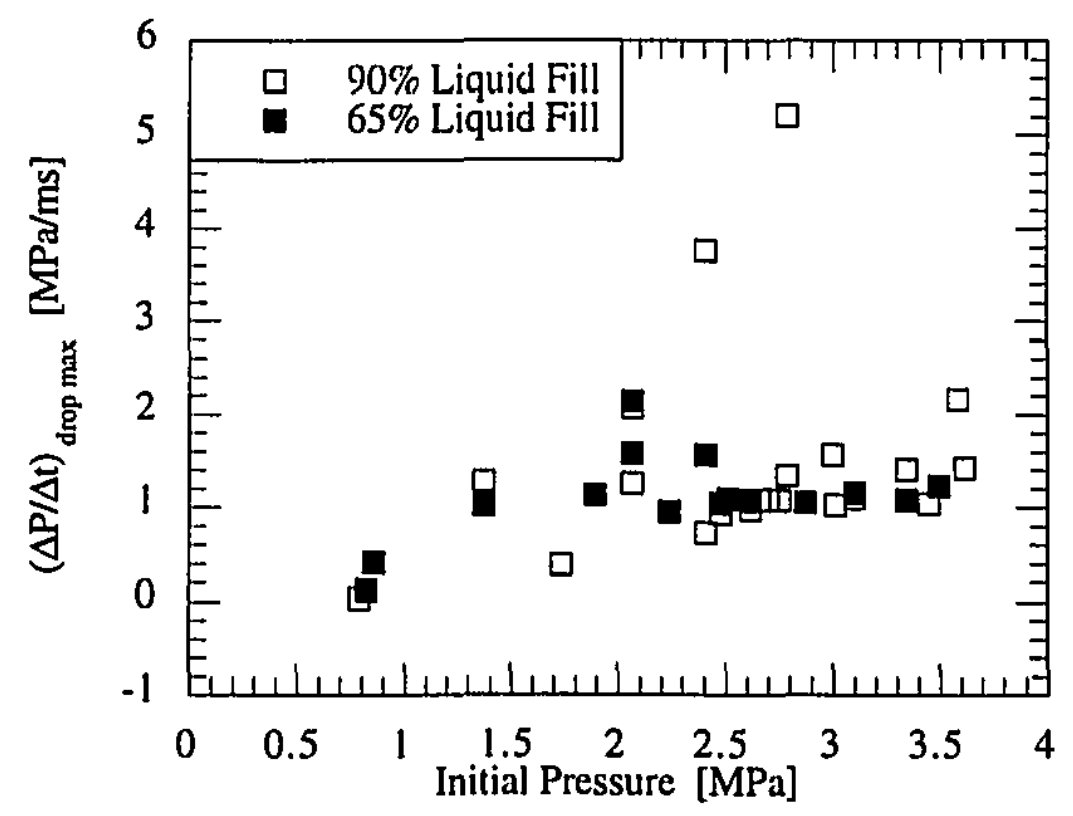

Figure 4.18 - Influence of initial pressure on rate of depressurization

The rates of repressurization are typically an order of magnitude slower than the rates of depressurization. The level of pressure drop and rise are dependent on the rate of depressurization and repressurization, respectively. A more rapid depressurization process will invariably lead to a greater pressure drop. Thus the level of repressurization within the vessel is not only dependent on the rate $(\Delta \mathrm{P} / \Delta \mathrm{t})_{\text {rise } \max }$ but also linked to the initial 
depressurization rate $(\Delta \mathrm{P} / \Delta \mathrm{t})_{\text {drop max. }}$. Any factor influencing $(\Delta \mathrm{P} / \Delta \mathrm{t})_{\text {drup mix }}$ will therefore have an effect on the pressurization level reached due to explosive boiling.

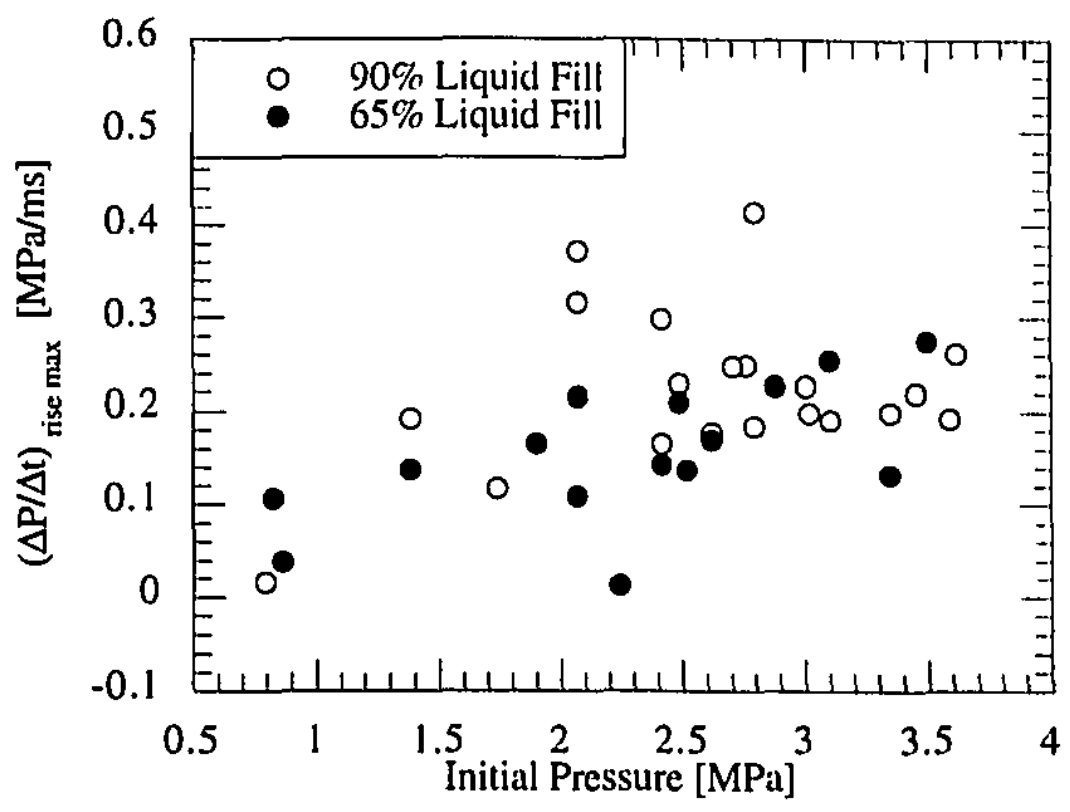

Figure 4.19 - Influence of initial pressure on rate of repressurization

\subsubsection{Mode of Nucleation}

The effect of the surface condition of the vessel walls on the explosive boiling phenomena was investigated using high-speed photography taken with a Hycam $16 \mathrm{~mm}$ movic camera. A knowledge of the mode of boiling not only compliments pressure measurements but also gives a more complete understanding of the explosive boiling process.

When the diaphragm seal of the vessel is suddenly ruptured and expansion waves propagate into the liquid, the liquid suddenly becomes superheated and shortly after begins to boil. The sudden depressurization brings the liquid to a non equilibrium state. Preexisting vapor or gas bubbles, trapped in the cracks located at the vessel walls, or gases dissolved in the liquid itself, serve as nucleation sites. When the bulk of the liquid is not pre-nucleated, boiling preferentially occurs at liquid-vapor interfaces, such as the free surface interface and on pre-existing nucleation sites. The initial boiling in the present study is dominated by heterogeneous nucleation on the Teflon-coated side walls of the 260 $\mathrm{ml}$ vessel and at the free liquid-vapor surface.

Figure 4.20 shows a simplified sketch of the development of the boiling wave within the $260 \mathrm{ml}$ vessel, as deduced from high-speed film records of similar trials. Following diaphragm rupture at the top (middle sketch), the boiling front is initiated on the inside 
walls and moves inward, displacing the central liquid region vertically. The liquid-vapor free surface of the liquid also begins to break up, as a two-phase vaporized front propagates downward from the interface.
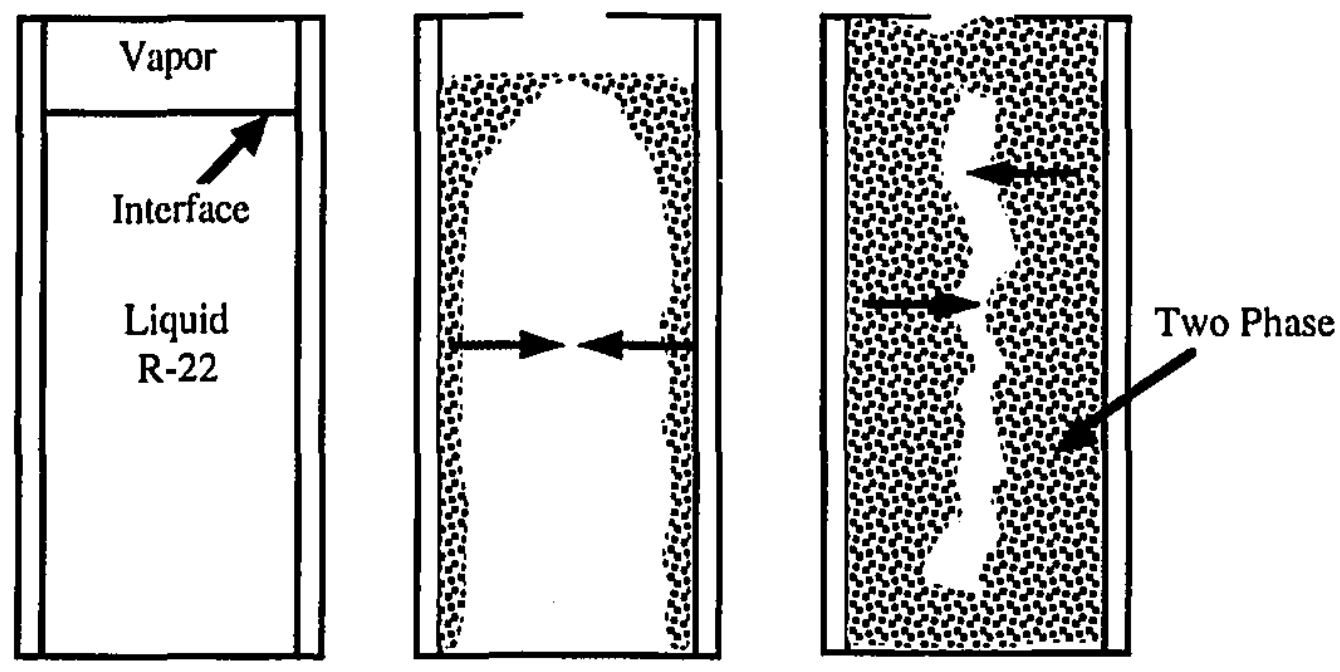

Figure 4.20 - Schematic of heterogeneous boiling from walls of $260 \mathrm{ml}$ vessel

A sequence of high-speed photographs shown in Fig. 4.21 illustrates the boiling process that occurs within the vessel. Heterogeneous nucleation on the Teflon-coated walls dominates and the boiling propagates from the side walls towards the center of the vessel as a wave front with an average speed of the order of $1 \mathrm{~m} / \mathrm{s}$. The two-phase mixture appears as dark regions since the back lighting is diffracted and does not reach the film. Since there are no bubbles within the bulk of the liquid and the glass windows offer very few nucleation sites, heterogeneous boiling dominates at the side walls.

Heterogeneous boiling takes place as a result of trapped gases along the surface of the vessel walls and also due to the fact that it requires less energy to grow a vapor bubble on a surface than within the liquid itself. Figure 4.22 shows a close up view of a trial similar to the one in Fig 4.21. One can readily observe the rapid vapor generation at the walls.

By varying the surface conditions of the vessel walls, while keeping all the remaining parameters constant, it is possible to observe the tendency for a surface to promote or hinder heterogeneous boiling. Figure 4.23 shows the instantaneous velocity of the twophase "wave front" for three different surfaces, as measured (from photographic records) by the rate of displacement of the advancing wave within the liquid from both sides. 


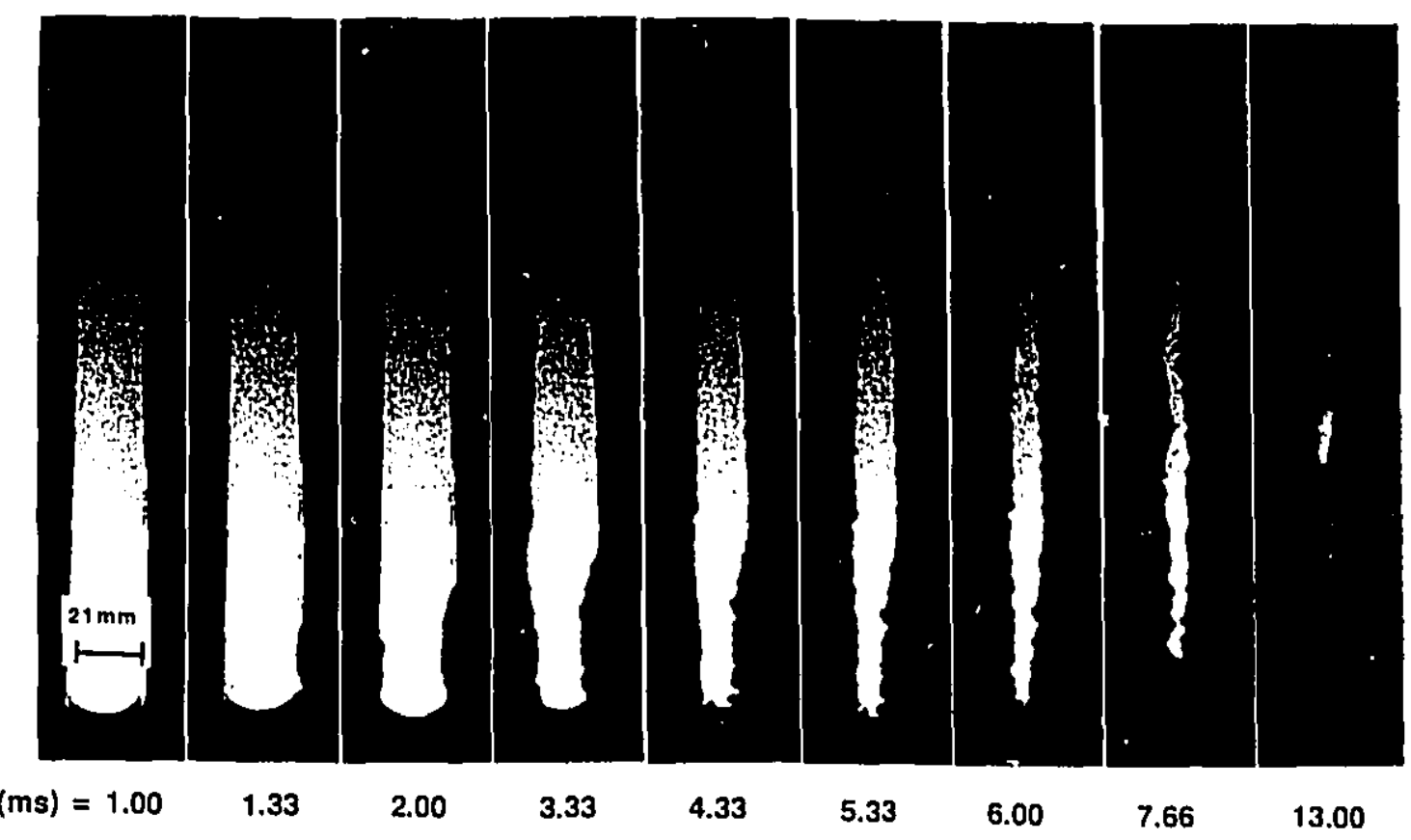

Figure 4.2I - Sequence of high-speed photographs showing heterogencous boiling of R22 from the Teflon-coated walls in the $260 \mathrm{ml}$ vessel $\left(\mathrm{P}_{\mathrm{i}}=1.03 \mathrm{MPa}\right)$

In the interpretation of these results one must note that the photographic records provide an integrated view of the boiling front over the channel thickness. This may introduce some error in the wave speed that is deduced since the advancing boiling wave may not be uniform across the channel.

The velocities reported in Fig. 4.23 should thus be considered only in a relative context. In any case, the rate of boiling, which is manifested through the speed of the two-phase wave front, is dependent on the degree of superheat attained by the liquid. The ability of a surface to suppress heterogeneous boiling will allow the pressure to drop to a lower value before any boiling occurs. A higher pressure drop within the liquid will increase the level of achieved superheat and thus increase the rate of boiling. From Fig 4.23 it is clear that the glass lined vessel is the most effective in suppressing heterogencous boiling, as it yields the greatest boiling wave speed. These results imply that increasing the level of heterogeneous boiling should cause a reduction in the severity of explosive boiling. 


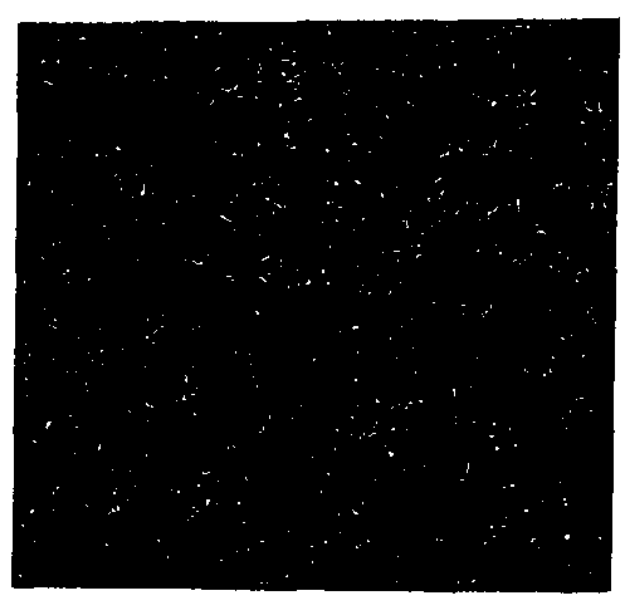

$t_{1}=1.00 \mathrm{~ms}$

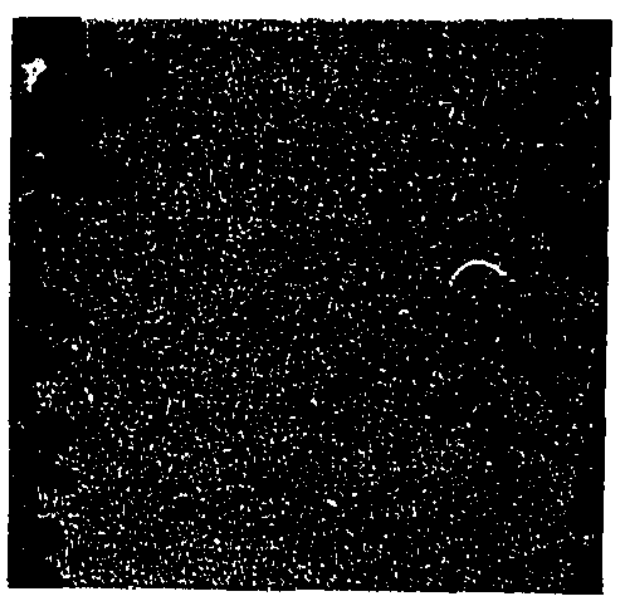

$t_{2}=1.33 \mathrm{~ms}$

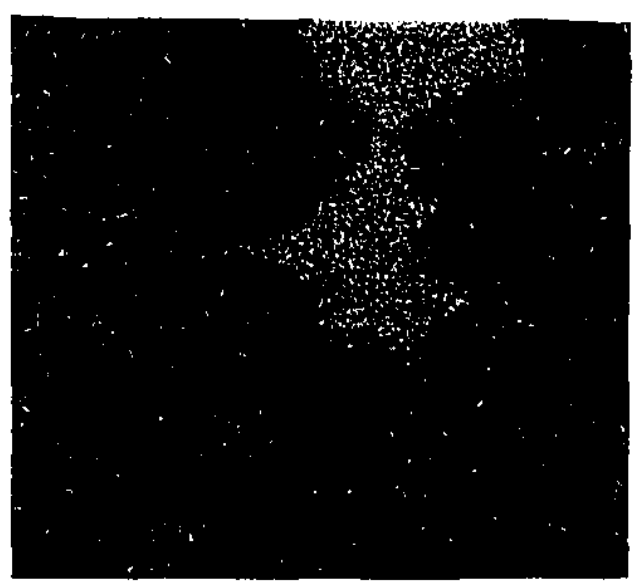

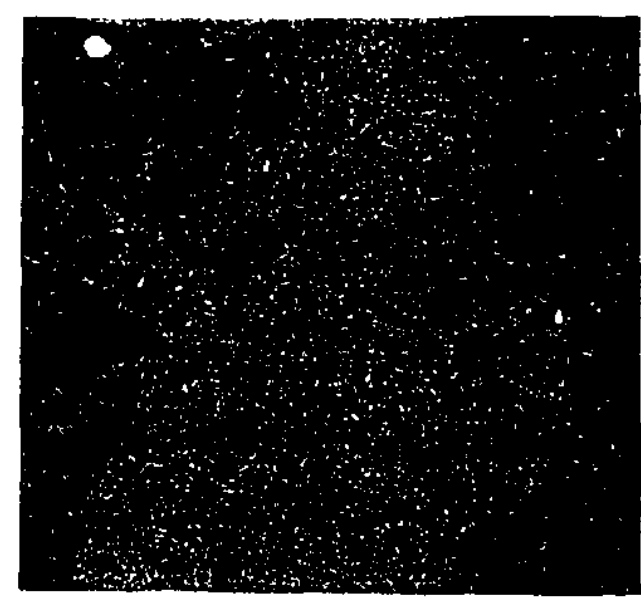

$\mathrm{t}_{3}=2.00 \mathrm{~ms}$

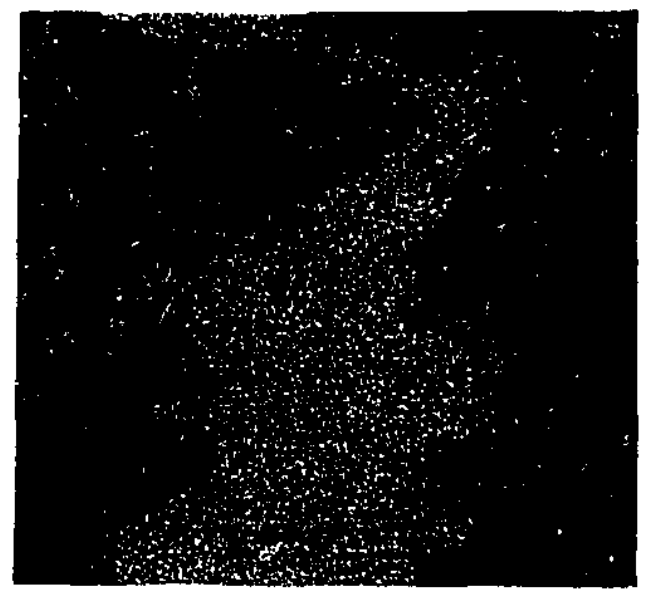

$\mathrm{t}_{4}=2.66 \mathrm{~ms}$

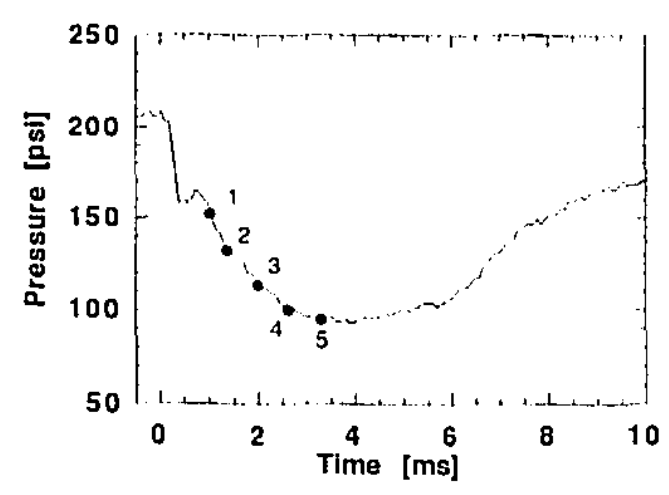

Figure 4.22 - Sequence of high-speed photographs showing heterogeneous boiling of R22 from the Teflon-coated walls in the $260 \mathrm{ml}$ vessel $\left(\mathrm{P}_{\mathrm{i}}=1.43 \mathrm{MPa}\right)$ 


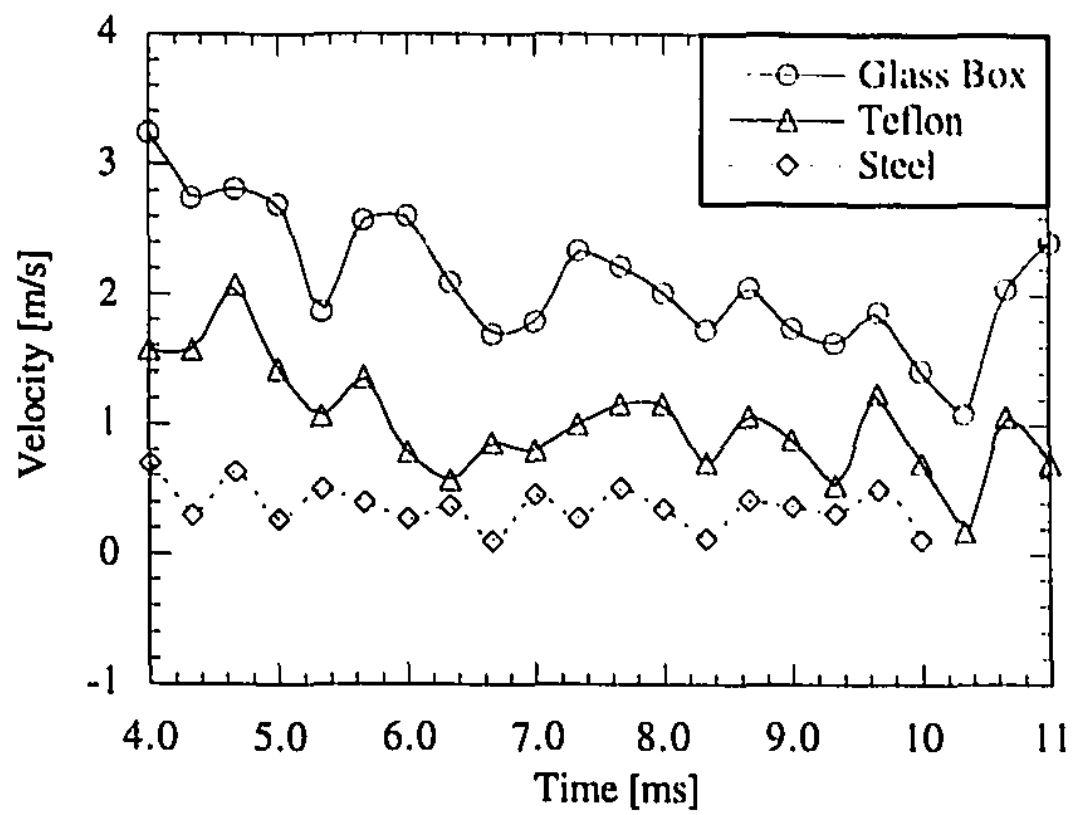

Figure 4.23 - Instantaneous velocity of leading edge of two phase, heterogeneous, boiling wave.

\subsubsection{Explosive Boiling in $75 \mathrm{ml}$ Glass Tube}

In an attempt to reduce the effects of heterogeneous wall boiling a second vessel was used. The next series of trials was performed in a $75 \mathrm{ml}$ glass tube $(25 \mathrm{~mm}$ inner diameter) using a $9.5 \mathrm{~mm}$ diameter orifice and $90 \%$ liquid fill volume.

\subsubsection{Initial Pressure}

Figure 4.24 shows the degree of repressurization as a function of the initial pressure for the experiments in the glass tube. Despite the fact that two modes of boiling were observed (evaporation wave and heterogeneous wall boiling), the repressurization reaches a maximum near an initial pressure of $2 \mathrm{MPa}$, similar to that observed earlier with the steel vessel. This indicates that although two geometrically different vessels were used, with different wall conditions and vent areas, the maximum pressure recovery is largely a function of the initial R-22 vapor pressure (or temperature), i.e., the initial thermodynamic state of the liquid. 


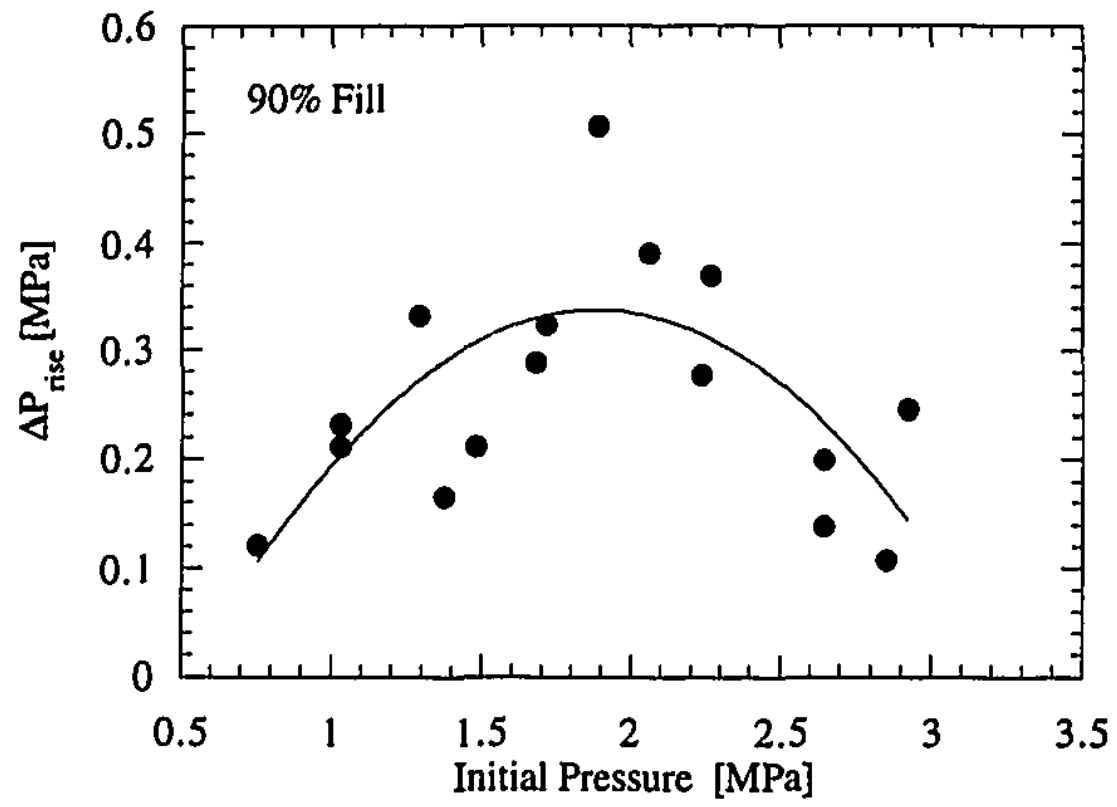

Figure 4.24 - Degree of repressurization as a function of initial pressure within glass tube. A second order polynomial fit through the data illustrates the observed trend.

\subsubsection{Mode of Nucleation}

Two modes of boiling were observed which depended on the initial temperattire of the liquid. For initial $\mathrm{R}-22$ temperatures less than $25^{\circ} \mathrm{C}$ (corresponding to a saturation vapor pressure of $1.03 \mathrm{MPa}$ ) the boiling occurred as an evaporation wave moving from the free surface of the liquid vertically downwards. Figure 4.25 shows an enlarged view of the liquid-vapor interface in the early stages following depressurization. After the diaphragm is ruptured, the vapor above the liquid condenses, signaling the passage of an expansion wave, and $7.33 \mathrm{~ms}$ later the surface of the liquid erupts violently into a two-phase flow consisting of vapor and fine droplets moving vertically at high speed. Initial perturbations of the top surface by the expansion waves and liquid stripping produce local vapor nuclei, which are essentially 'embryos' that supply the necessary liquid-vapor interfaces required for boiling of the R-22 to occur. Additional vapor nuclei are continuously generated ahead of the two phase wave, allowing for a sustained propagation. In essence, the wave preconditions the liquid ahead of it in the form of liquid-vapor interfaces serving as the "fuel" for the boiling wave propagation. A detailed discussion of the mechanism of propagation of the evaporation wave can be found in Hill[23]. 

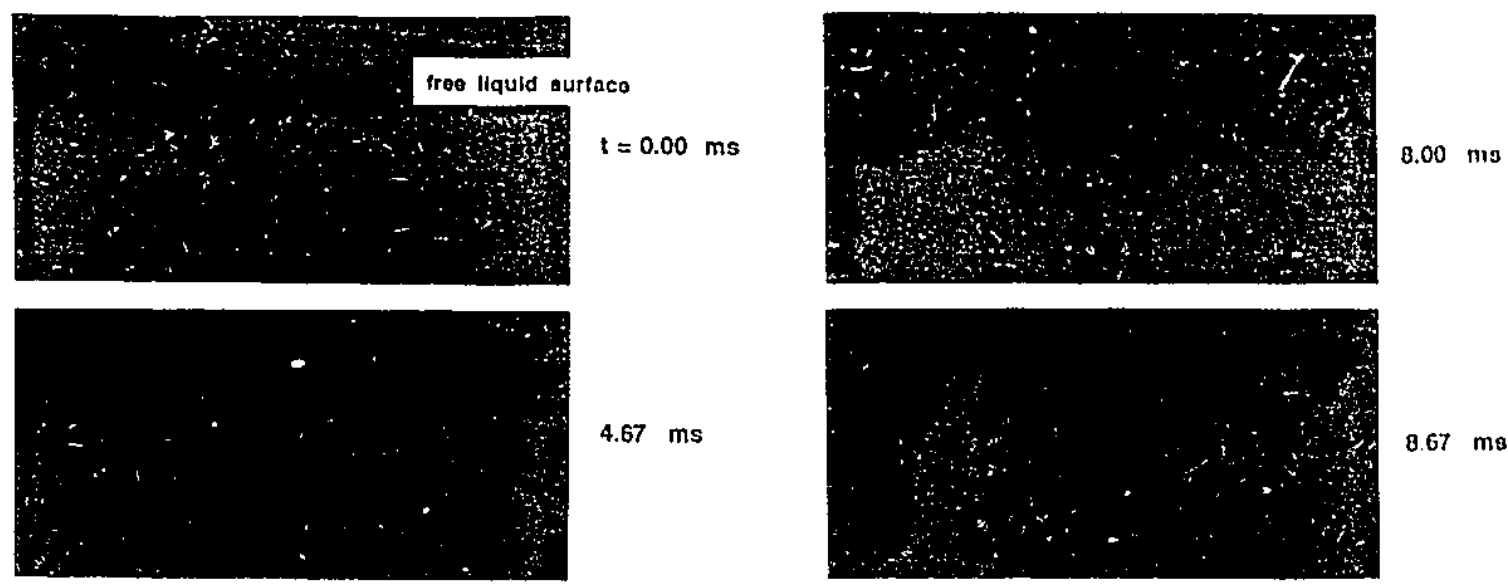

$8.67 \mathrm{~ms}$
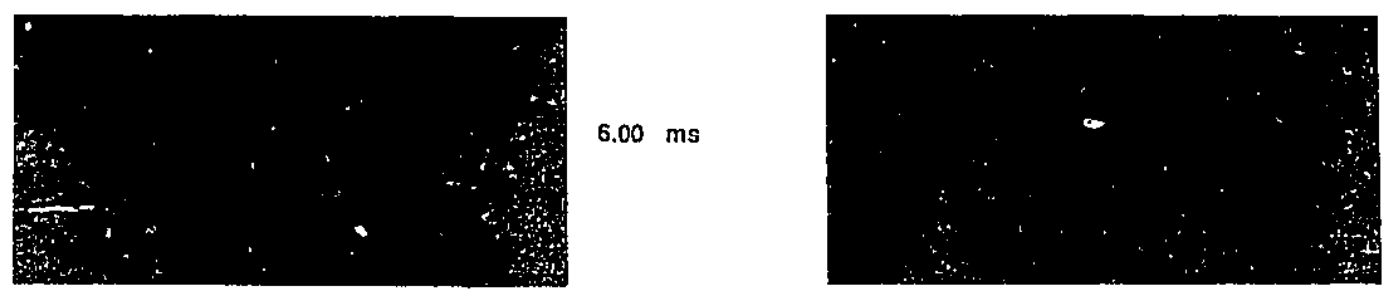

$10.00 \mathrm{nis}$

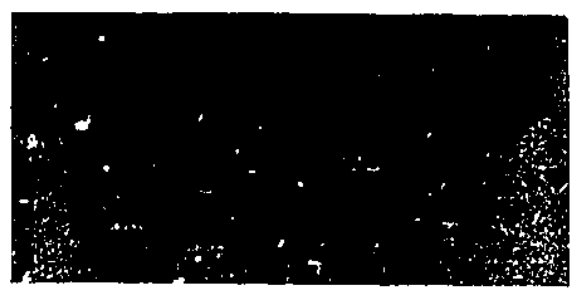

$7.33 \mathrm{~ms}$

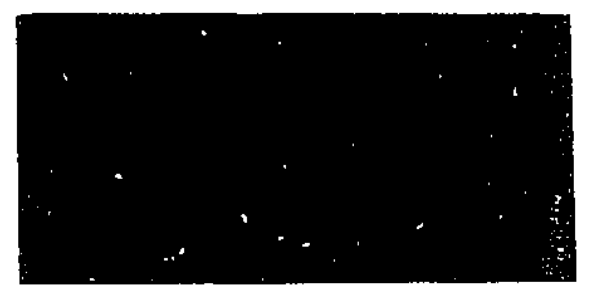

$11.33 \mathrm{~ms}$

Figure 4.25 - Breakup of free surface of liquid R-22 contained within a glass tube following depressurization $\left(\mathrm{P}_{\mathrm{i}}=1.20 \mathrm{MPa}\right)$

Figures 4.26 and 4.27 show the average displacement versus timc and a schematic of the propagation of the evaporation wavefront within the glass tube, illustrating the random variations in the shape and velocity of the evaporation wave that occur for two trials with the same initial conditions. In both cases the wave initially propagates rapidly downwards from the free surface in a highly asymmetric manner. The wavefront becomes relatively more planar after a short time (denoted $a$ on Fig. 4.26) which corresponds to a decrease in the average wavefront velocity. After about $300 \mathrm{~ms}$ the wavefront asynımetry begins to become more pronounced, and the velocity increases beyond the point denoted $c$ in the figures.

Figure 4.28 shows single frames from a Hycam film of the propagation of an evaporation wave in the liquid R-22 for an initial vapor pressure of $1.03 \mathrm{MPa}$. Note that the initial rapid depressurization is sufficient to cause a nucleation site to grow on the right side of the tube wall ahead of the wave front. The vapor bubble growth and pressure buildup within 
the vessel cause the evaporation wave to virtually stop propagating until the subsequent pressure drop within the vessel reinitiates the wave propagation.

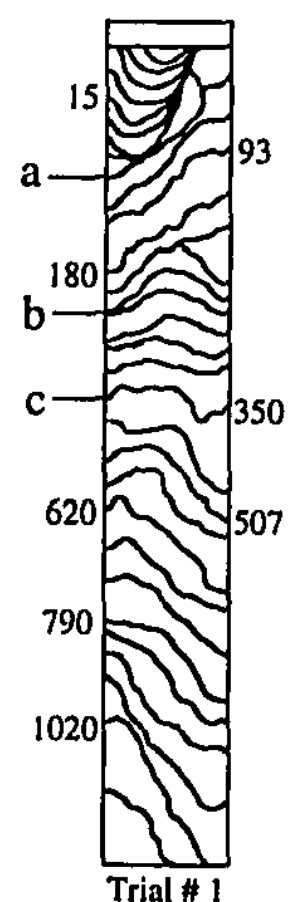

Trial \# 1

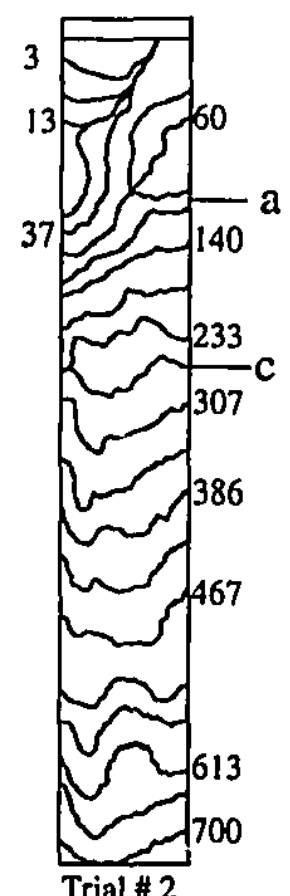

Trial \# 2

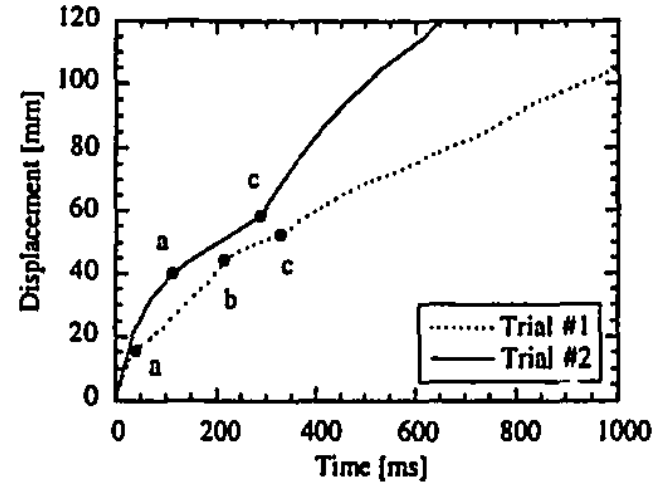

Figure - 4.26 (above) Evaporation wave displacement versus time $(\mathrm{Pi}=1.03 \mathrm{MPa}$ )

Figure - 4.27 (left) Schematic of the propagation of evaporation wave in liquid $\mathrm{R}-22$. $(\mathrm{Pi}=1.03$ $\mathrm{MPa}$ )

For initial R-22 temperatures above about $25^{\circ} \mathrm{C}$ (corresponding to an initial vapor pressure greater than about $1 \mathrm{MPa}$ ), the superheat attained by the liquid following depressurization is sufficient to induce heterogeneous nucleation on the tube walls. This is illustrated in Fig. 4.29 which shows a sequence of photographs for the boiling of R-22 with an initial pressure of $2.24 \mathrm{MPa}$ (corresponding to an initial saturation temperature of $60^{\circ} \mathrm{C}$ ). The growth of the nucleation sites along the length of the tube forces the remaining liquid out the orifice and prevents the propagation of an evaporation wave within the tube. Due to the large increase in liquid-vapor interface area, the liquid R-22 is partially vaporized and expelled from the tube in a time about an order of magnitude faster than when the boiling occurs via an evaporation wave.

The glass test tube thus has a finite ability to suppress heterogeneous boiling since minute scratches and pits on the glass surface will eventually serve as nucleation sites for boiling to occur. At best the glass surface can suppress local heterogeneous nucleation for a limited period of time and for low superheats, since at higher superheats the ability to suppress heterogeneous wall boiling decreases. 

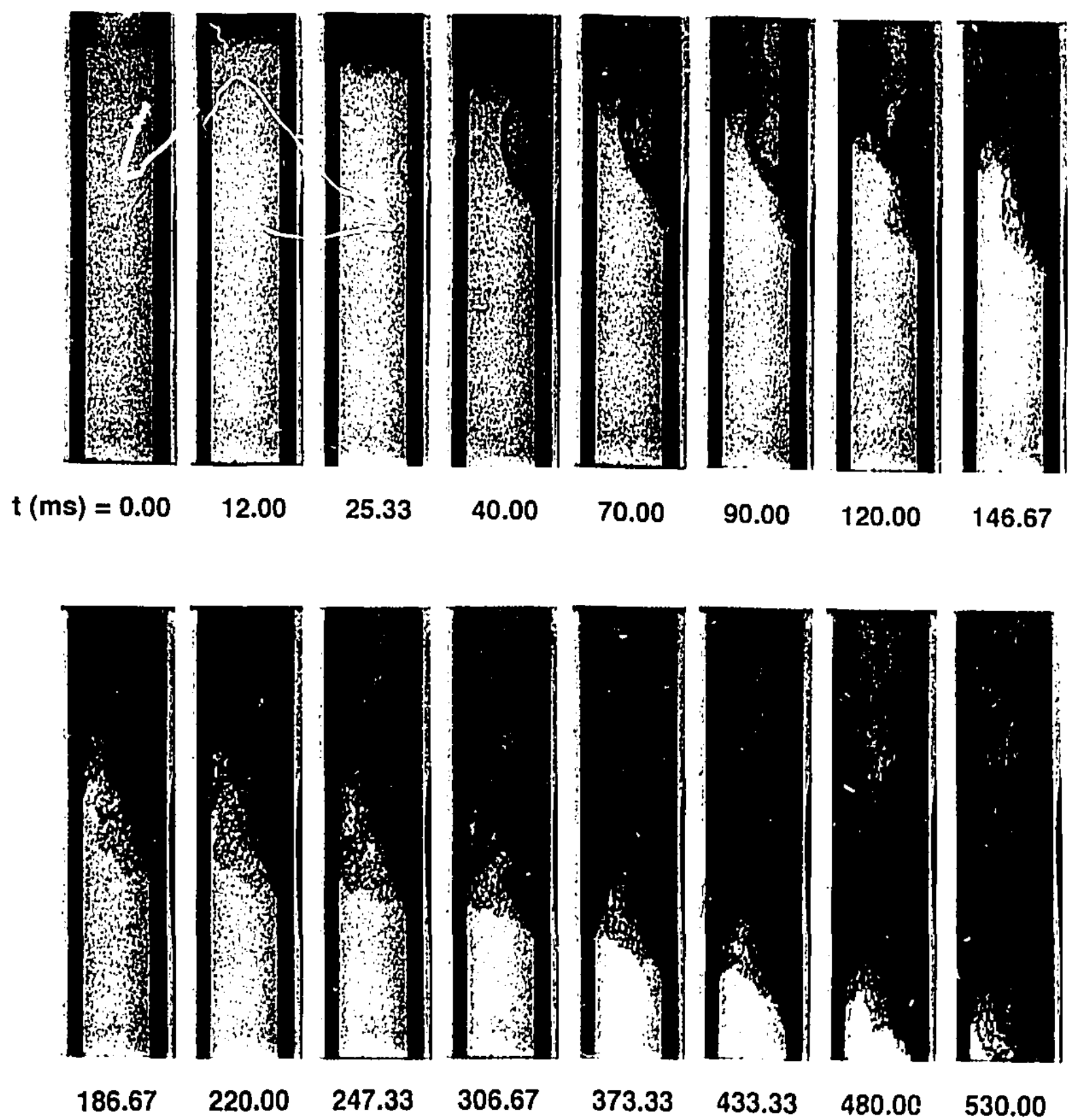

Figure 4.28 - Sequence of high-speed photographs showing the propagation of evaporation wave throughout length of glass tube. $(\mathrm{Pi}=1.03 \mathrm{MPa})$ 


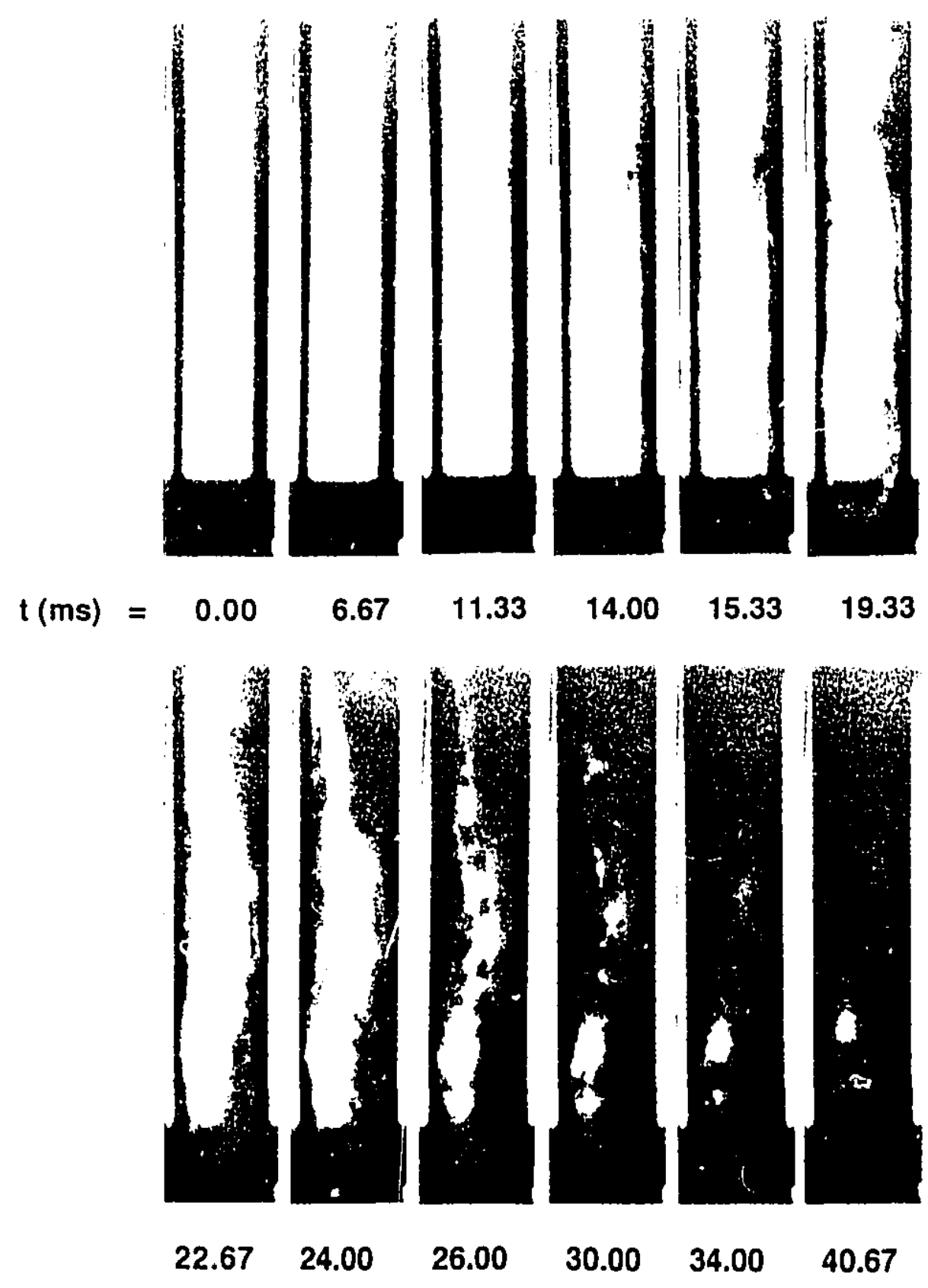

Figure 4.29 - Sequence of high-speed photographs showing the heterogeneous boiling of $\mathrm{R}-22$ within a glass tube. $(\mathrm{Pi}=2.24 \mathrm{MPa})$ 


\subsubsection{Pre-Nucleation Experiments}

In order to stimulate the participation of the bulk of the liquid in the boiling. as would be expected in a homogeneous boiling scenario, $\mathrm{CO}_{2}$ gats was dissolved in the liçuid refrigerant by exposing it to an overpressure of 1-2 MPa for 48 hours. The intent wals (t) precondition the liquid so that upon sudden depressurization, the $\mathrm{CO}_{2}$ would exsolute, i.c.. come out of solution, throughout the liquid refrigerant. The increase in liquicl-vapor interfacial surface area would promote boiling around each growing $\mathrm{CO}_{2}$ bubble.

Figures 4.30 and 4.31 show a sequence of high speed photographs of the explosive boiling of $\mathrm{R}-22$ dissolved with and without $\mathrm{CO}_{2}$, respectively, and contained within a glass test tube. At first glance both sets of photographs essentially illustrate the same general type of behavior. It appears that upon sudden depressurization, some boiling lakes place at locial pits and scratches on the glass surface. However, comparing the time at which the boiling starts in the two experiments, it is evident that boiling appears much sooner in the R-22 dissolved with $\mathrm{CO}_{2}$, i.e., at $1.5 \mathrm{~ms}$ compared to $8 \mathrm{~ms}$ for R-22 without any dissolved $\mathrm{CO}_{2}$.
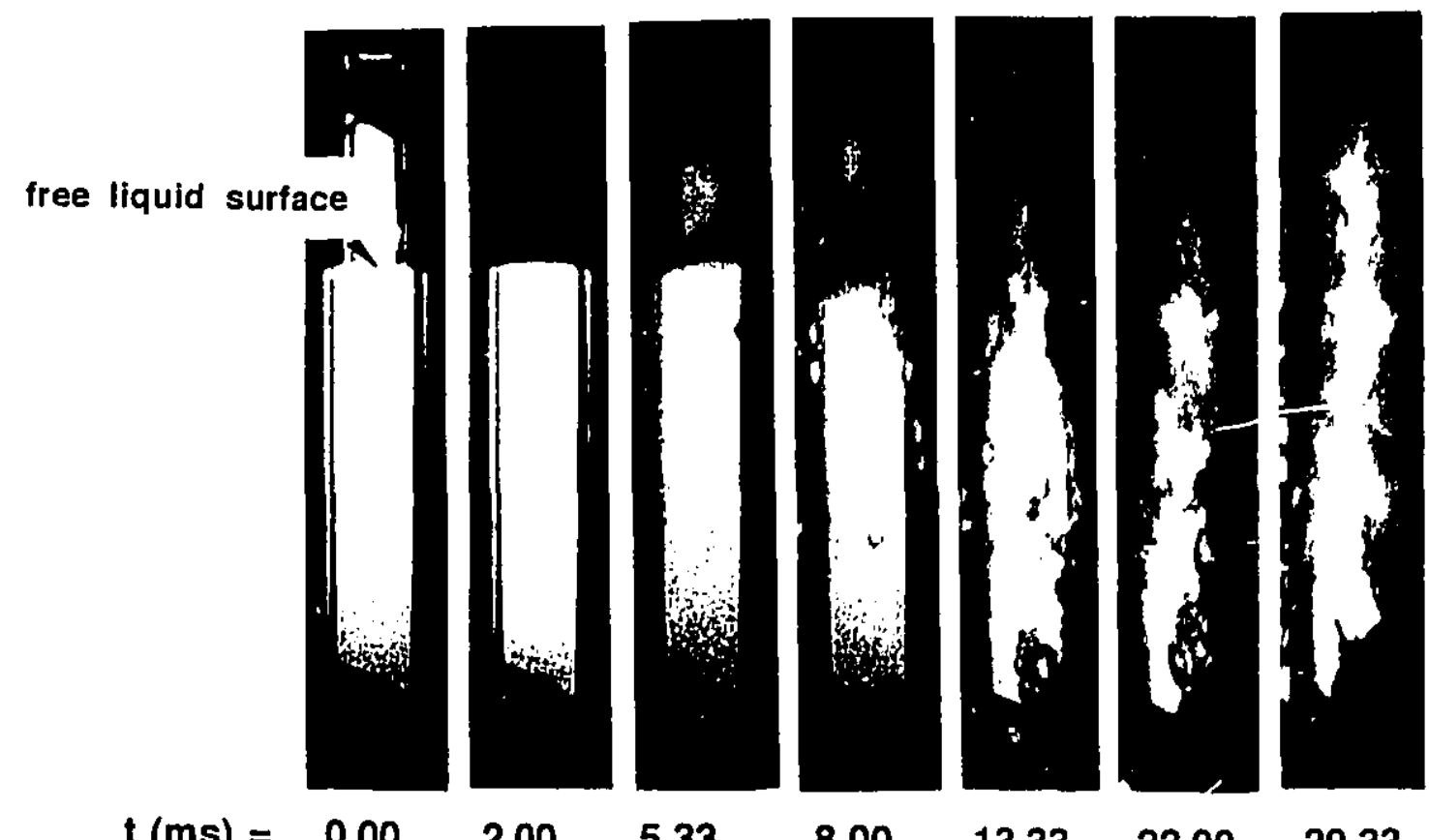

$t(m s)=0.00$

5.33

8.00

13.33

22.00

29.33

Figure 4.30 - Sequence of high-speed photographs showing the heterogeneous boiling of $\mathrm{R}-22$ without $\mathrm{CO}_{2}$ within the glass tube. $(\mathrm{Pi}=1.20 \mathrm{MPa})$ 


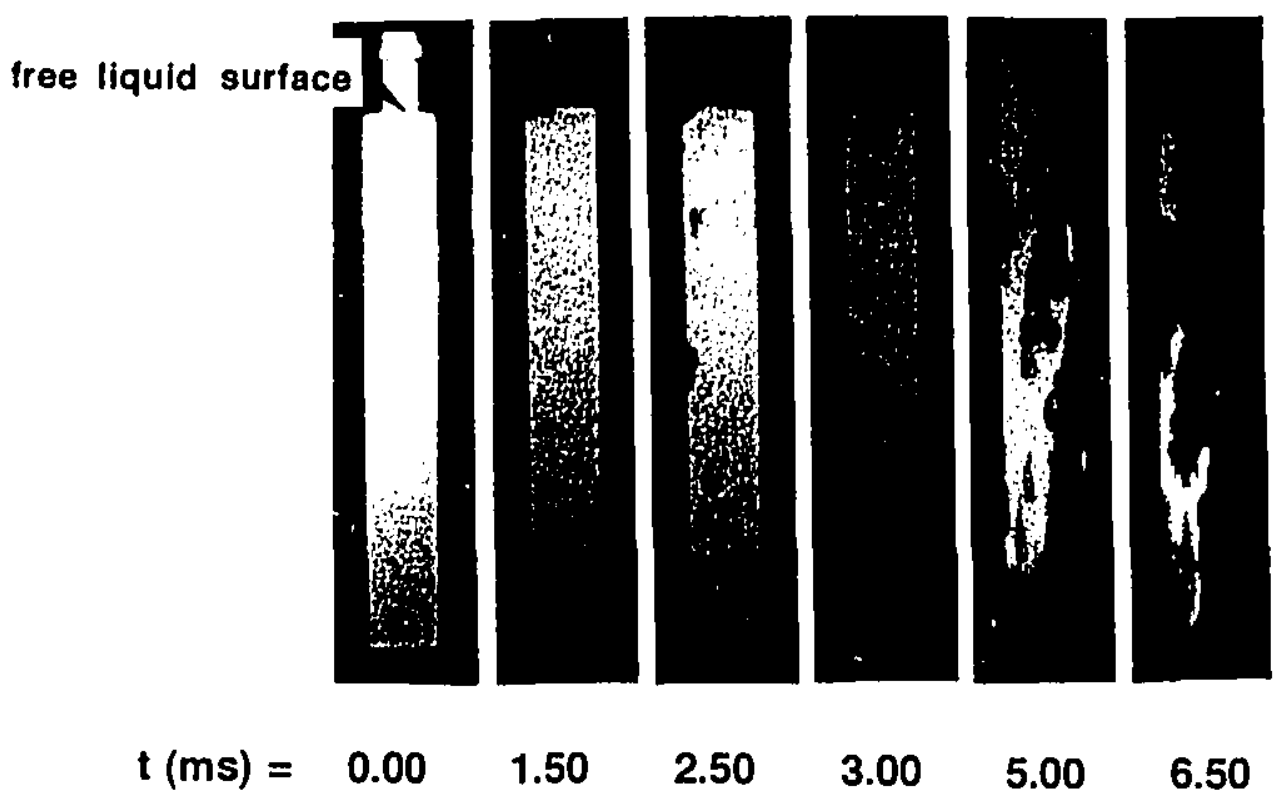

Figure 4.31 - Sequence of high-speed photographs showing the heterogeneous boiling of $\mathrm{R}-22+\mathrm{CO}_{2}$ within the glass tube. $(\mathrm{Pi}=1.38 \mathrm{MPa})$

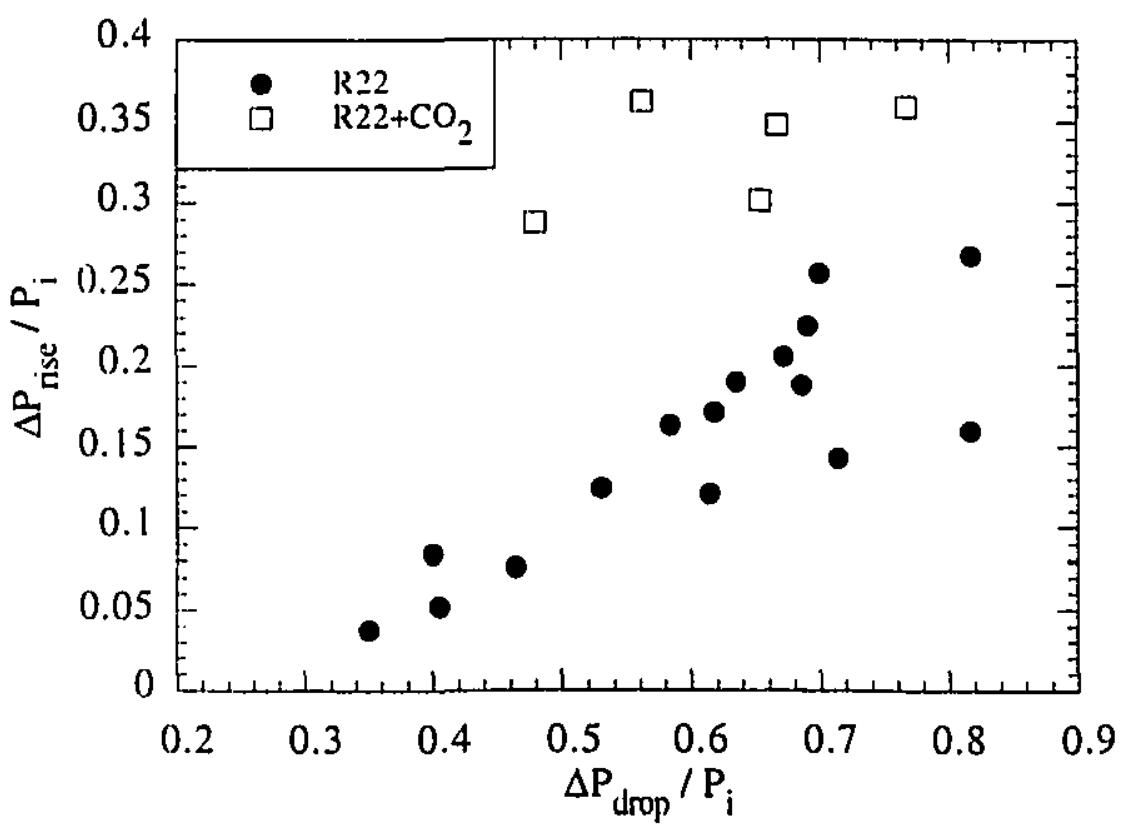

Figure 4.32 - Effect of dissolving $\mathrm{CO}_{2}$ in refrigerant 22 on the boiling response. 
Although the $\mathrm{CO}_{2}$ was primarily used in an attempt to promote homogenous boiling throughout the liquid, the experiments performed within the glass test tube reveal that it only increases the likelihood of heterogeneous boiling. Based on limited photographic data it seems as though the $\mathrm{CO}_{2}$ does not exsolute fast enough for it to promote homogenous boiling, but nevertheless has an effect on the boiling response.

Figure 4.32 shows the normalized repressurization as a function of depressurization for experiments with and without $\mathrm{CO}_{2}$ dissolved in the refrigerant. For the limited number of experiments with dissolved $\mathrm{CO}_{2}$ we can see that, as demonstrated by the high speed photographs, the $\mathrm{CO}_{2}$ increases the boiling response of the boiling refrigerunt.

\subsection{Other Experiments}

The data presented in section 4.3 were obtained under strict control of initial and boundary conditions. Appendix B contains additional experimental data corresponding to the complete set of experiments performed with the $260 \mathrm{ml}$ vessel, including the initial stages of the investigation. For the earlier data obtained during the scoping trials, the experimental conditions, apparatus and procedure were continuously being changed and improved and consequently in view of the delicate nature of the experimental procedurc (preservation of saturation conditions prior to diaphragm rupture), they were excluded from the main data presented in the previous section. Nevertheless, by comparison, Figs. 4.2, 4.14 and 4.15 with the corresponding figures in Appendix B, comprising all of the data, one observes that the same general trends can be found. An apparent difference is in the increase in scatter that is exhibited, which in retrospect is not surprising in view of the larger pool of data. Tables containing the raw data of all experiments included in this report are found in Appendix C.

\subsection{Semi-Empirical Model for Pressure Undershoot}

A method for correlating the amount of pressure undershoot that occurs when saturated water is suddenly depressurized has been developed by Alamgir and Lienhard ${ }^{[6]}$ (a similar correlation has also been used by Bartak[7]). Although the correlation was originally applied to experiments with very rapid depressurization, it is of interest to apply it to the results of the present investigation to test its applicability. 
Based on classical homogeneous nucleation theory [14], the critical work $\Delta \Phi$, necessary to create a bubble capable of further growth, i.e., the "potential barrier" for nucleation to occur is

$$
\Delta \Phi=\frac{16 \pi \sigma^{3}}{3 \Delta P^{2}\left(1-\frac{v_{l i q}}{v_{v a p}}\right)^{2}},
$$

wherc $\Delta P=P_{i}-P_{f}, \sigma$ is the surface tension and $v$ is the specific volume. The probability that a molecule has the critical work is $e^{(-\Delta \Phi / k T)}$ with the ratio $\Delta \Phi / k T$ defined as the Cribbs number $G b$, where $k$ is the Boltzmann's constant and $T$ the temperature. The critical work required for heterogeneous nucleation is $\Delta \Phi^{\prime}=f \cdot \Delta \Phi$, where $f<1$ is an arbitrary heterogeneous factor. The magnitude of depressurization, $\Delta P$, that is necessary to produce the critical work necessary for heterogeneous nucleation to occur is obtained from equation 27 as,

$$
\Delta P=\left[\frac{16 \pi \sigma^{3}(f / G b)}{3 k T\left(1-\frac{v_{l}}{v_{g}}\right)^{2}}\right]^{1 / 2} .
$$

Since experimentally the pressure drop depends on the initial pressure (or temperature) and rate of depressurization, the ratio $G b / f$ is assumed to be a product of two functions $f(T)$ and $g(d P / d t)$. The functions $f$ and $g$ were correlated using experimental data, i.e., $T i$, $\Delta P_{d r o p}, d P / d t$, and equation 28 and were shown to have the final form, $f(T)=1.3 \times 10^{-5}$ $(T / T c)^{\prime 2}$ and $g(d P / d t)=\left(l+33.09(d P / d t)^{1.27}\right)$. The experimental data for the pressure drop in the $260 \mathrm{ml}$ vessel at $90 \%$ liquid fill and the theoretical pressure drop, as given by equation. 28, are shown in Fig. 4.33.

The correlation shows the dependence of the magnitude of depressurization on the initial liquid temperature for a given rate of depressurization and exhibits the general features of the experimental data. In particular, the correlation predicts that the pressure undershoot reaches a maximum for a certain initial temperature. 


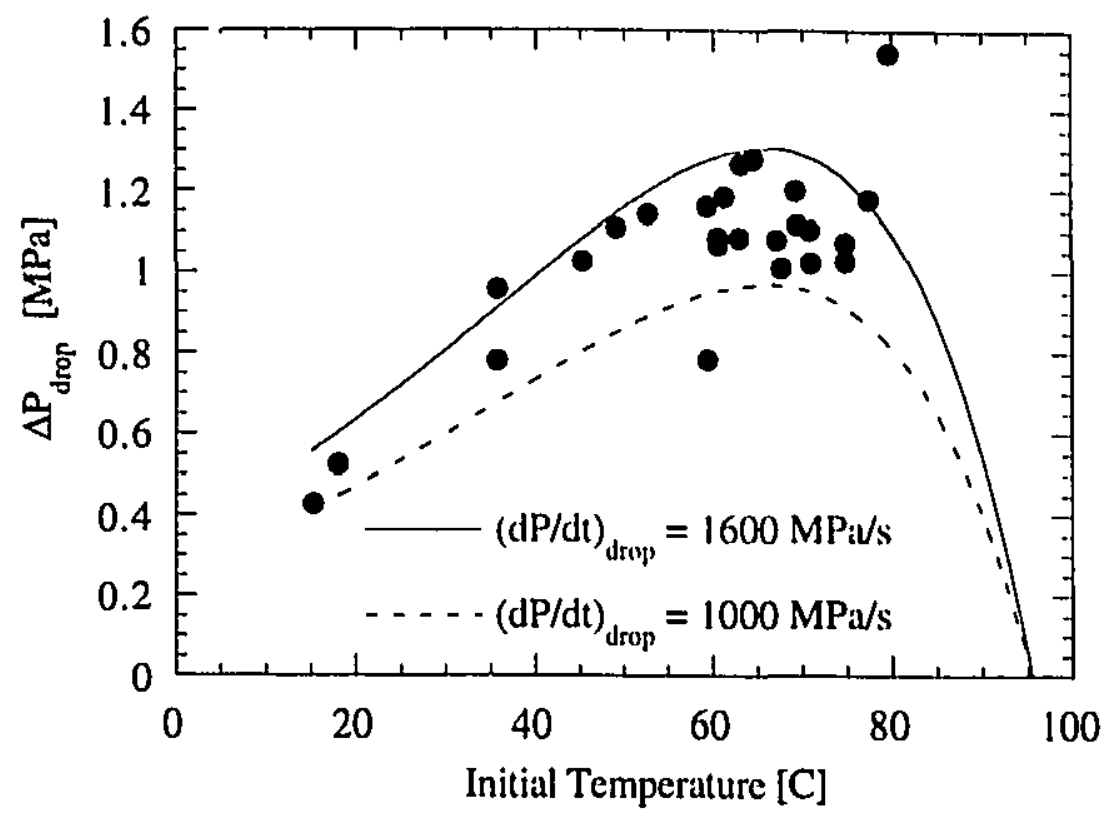

Figure 4.33 - Correlation for pressure undershoot as a function of initial temperature and rate of pressure drop. Two curves shown bound the rates of depressurization observed experimentally.

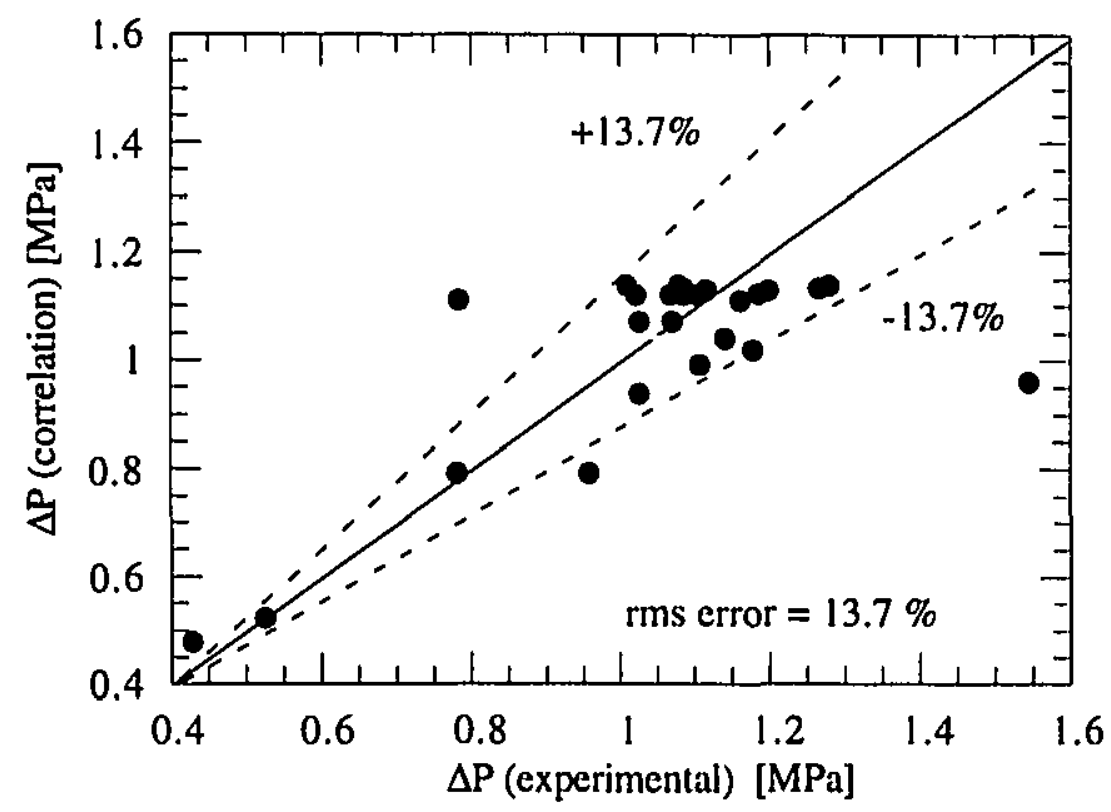

Figure 4.34 - Comparison of pressure undershoot predicted by the correlation, using the average rate of depressurization of $1285.1 \mathrm{MPa} / \mathrm{s}$, with experimental values.

Since experimentally the repressurization was found to be linearly proportional to the pressure undershoot (Fig. 4.2), the maximum observed for the repressurization (see Fig. 
4.14) is consistent with the correlation predictions. The experimental data are approximated by the correlation with a mean relative error of $13.7 \%$ (Fig. 4.34).

\subsection{Thermodynamic Modeling}

The explosive boiling occurring in a sudden depressurized vessel can be broken down into two main contributing factors; the venting of the two phase mixture and the generation of vapor due to boiling. The competition between the rate of venting and rate of vapor gineration will determine the pressure history of the explosive boiling process.

By incor ${ }_{i}^{\prime}$ Jrating both of these effects into a model, the repressurization within the vessel can be examined as a function of the various physical and thermodynamic parameters. Such a model can then be used to investigate the influence of scale and to consolidate the existing experimental data. This section describes some of the preliminary modeling efforts performed and discusses some of the key issues that should be addressed in future modeling attempts.

\subsubsection{Venting Model}

The first step in modeling the explosive boiling scenario is to model the venting of the vapor. The model assumes that a given volume of single-phase gas expands isentropically through a given vent area. The rate of mass loss through the vent is a function of the pressure ratio across the vent orifice and depends on whether the flow is choked or not. By using a discrete time step approach the mass flow rate is used to determine how much vapor has left for a given time step. The pressure within the vessel is then determined from the quantity of vapor remaining. Details of the source code can be found in Appendix D.

The venting model was validated by comparison with experiments by varying initial pressure and vent area. The characteristic feature of interest in the venting model was the rate of pressure drop. Figure 4.35 shows the superposition of experimental pressure traces and those obtained from the venting model for similar initial conditions. In both cases we observe that the venting model reproduces the rate of pressure drop of the experimental pressure trace. The model assumes that the gas is expanded to atmospheric conditions and thus once the pressure within the vessel has dropped to atmospheric pressure no further venting occurs. The experimental traces in Fig. 4.35 show that the pressure does not 
asymptote to atmospheric pressure indicating that there may have been a slight error in the transducer calibration. Nevertheless the model seems to properly exhibit the rate of pressure drop.

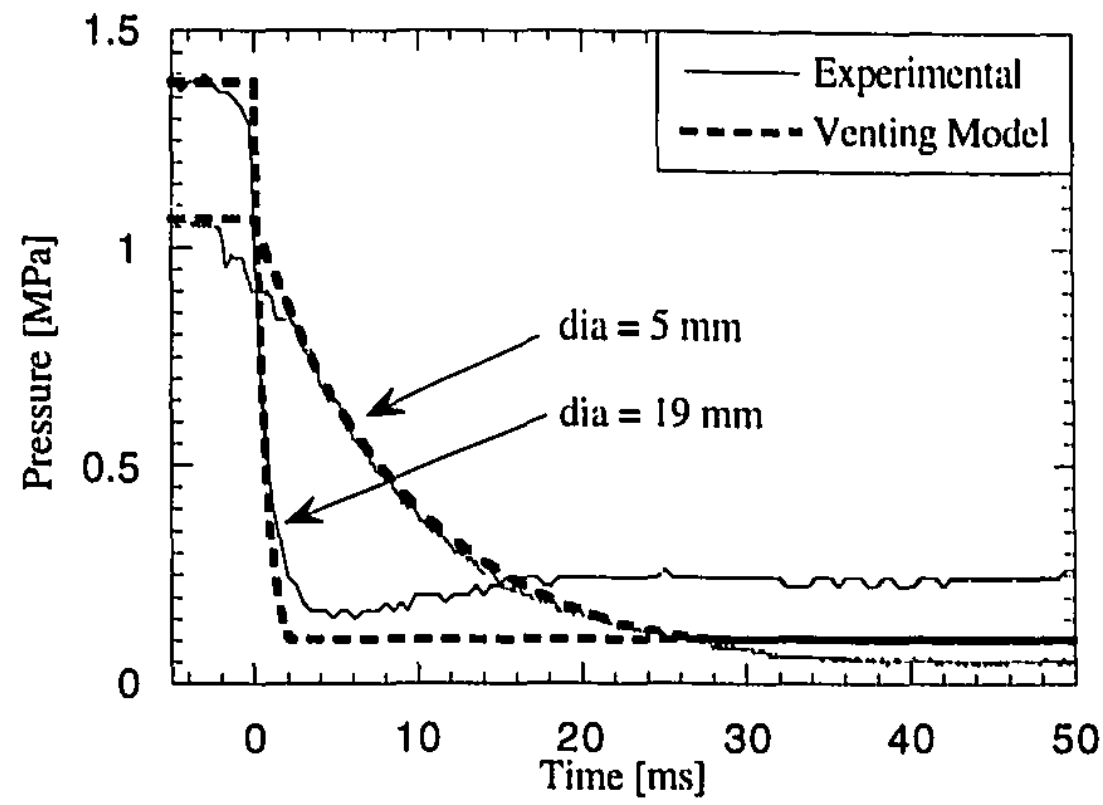

Figure 4.35 - Superposition of Experimental and Venting model Pressure Traces

For the case of venting of a pressure liquefied gas the pressure drop beyond an initial liquid temperature of $53^{\circ} \mathrm{C}$ is limited by the spinodal curve and therefore cannot drop to atmospheric pressure. For the model to exhibit this behavior the pressure within the vessel should be couple with the boiling. The coupling mechanism will depend on the assumptions made about the boiling and will be discussed in section 4.6.3.

\subsubsection{Bubble Growth}

The next stage is to model the generation of vapor. In light of the fact that the goal of the final model is to determine the conditions which produce the most violent boiling, the boiling within the liquid should be assumed to be of a homogeneous nature. This avoids the problem of modeling the stochastic nature of heterogeneous boiling. By "seeding" the bulk of the liquid with a fixed quantity of critically sized nuclei and allowing these nuclei to grow through heat diffusion, it is possible to simulate the effects of homogeneous boiling. Alternatively, it can be assumed that no nuclei are present until the depressurization is sufficient that the spinodal is reached. At this point, a large number of nuclei can be 
assumed to form uniformly throughout the bulk of the liquid. The number of nuclei can be prescribed as a parameter.

The nuclei that are formed (or are assumed to pre-exist) grow with a growth rate limited by thermal diffusion according to equation 26. As the bubbles grow they consume the surrounding liquid (through vaporization) and occupy more space within the bulk of the liquid. The growing bubbles compress the above vapor space, as shown in Fig. 4.36. If the rate of bubble growth occurs at a fasier rate than the exhausting vapor the vapor space will experience an increase in pressure.

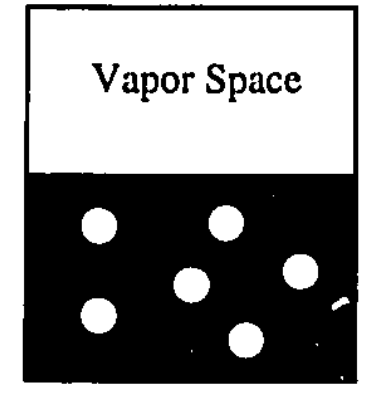

Time $=\mathrm{t}$

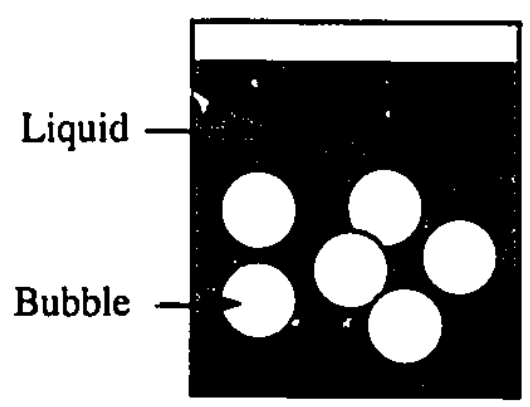

Time $=t+\Delta t$

Figure 4.36 - Schematic of Bubble Growth and Effect on Vapor Space

The bubbles will stop growing when the thermal boundary layer surrounding adjacent bubbles touch and when there no longer exists any liquid or vapor space above the liquid.

\subsubsection{Coupled Venting and Bubble Growth}

With the assumption of diffusion-limited bubble growth, the difference in pressure between the bubble and the surrounding liquid is minimal. However, as the pressure in the vapor space above the bubbly liquid grows, the pressure rise will retard the bubble growth. If a significant pressure gradient exists between the bubble and the surrounding liquid, the bubble growth will be influenced by inertial effects as described by the Rayleigh bubble growth (equation 22) as described earlier. In addition, the increase in system pressure will lower the effective superheat of the liquid, which lowers the driving force behind the boiling and hence the rate of vaporization. With both of these effects, the bubble growth will then be coupled to the repressurization within the vessel and the maximum repressurization attained will be limited. As the scale of the vessel increases, wave prcpagation effects will begin to play a role since the pressurization of the vapor space may 
take some time (due to the low sound speed in a bubbly liquid) to be communicated to the rest of the bubbly liquid. For rapid changes in the vessel pressure, non-equilibrium vaporization effects may also play a role. Correctly accounting for the coupling between the vessel pressure rise and the bubble growth is necessary for determining the maximum degree of pressurization that is attained.

In practice, the spinodal is not attained and the pressure drop is limited by heterogencous boiling on the walls of the vessel or from impurities within the bulk of the liquid or on the surface. In this case, a mechanistic description of the nucleation phenomena is more complex due to the stochastic nature of the boiling. 


\section{Conclusions}

The explosive boiling response of suddenly depressurized refrigerant 22 has been investigated experimentally in a small-scale steel vessel and a glass tube. In both cases, rapid boiling caused a repressurization within the vessels which was linearly dependent on the pressure undershoot or the degree of superheat attained by the liquid. The degree of repressurization reached a maximum value in both vessels at an initial pressure of about 2 $\mathrm{MPa}$, regardless of the mode of boiling, vessel geometry or liquid fill volume.

The dependence of the repressurization on initial pressure observed experimentally was consistent with the predictions of a semi-empirical correlation based on :.omogeneous nucleation theory.

The orifice area was found to play an important role in that it controls the venting process, i.e., the rate and level of depressurization, and consequently the degree of superheat attained by the liquid. Experiments demonstrated that larger rates and levels of repressurization were measured for increasing vent areas, suggesting that large venting rates of tank cars containing LPG may be detrimental. Results also showed that the repressurization process was similarly enhanced with increasing liquid fill volume, i.e., decreasing initial vapor present. In this case depressurization occurred more rapidly and more liquid was available for boiling. The relative ability of the liquid to repressurize was found to be greater at lower initial pressures than for higher initial pressures.

The mode of nucleation observed depended primarily on the degree of superheat attained by the liquid as well as the surface characteristics of the vessel. For the steel vessel, heterogeneous boiling from the walls dominated. In the glass tube a self-sustained evaporation wave propagated from the free surface into the liquid for initial pressures at and below $1 \mathrm{MPa}$. For an initial pressure of $1 \mathrm{MPa}$, after an initial startup phase lasting about $100 \mathrm{~ms}$, the evaporation wave attained an average velocity between 5 and $20 \mathrm{~cm} / \mathrm{s}$. Since the wave velocity is relatively slow, fluctuations of the pressure in the vessel downstream of the wave due to the competition between the rates of vaporization and venting can influence the propagation of the wave. Deviations of the wavefront from a planar shape corresponded to an increase in the average propagation velocity and may be caused by spatial variations in the liquid temperature. 
For large initial pressures, the boiling in the present experiments was dominated by wall boiling so that the ratio of surface arealiquid volume played an important role in the rate of vapor generation. Therefore the present results cannot be scaled in a quantitative manner easily to larger scale cylindrical or spherical vessels, where boiling on the walls will be relatively less important compared to boiling within the bulk of the liquid. Nevertheless. the trend observed in the present tests, in particular that the violence of the boiling increases with initial pressure or temperature up to a maximum corresponding approximately to the superheat limit temperature at atmospheric pressure $\left(\sim 53^{\circ} \mathrm{C}\right)$, is expected to be reproduced in larger scale tests.

Pre-nucleation of the liquid refrigerant with $\mathrm{CO}_{2}$ increased the boiling response for a given pressure drop. Based on photographic observation, the dissolved $\mathrm{CO}_{2}$ increased the likelihood of heterogeneous nucleation and the rate at which the liquid is vaporized.

Due to the nature of the present small scale experiments, heterogeneous boiling dominated in all but a few situations. The nature of the heterogeneous boiling poses limitations on the level of simplicity that a model can have. In order to obtain a more complete understanding of the explosive boiling scenario occurring at larger scales more experiments with different geometry and aspect ratios are needed. Also, at larger scales heterogeneous boiling may not participate as much as in the present study and hence the occurrence of local homogeneous boiling (close to the vent hole) may be possible. The large scale experiments permit more flexibility in the assumptions chosen for a simple thermodynamic model as heterogeneous boiling may not be a contributing factor. 


\section{References}

1. Birk, A.M., Ye, Z., Maillette, J. \& Cunningham, M., "Summary on Medium Scale Fire Tests Investigating the BLEVE Event", Internal Report for TDC Transport Canada, 1991.

2. Wormuth, D.W. (ed.), "BLEVE! The Tragedy of San Juanico," J. Skandia International, 1985, pp.1-22.

3. Birk, A. M. \& Cunningham, M. H., "The Boiling Liquid Expanding Vapor Explosion", Presented at Dangerous Goods Tank Safety Seminar, Montreal, Quebec, 1994.

4. Hill, L.G. \& Sturtevant, B., "An Experimental Study of Evaporation Waves in a Superheated Liquid," IUTAM Symposium, Göttingen, Germany, in Adiabatic Waves in Liquid-Vapor Systems, edited by G.E.A. Meier and P.A. Thompson, Springer Berlin, 1989, pp. 25-37.

5. Chaves, H., Lang, H., Meier, G.E.A. \& Speckmann, H.-D., Lecture Notes in Physics: Flow of Real Fluids, edited by G.E.A. Meier and F. Obermeier, Springer Berlin, 1985.

6. Alamgir, M. \& Lienhard, J. H. "Correlation of Pressure Undershoot during Hot Water Depressurization," J. Heat Transfer, Vol. 103, 1981, pp. 52-55.

7. Bartak, J., "A Study of the Rapid Depressurization of Hot Water and the Dynamics of Vapor Bubble Generation in Superheated Water," Int. J. of Multiphase Flow, Vol. 16, No. 5., 1990, pp. 789-798.

8. Friedel, L. and Purps, S., "Models and Design Methods for Sudden Depressurization of Gas/Vapor-Liquid Reaction Systems," Int. Chem. Eng., Vol. 26, No. 3, 1986, pp. 396-407.

9. Hervieu, E., "Behavior of a Flashing Liquid within a Vessel following Loss of Containment: Application to Propane," ANS Proc. 1992 National Heat Transfer Conference, Vol. 6, pp. 227-235.

10. Ogiso et. al., "On The Mechanisms of Vapor Explosions,"Proc. Ist Pacific Chem. Eng. Conf., Part II, 1972.

11. Reid, R.C., "Possible Mechanism for Pressurized-Liquid Tank Explosions or BLEVE's," Science, Vol. 203, No. 23., 1979, pp. 1263-1265. 
12. Avedesian, C.T. "The Homogenous Nucleation Lirnits of Liquids",Journal of Physical and Chem: al Reference Data, 1985, Vol.14, No.3, pp. 695-729

13. Davies, J.T. , Rideal, E.K., "Interfacial Phenomena", Second Edition, Academic Press, 1963

14. Holden, B.S. and Katz, J.L.,"Homogeneous Nucleation”, AlChE Journal, 24, 1978, pp. 269.

15. Blander,M and Katz,J.L., "Bubble Nucleation in Liquids", AIChE Journal, 26, 1976. pp. 833.

16. Lord Rayleigh, "On the Pressure Developed in a Liquid during the Collapse of a Spherical Cavity", Philos. Mag., Vol. 34., 1917,pp. 94-98.

17. S.V. Stralen and R.Cole,"Boiling Phenomena",Series in Thermal and Fluids Engineering, Hemisphere Publishing Co.,1979, Vol. 1, pp. 204-207

18. Pavlov,P.A. and Skripov,V.P., High Temp. (USSR) 8, 540, 1970

19. Reynolds, W. C., "Thermodynamic Properties in SI", Stanford University Press, 1979.

20. Seluver, T. Jr., (English language edition editor),"Thermophysical Properties of FREONS : Methane Series Part I", National Standard Reference Data Service of the USSR, Hemisphere Publishing Co., 1987.

21. Hiscoke, B. A. \& Birk, A. M.,"Small Scale Investigations into the Sudden Depressurization of Superheated Propane", Presented at Dangerous Goods Tank Safety Seminar, Montreal, Quebec, 1994.

22. Venart, J. E. S., Sollows, K.F.,"Boiling Liquid Compressed Bubble Explosions", Presented at Dangerous Goods Tank Safety Seminar, Montreal, Quebec, 1994.

23. Hill, L. G. "An Experimental Study of Evaporation Waves in a Superheated Liquid", Ph.D. Thesis, California Institute of Technology, 1991. 


\section{Appendix A}

This Appendix contains relevant thermodynamic properties of refrigerant 22 as a iunction of temperature. The data for the properties were obtained from references $[19,20]$ and a function was obtained for each of the thermodynamic propertics by curve fitting the data points. The functions were used throughout this thesis when the variation of properties as a function of temperature was required. 


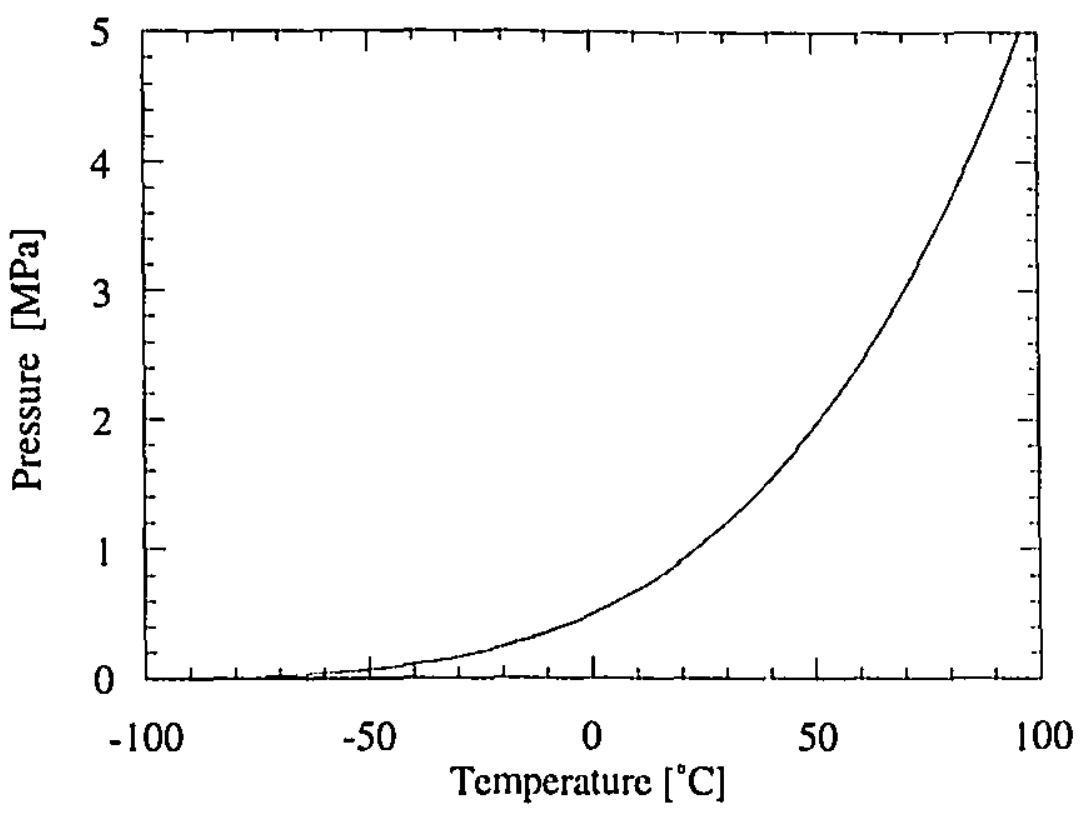

Figure A.1 - Saturation Pressure of R22 versus Temperature

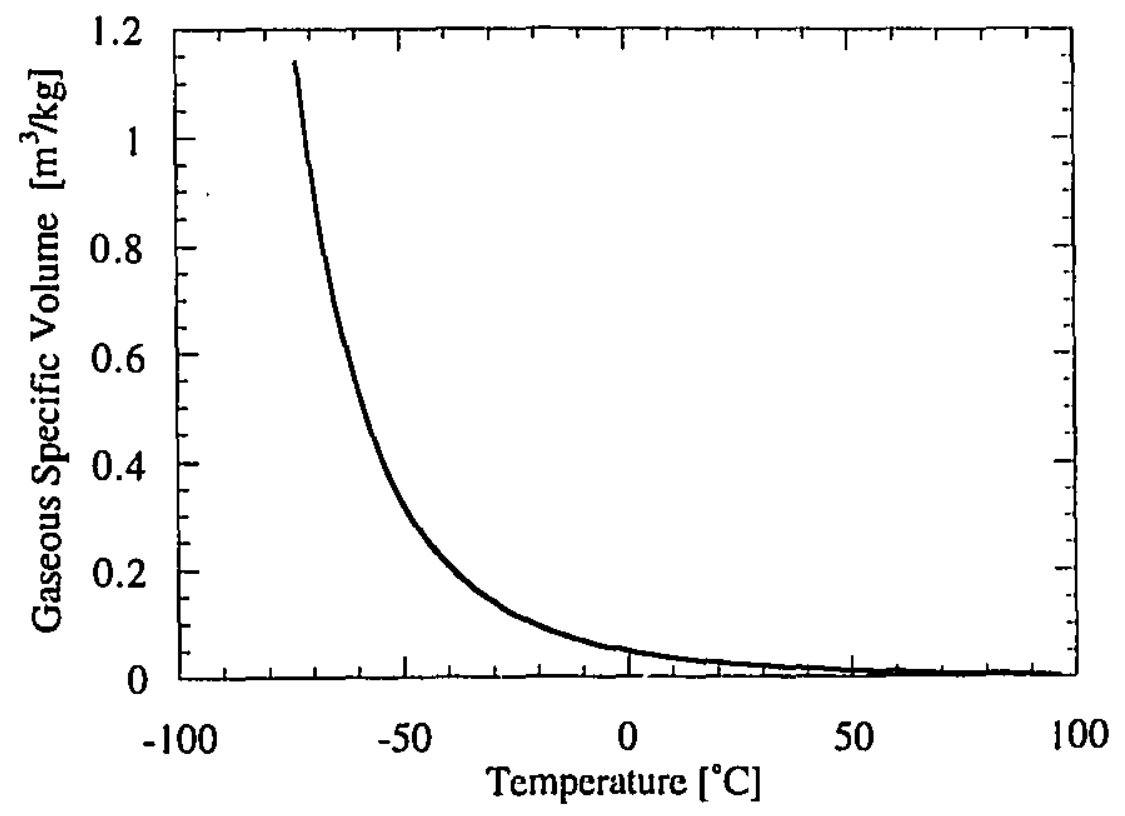

Figure A.2 - Gaseous Specific Volume for R22 versus Temperature 


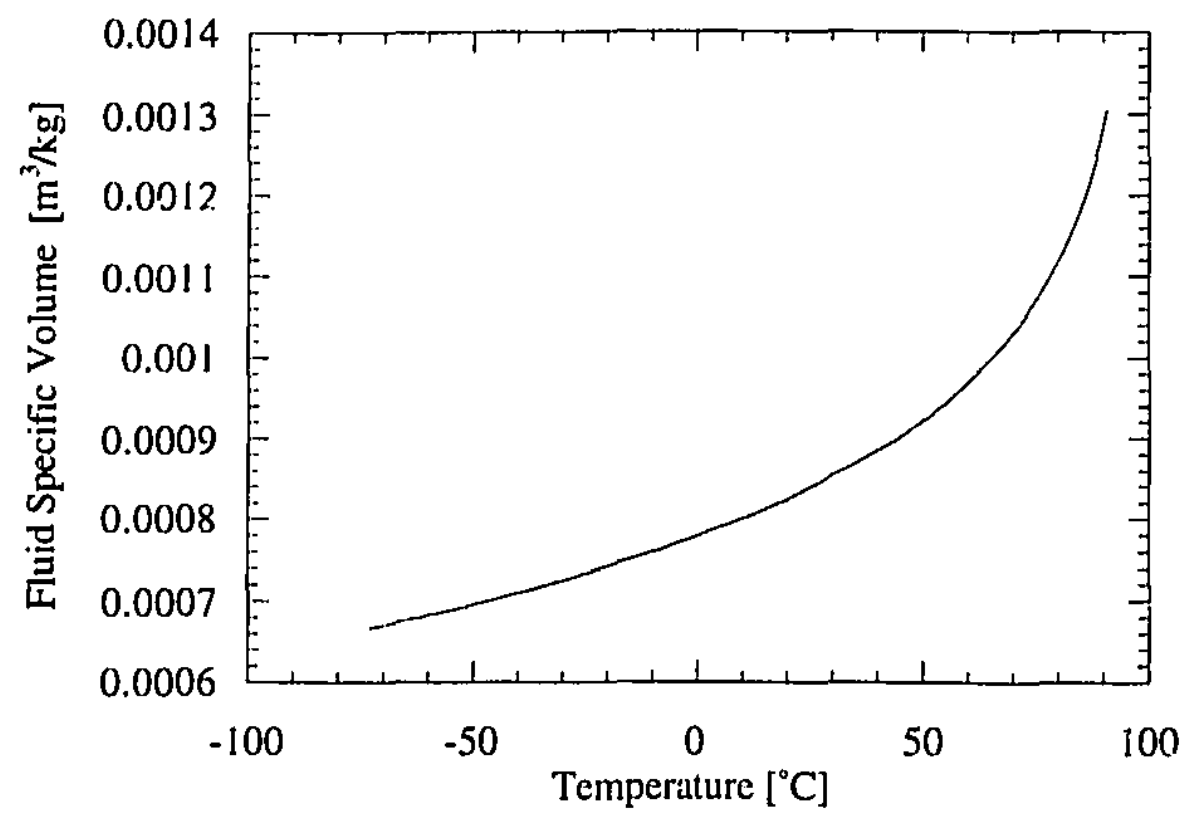

Figure A.3 - Fluid Specific Volume for R22 versus Temperature

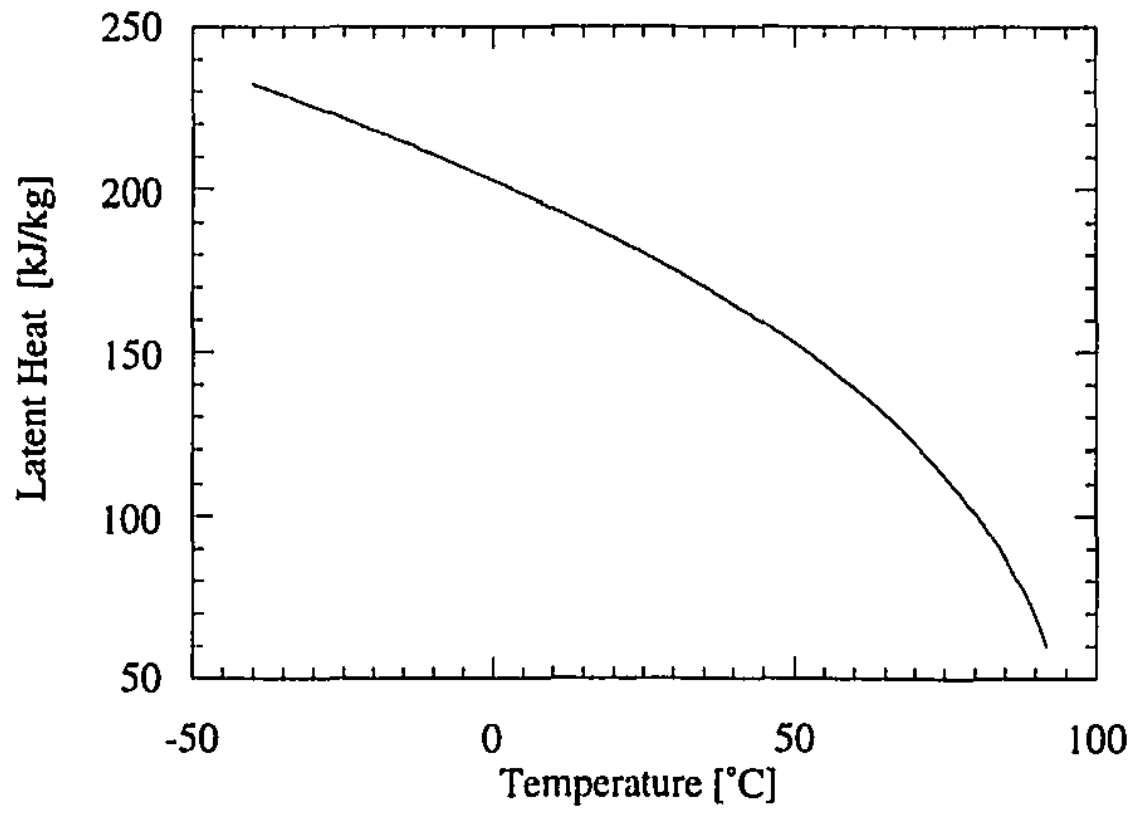

Figure A.4 - Latent Heat of vaporization for R22 versus Temperature 


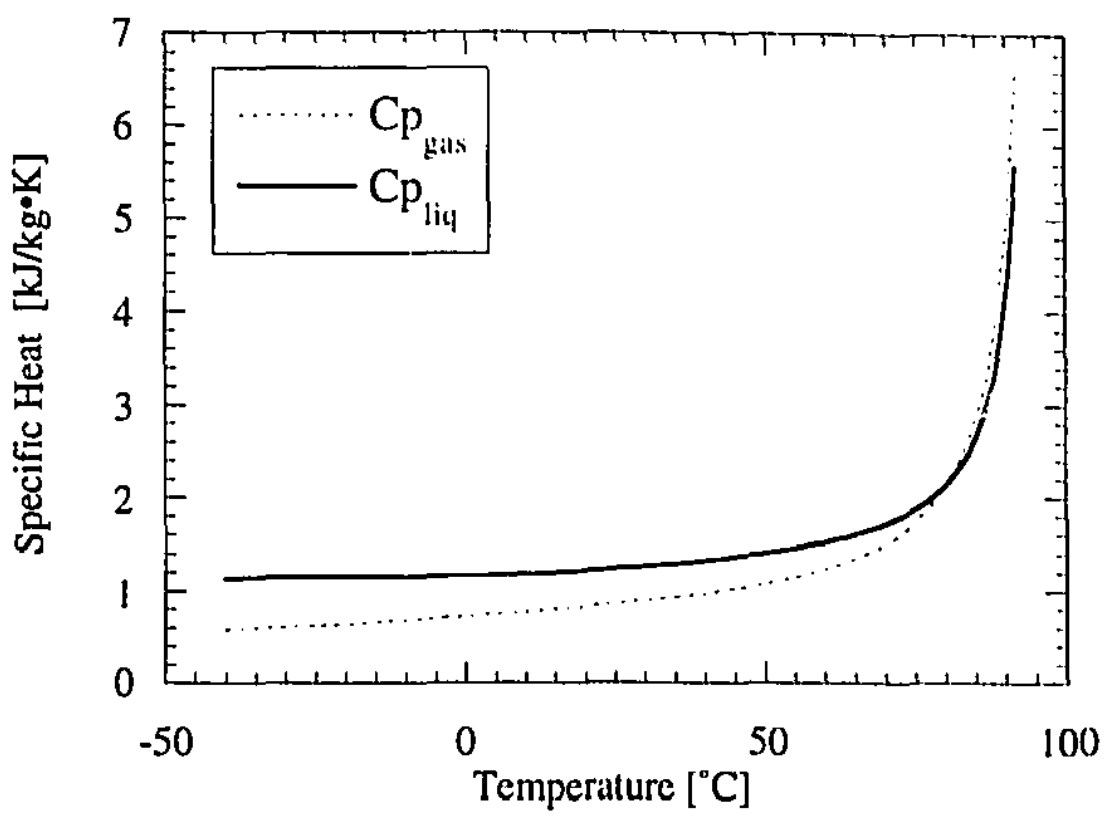

Figure A.5 - Liquid and vapor specific Heats for R22 versus Temperature

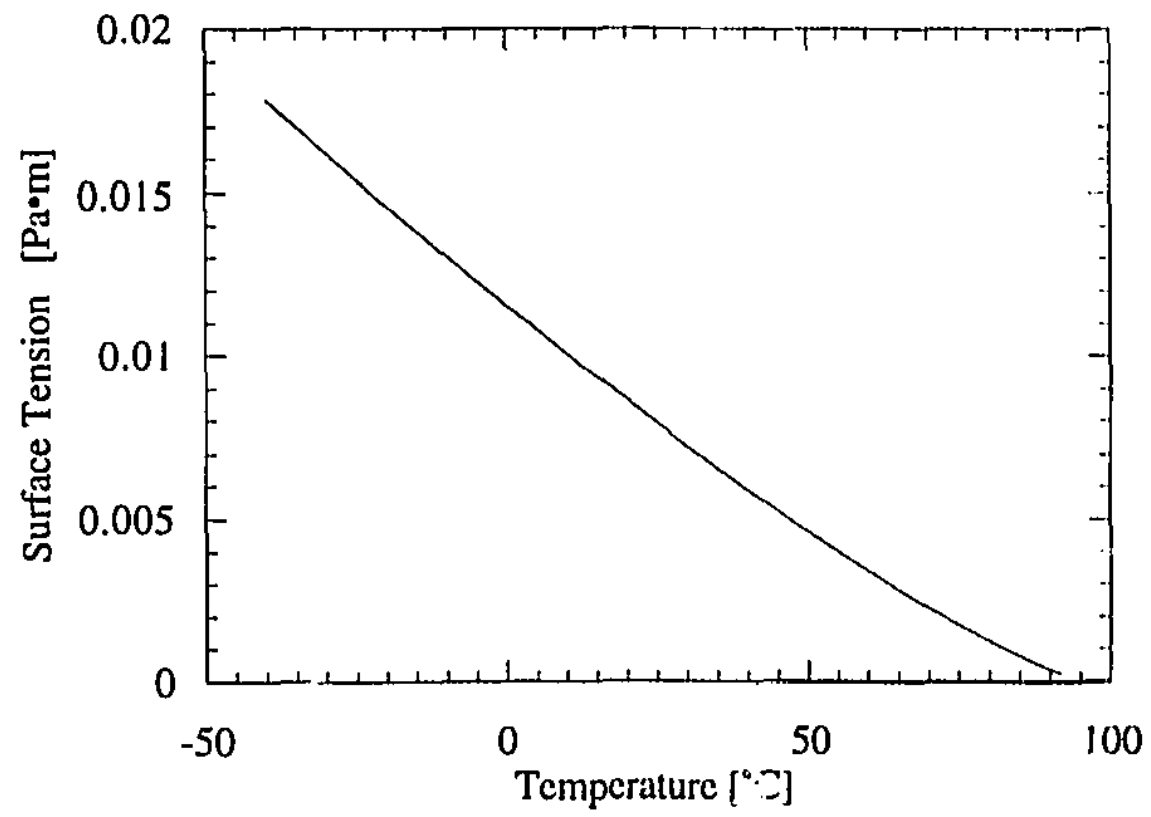

Figure ...6 - Surface Tension for R22 versus Temperature 


\section{Appendix B}

This Appendix contains the figures that go with section 4.4. They include preliminary experimental data along with the main data for the steel vessel. 


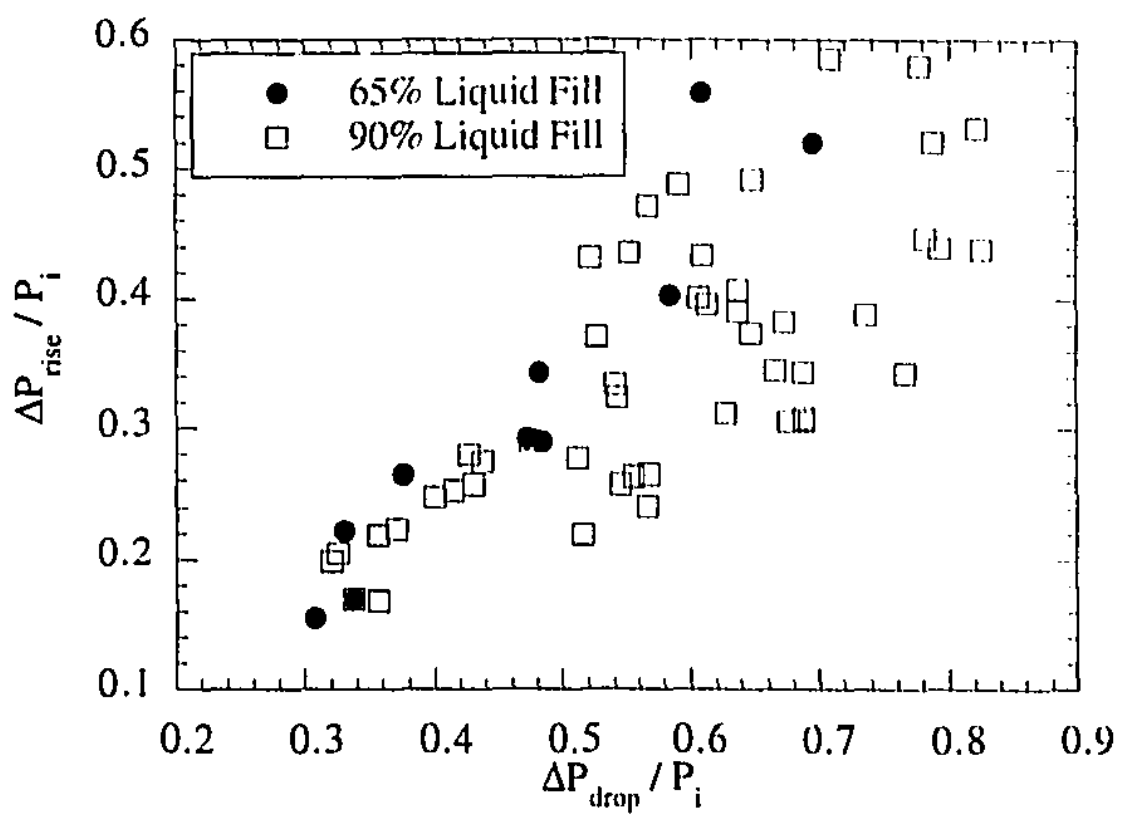

Figure B.1 - Normalized repressurization as a function of depressurization

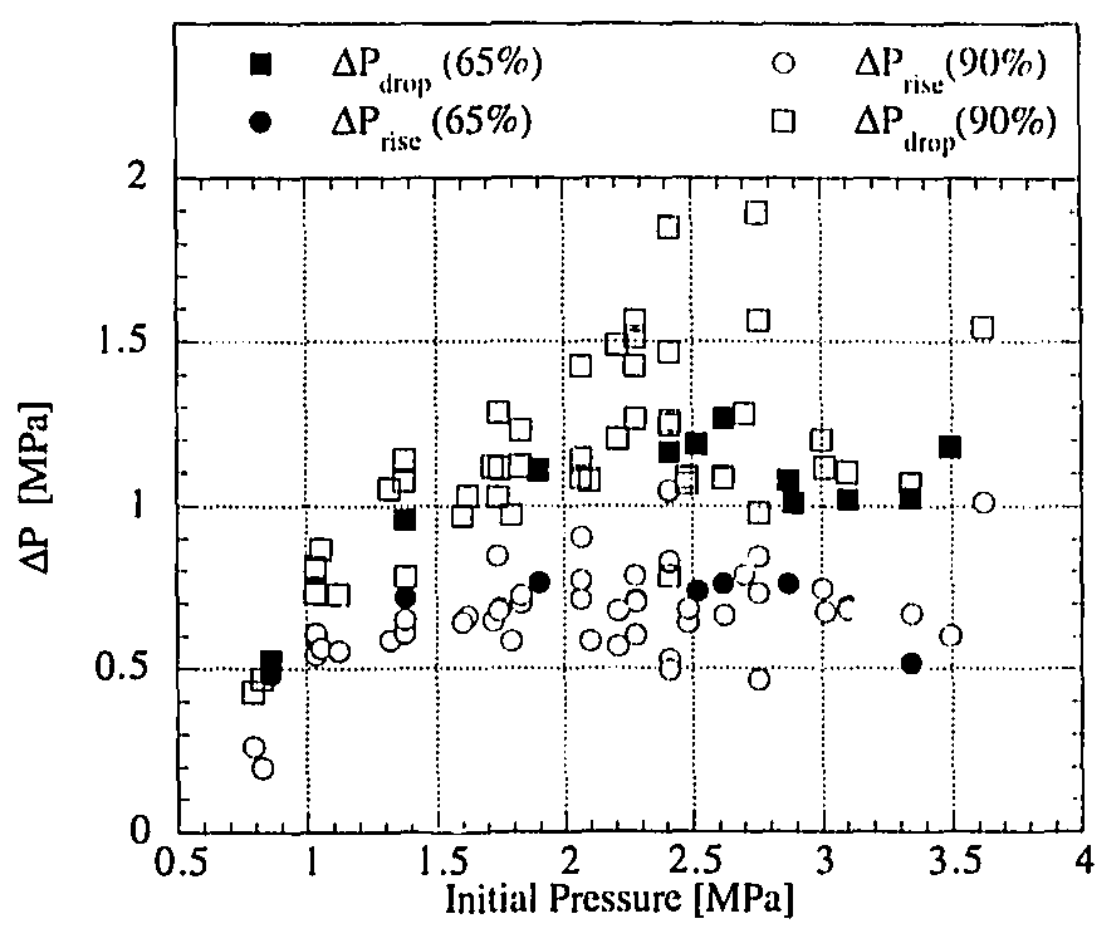

Figure B.2 - Influence of initial pressure on depressurization and repressurization 


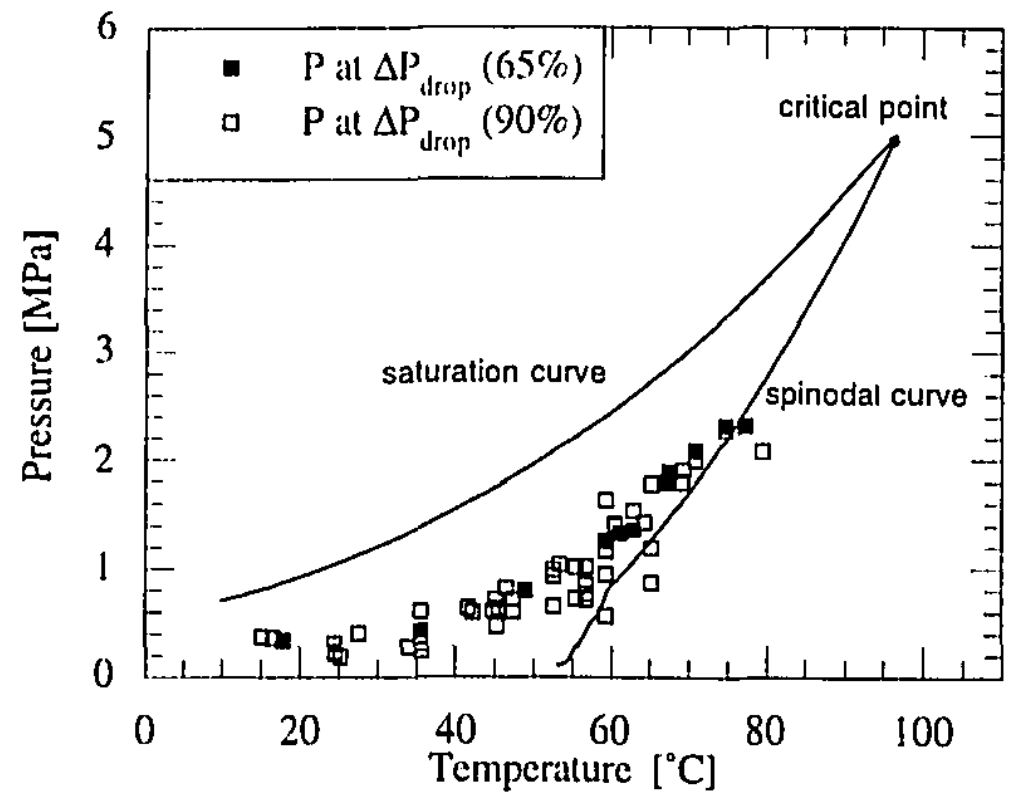

Figure B.3 - End state of liquid following depressurization shown with saturation and spinodal curves 


\section{Appendix C}

Appendix $\mathrm{C}$ contains the experimental data in tabulat form. The experimental data is divided into 9 tables. 
Table C.1 - Variation of Area Data (Steel Vessel)

\begin{tabular}{|c|c|c|c|c|c|c|c|c|c|c|c|}
\hline & Orifice Dimension & Orifice Area (mmn') & $\overline{P i}[p s i]$ & $\triangle P$ Prop & $\Delta$ Prise & $\triangle \mathrm{Pdrog} / \mathrm{Pi}$ & $\Delta$ Prise/Pi & 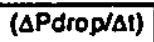 & (APdrop/ $\Delta t) / P i$ & (APrise/Al) & $(\Delta \mathrm{P}, \mathrm{ise} / \Delta \mathrm{t}) / \mathrm{Pi}$ \\
\hline 0 & 38 dam & 71.255 & 2.7579 & 0.78242 & 0.36997 & 0.28370 & 0.13415 & 1.0756 & 0.39000 & 0.24959 & 0.090500 \\
\hline 1 & $0.25^{\circ} \times 0.25^{\circ}$ & 40.320 & 2.2408 & 0.58000 & 0.19526 & 0.25884 & 0.087138 & 0.94899 & 0.42351 & 0.012411 & 0.0055325 \\
\hline 2 & $0.15^{\circ} \times 0.15^{\circ}$ & 14.520 & 1.0342 & 0.19781 & & 0.19127 & & 0.65155 & 0.63000 & 0.015513 & 0.015000 \\
\hline 3 & $0.15^{\circ} \times 0.15^{\circ}$ & 14.520 & 1.7237 & 0.13555 & & 0.078640 & & 0.098250 & 0.057000 & 0.021891 & 0.012700 \\
\hline 4 & $1 / 2$ diam & 126.60 & 2.0684 & 1.1514 & 0.53090 & 0.55660 & 0.25660 & 0.85219 & 0.41200 & 0.10549 & 0.051000 \\
\hline 5 & $1 / 2=$ dam & 126.00 & 2.0684 & 1.1032 & 0.34474 & 0.53300 & 0.16700 & 0.47367 & 0.22900 & 0.13238 & 0.064000 \\
\hline 6 & $3 / 4^{\circ}$ ciam & 285.00 & 2.2753 & 1.2824 & 0.78600 & 0.56000 & 0.34500 & 1.4835 & 0.65200 & 0.30716 & 0.13500 \\
\hline 7 & $3 / 4^{*} \mathrm{dam}$ & 285.00 & 2.2753 & 1.5582 & 0.77221 & 0.68000 & 0.33900 & 2.0477 & 0.90000 & 0.38452 & 0.16900 \\
\hline 8 & $38^{\circ}$ ciam & 71.255 & 2.4132 & 0.75842 & 0.17237 & 0.31400 & 0.072000 & 0.70706 & 0.29300 & 0.13514 & 0.056000 \\
\hline 9 & $3 / 4^{\circ}$ diam & 285.00 & 1.9650 & 1.1032 & 0.68948 & 0.60000 & 0.35000 & 1.6290 & 0.82900 & 0.30261 & 0.15400 \\
\hline 10 & $3 / 4^{\circ}$ dam & 285.00 & 2.0684 & 1.2656 & 0.76752 & 0.61100 & 0.37000 & 2.0712 & 1.0013 & 0.37232 & 0.18000 \\
\hline 11 & $3 / 4^{-}$dam & 285.00 & 0.82737 & 0.46815 & 0.19926 & 0.56500 & 0.24000 & 0.11583 & 0.14000 & 0.10687 & 0.12917 \\
\hline 12 & $0.44^{\circ} \times 0.44^{\circ}$ & 125.00 & 0.79290 & 0.42892 & 0.26503 & 0.54000 & 0.33400 & 0.20684 & 0.26087 & 0.016823 & 0.021217 \\
\hline
\end{tabular}

Table C.2 - Variation of Fill Volumes Data (Steel Vessel)

\begin{tabular}{|c|c|c|c|c|c|c|c|c|}
\hline & Fal Volume & Pi [psi] & $\triangle$ Pdrop & $\Delta$ Priso & $\triangle P d r o p / P i$ & $\Delta$ Prise/Pi & $(\Delta \mathrm{P} / \Delta \mathrm{t}) \mathrm{drop}$ & (AP/AY)rise \\
\hline 0 & 0.24000 & 300.00 & 168.60 & 50.520 & 0.56200 & 0.16840 & 1.8457 & 0.010687 \\
\hline 1 & 0.50000 & 300.00 & 159.23 & 80.130 & 0.53077 & 0.26710 & 1.9305 & 0.10894 \\
\hline 2 & 0.70000 & 300.00 & 169.73 & 96.470 & 0.5657 & 0.32157 & 2.1367 & 0.21581 \\
\hline 3 & 0.90000 & 300.00 & 183.56 & 111.32 & 0.61187 & 0.37107 & 2.0712 & 0.37232 \\
\hline
\end{tabular}


Table C.3 - Variation of initial Pressure (65\% Fill Volume, Steel Vessel, Magnitude Data)

\begin{tabular}{|c|c|c|c|c|c|c|c|c|c|c|c|c|}
\hline & $P$ [NPA $]$ & SPArod [MPD] & $\Delta P_{n s e}\left[N P_{a}\right]$ & APnswaperoo & $P=00, P_{1}$ & APnserpi & $P$ at $A$ Paros [LP ] & $T=4$ Poroo $[C]$ & TEA $[\mathrm{C}]$ & STruoprines $[C]$ & $C \infty L[1 . \times]$ & 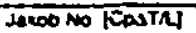 \\
\hline$\overline{0}$ & 0 बहाइ & 0.5247 & 048175 & 0.9985: & 06005s: & 0.55897 & 0.33737 & .56602 & 18068 & 23724 & 0,006397 & 0,5180 \\
\hline$T$ & 1.3750 & 095769 & 0.71747 & 0.74923 & $069 \mathrm{ma}$ & 052030 & 042135 & .140901 & 35.710 & 37119 & 00077576 & 020705 \\
\hline$\overline{2}$ & 1 essi! & 1.1079 & 0.76461 & 063016 & 0584301 & 0.40326 & 0.78818 & $15118 !$ & $49023:$ & 33905 & 00009990 & 030511 \\
\hline 3 & $24132 !$ & $11624 ;$ & 0.22796 & 071229 & 0.49168 & $0.3+3101$ & 1.2500 & $31.793 !$ & 59367 & $27574 i$ & 0.010717 & 029353 \\
\hline 4 & 2.2958 : & 1.0106 & & & $03+9009$ & & 1.8852 & 49778 & $57.5 \times 6$ & $88768^{\circ}$ & $0.013191 !$ & 024756 \\
\hline 5 & $28751 ;$ & 1.0799 & 0.76166 & 070534 & 0.37559 & 0.26492 & 1.79531 & 46.704 & 67.209 & 20.5061 & 0.013061 & 026782 \\
\hline 6 & $25: 661$ & 1.1859 & 073664 & 0.621161 & 047123 & 0.29271 & 1.3007 & $34267 !$ & 61200 & 26932 & 0011162 & 030061 \\
\hline 7 & 2.6200 & $12655 !$ & 0.76022 & 0.60071 & 048303 & 0.29016 & 13545 & 34903 & 62.979 & $27.996 !$ & $001164 B$ & 0.32810 \\
\hline 8 & 3.1026 & $1.024 !$ & 0.69092 & 0.67577 & 0.329531 & $0.22269 i$ & 2.0002 & 52.97 & 70898 & $17.921 i$ & 0014646 & 026247 \\
\hline 9 & 3340 & 1.0273 & 0.51711 & 0.50336 & 0.307001 & 015500 & 2.3166 & 57.599 & 74.858 & 17259 & 0016796 & 0.28068 \\
\hline iv & 3.4956 & 1.1790 & 060260 & $0.51111:$ & 0.33700 & 0.17000 & 2.3166 & $57.599 !$ & $77.433 \mid$ & 19834 & 00184861 & 036665 \\
\hline
\end{tabular}

Table C.4 - Variation of initial Pressure (90\% Fill Volume, Steel Vessel, Magnitude Data)

\begin{tabular}{|c|c|c|c|c|c|c|c|c|c|c|c|c|}
\hline & $P_{1}\left[M P_{2}\right]$ & $\triangle P$ Proo [MPa] & $\Delta P_{n \text { nse }}$ [MPa] & APnselapdrop & Spdroppip & APrisespl & Paf aPdroo (MPa) & $T$ an spdroo !C] & $\left.T=P_{1} \mid C\right]$ & AT superteat $[\mathrm{C}]$ & $\cos [1 / \mathrm{k}$ ! & Jatroo No. [CasTL] \\
\hline 0 & 2.4132 & 0.72373 & 0.49457 & 0.63105 & 032477 & 0.20495 & 1.6294 & 22616 & 39.367 & 15.751 & 0000717 & (1.10 \\
\hline 7 & 0.792901 & 0.42885 & $0.26+76$ & 0.61736 & 0.54067 & 0.33391 & 0.36408 & 42900 & $\$ 5.310$ & 19.600 & 0.0062210 & 0.12 .193 \\
\hline 2 & 3.0130 & 1.1170 & 0.67327 & 0.60278 & 0.37071 & 0.22346 & 1.8961 & 49.023 & 69.447 & 204231 & 0.013970 & 0.28548 \\
\hline 3 & 3.1026 & 3.1049 & 0.68051 & 0.61591 & 0.35611 & 0.21933 & 1.9978 & 51.249 & 70.898 & 19649 & 0.014646 & 0.28778 \\
\hline 4 & 2.6200 & 1.0857 & 0.66295 & 0.61061 & 0.41439 & 0.25303 & 1.5363 & 40.103 & 62.979 & 22.87 & 0.011648 & 0.26647 \\
\hline 5 & 2.4821 & 1.0667 & 0.63935 & 0.59826 & 0.43056 & 0.25758 & .01136 & 36.717 & 60.595 & 23.878 & 0.013009 & 0.26288 \\
\hline$\overline{0}$ & 2.7027 & 8.2797 & 0.78669 & 0.61476 & 0.47347 & 0.29107 & 1.4231 & 36.996 & 64.371 & 27.375 & 0.012071 & 0.33044 \\
\hline 7 & 2.4821 & 1.0857 & 0.62058 & 0.62685 & 0.43742 & 0.27419 & 1.3964 & 36.222 & 60.595 & 24.373 & 0.011009 & 0.26633 \\
\hline$\overline{8}$ & 3.3440 & 1.0719 & 0.65679 & 0.62205 & 0.32056 & 0.19940 & 2.2720 & 56.761 & 74.858 & $\$ 8.098$ & 0.016796 & 0.30396 \\
\hline 9 & 29992 & 1.1997 & 0.74463 & 0.62069 & 0.40000 & $0.2 \times 828$ & 1.7995 & 46.804 & 69.223 & $22 . \overline{419}$ & 0.013881 & 0.31119 \\
\hline 10 & 34956 & 1.1790 & 0.60260 & 0.51111 & 0.33700 & 0.17000 & 2.3168 & 57.599 & 77.433 & 19.836 & 0.018486 & 0.36665 \\
\hline$\overline{11}$ & 3.6197 & $1.5 \mathrm{sed}$ & 1.0135 & 0.65625 & 0.42660 & 0.28000 & 2.0753 & 52.876 & 79.619 & 26.743 & 0.020125 & 0.53820 \\
\hline 12 & 1.7375 & 1.0250 & 0.84709 & 0.82495 & 0.59099 & 0.48755 & 0.71084 & 18.888 & 45.319 & 33.431 & 0.0005948 & 0.28733 \\
\hline 13 & 2.0688 & 1.1417 & 0.90163 & 0.78972 & 0.55196 & 0.43590 & 0.92672 & 20.562 & 52.734 & 32.172 & 0.0094924 & 0.30530 \\
\hline 14 & 1.3790 & 0.78187 & 0.64969 & 0.83095 & 0.56700 & 0.47115 & 0.59709 & 6.9094 & 35.710 & 28.801 & 0.0077576 & 0.22342 \\
\hline
\end{tabular}


Table C.5 - Variation of initial Pressure (90\% Fill Volume, Preliminary Experiments)

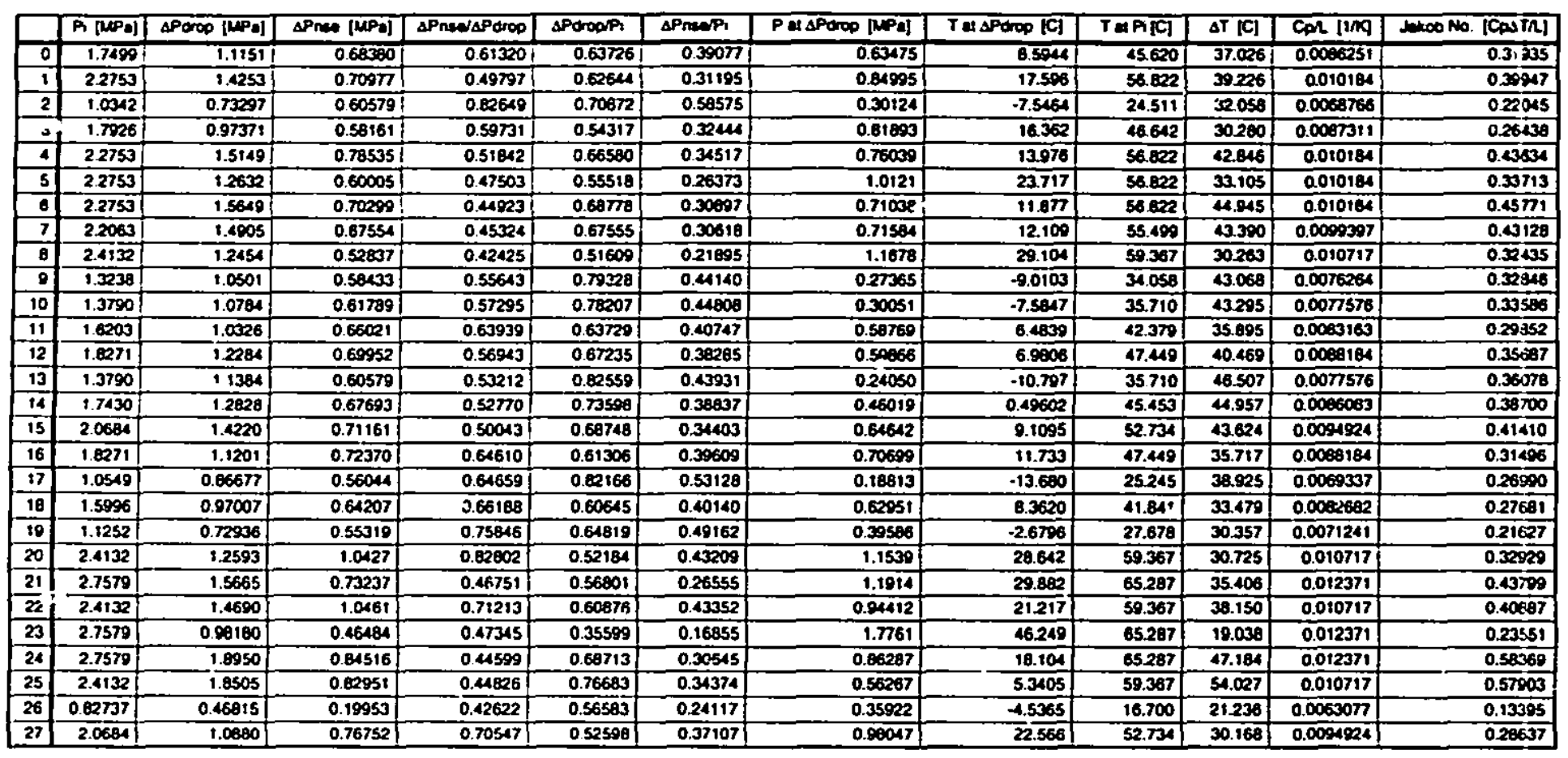


Table C.6 - Variation of initial Pressure (65\% Fill Volume, Steel Vessel, Rate Data)

\begin{tabular}{|c|c|c|c|c|c|c|c|}
\hline & $P_{1}\left(M P_{a}\right)$ & (APArop/AS) IMPD/ms] & Wogon! & (APdrop/St) [MP $/ \mathrm{ms}]$ & Woight 2 & (APOrop/Al)ovg (MPUmal) & (APriso/AS) [MPDIms] \\
\hline 0 & 2.2400 & 0.98899 & 0.70000 & 0.015168 & 0.30000 & 0.65707 & 0.012431 \\
\hline 1 & 2.0684 & 2.1367 & 0.52000 & $0.1547 \%$ & 0.48000 & 0.77428 & 0.21581 \\
\hline 2 & 2.0584 & 1.3789 & 0.37000 & 0.006460 & 0.63000 & 0.63845 & 0.10094 \\
\hline 3 & $0.8215:$ & 0.11583 & 0.30000 & 0.076532 & 0.70000 & 0.000322 & 0.10607 \\
\hline 4 & 0.86184 & 0.40403 & 0.45000 & 0.099974 & 0.55000 & 0.23649 & 0.038129 \\
\hline 5 & 1.3700 & 1.0100 & 0.37000 & 0.13031 & 0.63000 & 0.45574 & 0.13721 \\
\hline 6 & 1.8961 & 8.1225 & 0.43000 & 0.16065 & 23.300 & 0.57433 & 0.16547 \\
\hline 7 & 2.4821 & 1.0363 & 0.63000 & 0.10857 & 0.37000 & 0.73015 & 021029 \\
\hline$\theta$ & 2.4132 & 1.5560 & 0.53000 & 0.14617 & 0.47000 & 0.69356 & 0.14272 \\
\hline 9 & 2.8751 & 1.0515 & 0.58000 & 0.12204 & 0.42000 & 0.66121 & 0.22750 \\
\hline 10 & 2.5166 & 1.0052 & 0.55000 & 0.12411 & 0.45000 & 0.65293 & 0.13700 \\
\hline 11 & 2.6200 & 1.0646 & 0.53000 & 0.14065 & 0.47000 & 0.63018 & 0.17030 \\
\hline 12 & 3.1026 & .1549 & 0.57000 & 0.091011 & 0.43000 & 0.69775 & 025511 \\
\hline 13 & 3.3440 & $1.072 \theta$ & 0.68000 & 0.097906 & 0.32000 & 0.78118 & 0.13304 \\
\hline 84 & 3.4956 & 1.2259 & 1.0000 & 0.0000 & 0.0000 & 1.2259 & 0.27579 \\
\hline
\end{tabular}

Table C.7 - Variation of initial Pressure (90\% Fill Volume, Steel Vessel, Rate Data)

\begin{tabular}{|c|c|c|c|c|c|c|c|}
\hline & Pi(MPD) & (APAROQ/AS]1 [MPAIms] & Woophin & [SPdrop/AlR [MP Nimal] & Whon 2 & (APdrop/Aj)avg [MPA/ms] & (APrisoldS) (MPA/ma) \\
\hline$\sigma_{1}$ & 2.7924 & 5.1066 & 0.59000 & 0.30475 & 0.41000 & 3.1000 & 0.41506 \\
\hline 1 & 2.4132 & 3.7625 & 0.59000 & 0.33646 & 0.41000 & 2.2580 & 0.20854 \\
\hline 2 & $2.4 \$ 32$ & 0.71843 & 0.45000 & 0.17237 & 0.55000 & 0.41782 & 0.16547 \\
\hline 3 & 2.7924 & 1.3465 & 0.50000 & 0.19403 & 0.50000 & 0.77063 & 0.18478 \\
\hline 4 & 2.7579 & 1.0756 & 0.86000 & 0.037232 & 0.13600 & 0.097906 & 0.24059 \\
\hline 5 & 2.0684 & 2.0712 & 0.70000 & 0.32819 & 0.30000 & 1.5540 & 0.37232 \\
\hline 6 & 0.79200 & 0.020684 & 0.16000 & 0.062742 & 0.84000 & $0.05 \sin \theta$ & 0.016823 \\
\hline 7 & 3.0130 & 1.0184 & 0.87000 & 0.13790 & 0.13000 & 0.90300 & 0.19926 \\
\hline 8 & 3.1026 & 1.0908 & 0.00000 & 0.062742 & 0.11000 & 0.97760 & 0.19098 \\
\hline 9 & 2.0200 & 0.97285 & 0.67100 & 0.22691 & 0.32900 & 0.72000 & 0.17780 \\
\hline 10 & 2.7027 & 1.0004 & 0.60000 & 0.25511 & 0.31000 & 0.82461 & 0.24821 \\
\hline 11 & 2.4821 & 0.93217 & 0.70500 & 0.17237 & 0.29500 & 0.70000 & 0.22060 \\
\hline 12 & 3.5853 & 2.1650 & 0.60000 & 0.80222 & 0.40000 & 1.6547 & 0.19305 \\
\hline 13 & 3.3440 & 1.4065 & 0.66000 & 0.81630 & 0.33000 & 1.1997 & 0.19095 \\
\hline 74 & 2.0992 & 1.5637 & 0.64000 & .24603 & 0.34000 & 1.1238 & 0.22753 \\
\hline 15 & 3.4474 & 1.0446 & 0.30000 & 1.6678 & 0.61000 & 1.0391 & 0.22063 \\
\hline 16 & 3.6197 & 9.4245 & 1.0000 & 0.0000 & 0.0000 & 1.4245 & 0.26200 \\
\hline 17 & 1.3790 & 1.2742 & 0.33000 & 0.28200 & 0.67000 & 0.60980 & 0.19236 \\
\hline 18 & $1 . \overline{7375}$ & 0.37645 & 0.59000 & 0.15996 & 0.41000 & 0.20751 & 0.11652 \\
\hline 19 & 2.0688 & .2569 & 0.65000 & 0.18133 & 0.35000 & 0.86046 & 0.31647 \\
\hline
\end{tabular}


Table C.8 - Variation of initial Pressure (90\% Fill Volume, Glass Test Tube)

\begin{tabular}{|c|c|c|c|c|c|c|}
\hline & $\mathrm{Pi}_{\text {i }}(\mathrm{MPa}$ ) & $\triangle P$ diop [MPa] & $\triangle \mathrm{P}$ rise[$[\mathrm{MPa}]$ & SPrise/APdrop & $\Delta \mathrm{Pdrop} / \mathrm{P}_{\mathbf{I}}$ & APriso/Pi \\
\hline 0 & 1.0313 & 0.69236 & 0.21190 & 0.30606 & 0.67133 & 0.20547 \\
\hline 1 & 1.0313 & 0.71216 & 0.23163 & 0.32526 & 0.69053 & 0.22460 \\
\hline 2 & 1.7189 & 1.1780 & 0.32280 & 0.27403 & 0.68532 & 0.18780 \\
\hline 3 & 2.0626 & 1,3084 & 0.39052 & 0.29848 & 0.63433 & 0.18933 \\
\hline 4 & 1.6845 & 1.0403 & 0.28808 & 0.27693 & 0.61755 & 0.17102 \\
\hline 5 & 2.2689 & 1.3242 & 0.36990 & 0.27934 & 0.58364 & 0.16303 \\
\hline 6 & 2.6470 & 1.2307 & 0.19939 & 0.16201 & 0.46494 & 0.075325 \\
\hline 7 & 2.6470 & 1.0726 & 0.13820 & 0.12885 & $0 . \overline{40519}$ & 0.052208 \\
\hline 8 & 2.2345 & 1.1853 & 0.27722 & 0.23387 & 0.53046 & 0.12406 \\
\hline 9 & 2.8533 & 1.0004 & 0.10726 & 0.10722 & 0.35060 & 0.037590 \\
\hline 10 & 2.9221 & 1.1688 & 0.24614 & 0.21059 & 0.40000 & 0.084235 \\
\hline 11 & 1.8907 & 1.5470 & 0.50644 & 0.32738 & 0.81818 & 0.26785 \\
\hline 12 & 0.75630 & 0.61759 & 0.12062 & 0.19531 & 0.81659 & 0.15949 \\
\hline 13 & 1.3751 & 0.84437 & 0.16525 & 0.19571 & 0.61405 & 0.12018 \\
\hline 14 & 1.4782 & 1.0554 & 0.21109 & 0.20000 & 0.71400 & 0.14280 \\
\hline 15 & 1.2926 & 0.90467 & 0.33171 & 0.36667 & 0.69980 & 0.25663 \\
\hline
\end{tabular}

Table C.9 - Variation of initial Pressure (90\% Fill Volume, Glass Test Tubc+CO

\begin{tabular}{|r|r|r|r|l|r|r|}
\hline & $\overline{P i}[\overline{M P a}]$ & $\Delta \mathrm{P}$ drop $[\mathrm{MPa}]$ & $\Delta \mathrm{P}$ rise[MPa] & \multicolumn{1}{|c|}{$\Delta \mathrm{Prso} / \Delta \mathrm{Pdrop}$} & $\Delta \mathrm{Pdrop} / \mathrm{Pi}$ & $\Delta \mathrm{Prise} / \mathrm{Pi}$ \\
\hline 0 & 1.5470 & 1.0313 & 0.53835 & 0.52200 & 0.66667 & 0.34800 \\
\hline 1 & 1.6157 & 0.90824 & 0.58510 & 0.64421 & 0.56213 & 0.36213 \\
\hline 2 & 0.89381 & 0.58510 & 0.26952 & 0.46063 & 0.65462 & 0.30154 \\
\hline 3 & 0.96256 & 0.46203 & 0.27722 & 0.60000 & 0.48000 & 0.28800 \\
\hline 4 & 1.8907 & 1.4507 & 0.67998 & 0.46872 & 0.76727 & 0.35964 \\
\hline
\end{tabular}




\section{Appendix D}

This Appendix contains the source code for the venting model used in section 4.6. The program was written in FORTRAN and uses the Reynolds Thermodynamic Subroutines PROP and SAT obtained from reference [19] 


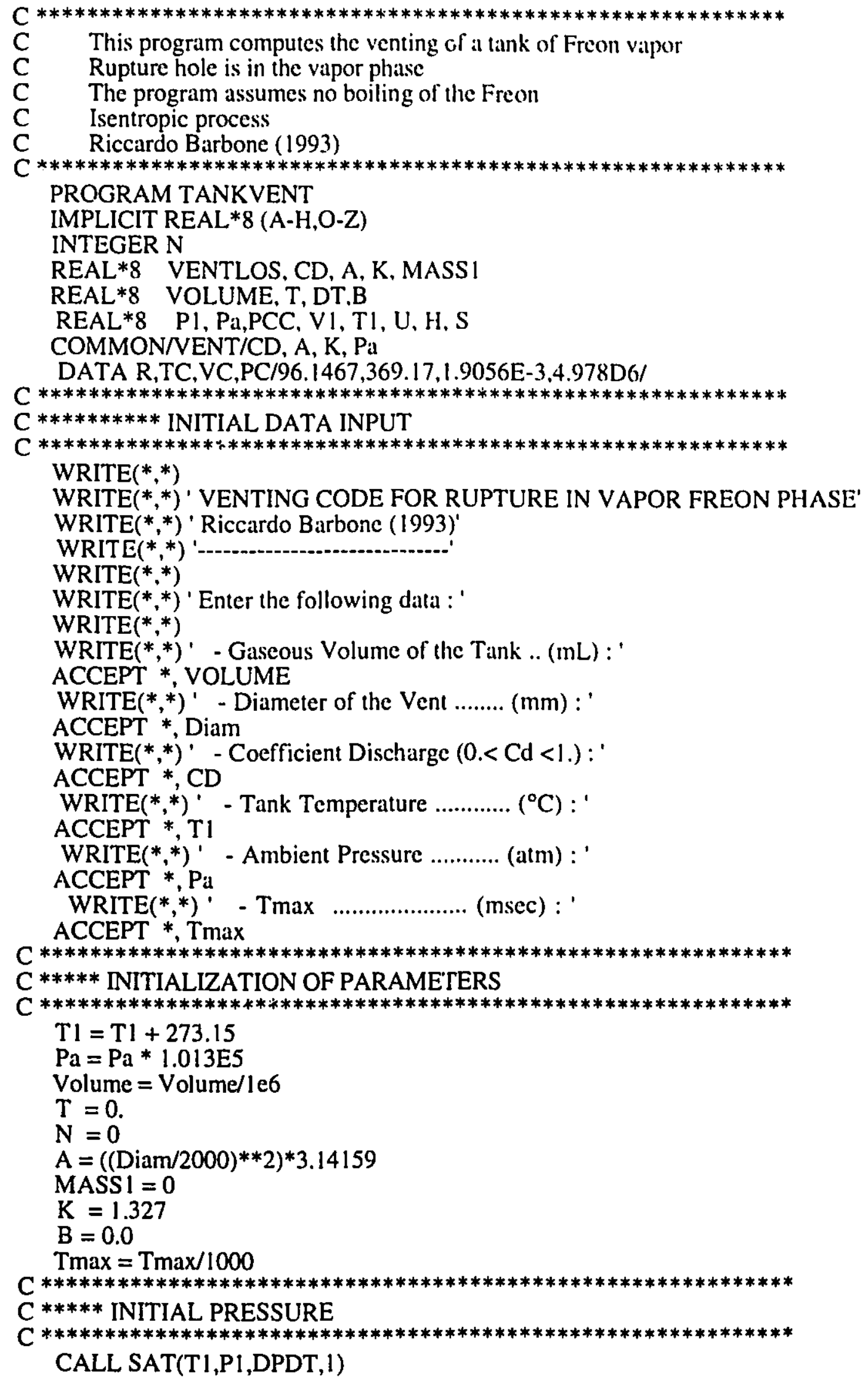




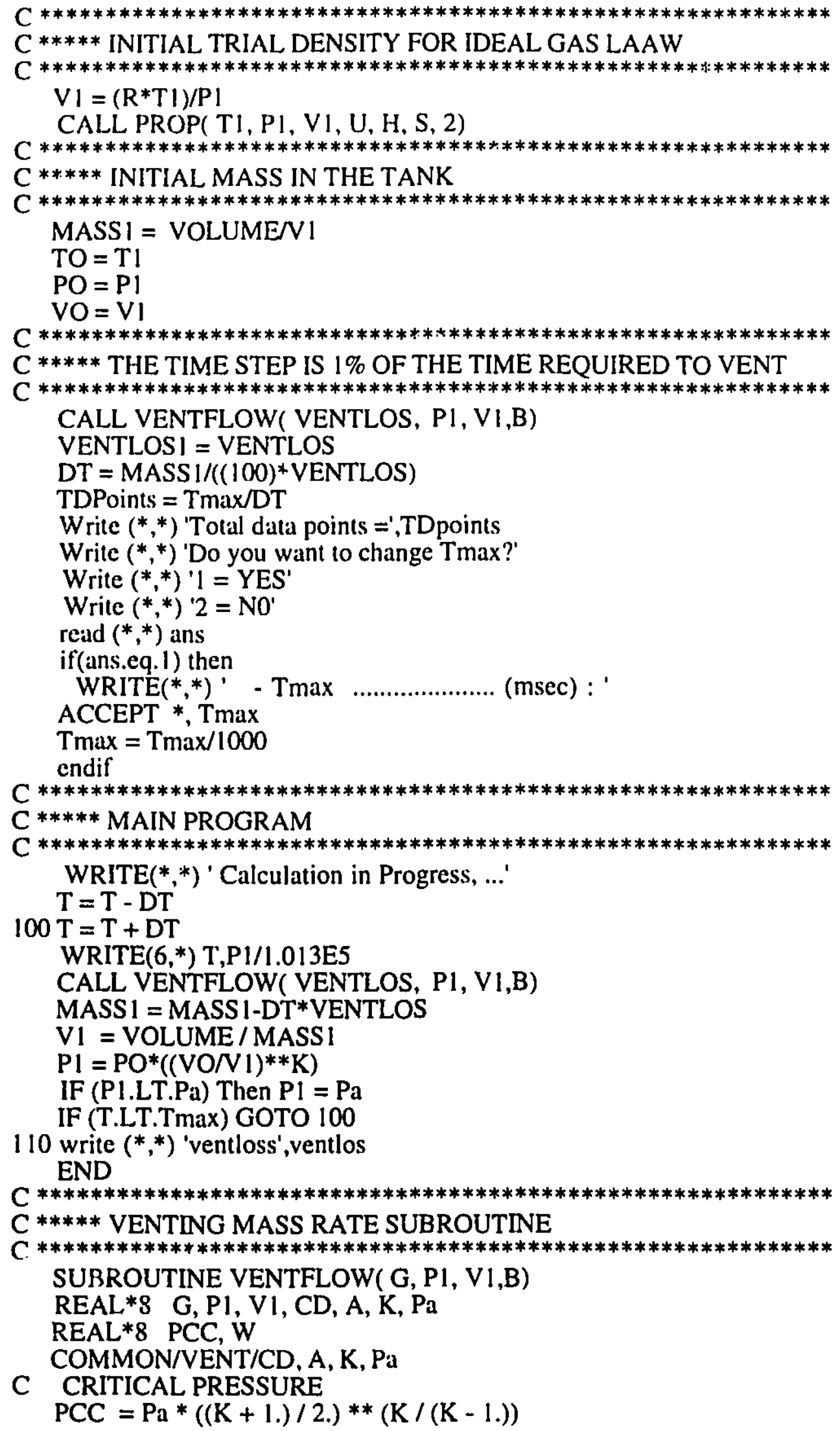




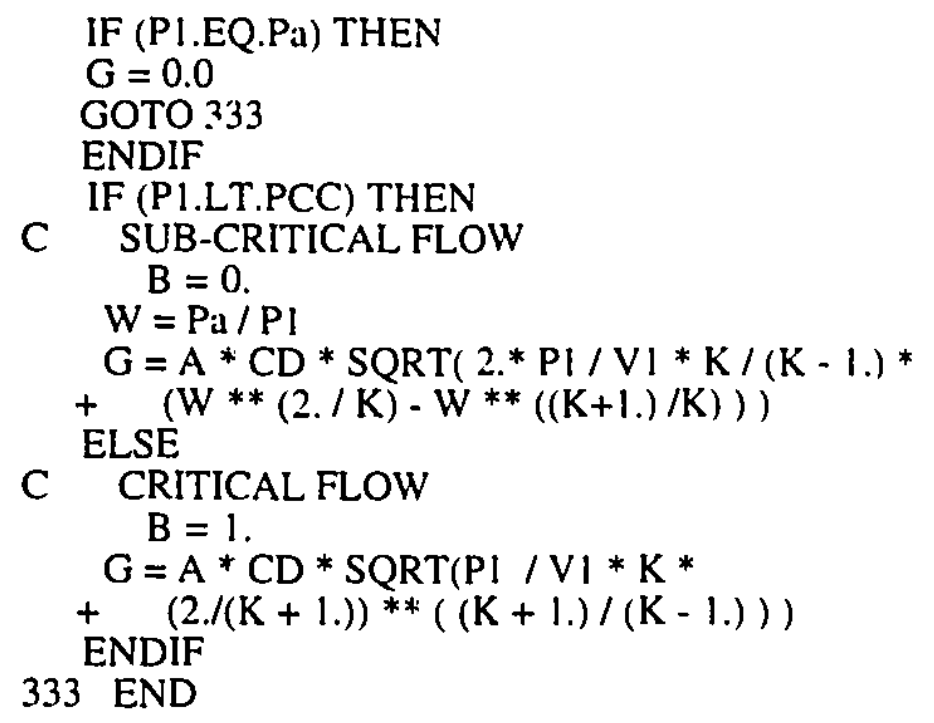

